\title{
Paleozoic Origin of the Cycads
}

GEOLOGICAL SURVEY PROFESSIONALAPAR 934

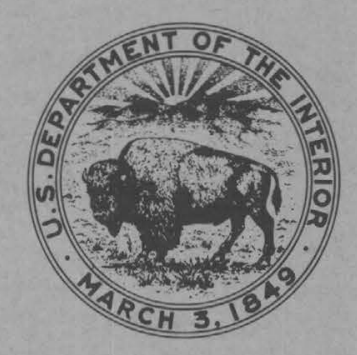





\title{
Paleozoic Origin of the Cycads
}

\author{
By SERGIUS H. MAMAY
}

GE OLOGICAL S UR VEY PROFESSIONAL PAPER 934

Megasporophylls and associated plant parts from the

Upper Pennsylvanian and Lower Permian rocks of the

southwestern United States are interpreted as a

lineage of cycads, derived from the pteridosperms.

Cycadean foliage is thought to be derived

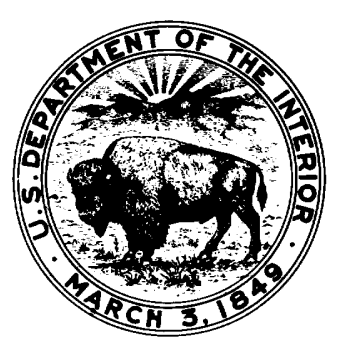

from Paleozoic taeniopterids 


\section{UNITED STATES DEPARTMENT OF THE INTERIOR}

THOMAS S. KLEPPE, Secretary

\section{GEOLOGICAL SURVEY}

V. E. McKelvey, Director

Library of Congress Cataloging in Publication Data

Mamay, Sergius H. 1920-

Paleozoic origin of the cycads.

(Geological Survey professional paper; 934)

Bibliography: $p$.

Includes index.

1. Cycadales, Fossil. 2. Paleobotany--Paleozoic. 2. Paleobotany--Southwest, New. I. Title. II. Series: United States. Geological Survey. Professional paper; 934. \begin{tabular}{lr} 
QE976.2.M35 & 561'.591 \\
\hline
\end{tabular}

For sale by the Superintendent of Documents, U.S. Government Printing Office Washington, D.C. 20402

Stock Number 024-001-02831-0 


\section{CONTENTS}

Abstract

Introduction

Acknowledgments

Terminology

Sources of material

Previous work

Systematic descriptions

Spermopteris sp !

Archaeocycas Mamay

Archaeocycas whitei Mamay

Phasmatocycas Mamay

Phasmatocycas kansana Mamay

?Phasmatocycas $\mathrm{sp}$

?Phasmatocycas spectabilis Mamay, $\mathrm{n}$. sp
Page

1

1

3

4

4

5
Systematic descriptions-Continued ?Cycadean male cones _....- 23 Cycadospadix yochelsoni Mamay, n. sp _........- 24 Associated plants _-_._- 26

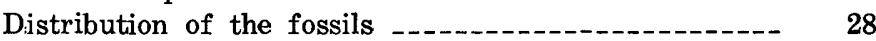

Morphologic and evolutionary considerations _....... $\quad 29$ Interrelationships of the American fossils _.....- 29 An alternative interpretation of Archaeocycas _.. 33 Relationships of the American fossils to other fossil cycads

Evolution of the pinnate habit in cycadalean foliage

Conclusions -..-.

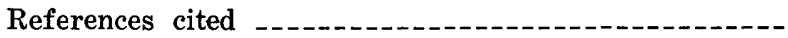
Index . (1) 8

\section{ILLUSTRATIONS}

[Plates follow index]

Plate 1. Archaeocycas whitei Mamay.

2. Archaeocycas whitei Mamay, ?Phasmatocycas sp., Spermopteris sp., Cycadospadix yochelsoni Mamay, n. sp., and ?cycadean male cone.

3. Phasmatocycas kansana Mamay.

4. Seed cuticles of Phasmatocycas kansana Mamay.

5. '?Phasmatocycas spectabilis Mamay, n. sp., and Taeniopteris sp.

FigURE 1. Reconstruction of part of seed-bearing leaf of Spermopteris coriacea

2. Diagrams showing hypothetical reduction of the megasporophyll and evolution of the ovulate cone implied by living cycads

3. Semidiagrammatic reconstruction of megasporophyll of Archaeocycas

4. Semidiagrammatic reconstruction of megasporophyll of Phasmatocycas

5. Stratigraphic correlations showing vertical distribution of late Paleozoic cycads and related plants --.-

6. Diagrams showing hypothetical evolutionary development of Cycas-like megasporophyll from spermopterid pteridosperm

7. Semidiagrammatic representation of hypothetical evolution of Cycas-like megasporophyll from Archaeocycas -

8. Semidiagrammatic representation of hypothetical evolution of carpellike organ from Archaeocycas ---

9. Reconstructions of Dioonitocarpidium -

10. Reconstructions of Palaeocycas-Bjuvia

11. Diagrams depicting suggested evolution of cycadalean leaves from taeniopterid ancestral forms 



\title{
PALEOZOIC ORIGIN OF THE GYCADS
}

\author{
By Sergius H. Mamay
}

\section{ABSTRACT}

Upper Paleozoic rocks in the southwestern United States contain several taxa of fassil plants that appear to represent a lineage from the Pennsylvanian pteridosperms to the modern cycads. The oldest genus, Spermopteris Cridland and Morris, is a megasporophyll that has surficial seeds borne in two rows along the sides of presumably abaxial faces of taeniopterid foliage; it was first found in the Virgilian Lawrence Formation of Kansas, and a poorly preserved specimen is now known from the Leonardian Wellington Formation of Oklahoma.

The putatively derivative cycadean genera Phasmatocycas Mamay and Archaeocycas Mamay occur in lower Leonardian rocks of Kansas and Texas. Phasmatocycas (type-species: $P$. kansana Mamay) is a fertile axis that has two lateral rows of naked ovules. In $P$. kansana, the ovules are represented by well-preserved double cuticles similar to those of the Jurassic cycad Beania; small resinoid spherules, interpreted as remains of glands, alternate with the ovules. Taeniopterid foliage associated with $P$. kansana bears abundant spherules identical with those on the fertile axis; on the basis of the spherules and the known seed habit of Taeniopteris, Phasmatocycas is reconstructed as a cycadlike megasporophyll with an elaminar, fertile base and a taeniopterid distal lamina. The glands may be primitive nectaries, possibly involved in an early stage in the development of entomophily. Phasmatocycas is regarded as having been derived from a spermopterid ancestor through reduction of numbers of seeds and loss of the basal foliar lamina. Although the type specimen of Phasmatocycas is from the Wellington Formation of Kansas, a poorly preserved specimen is known from the younger Vale Formation of Texas, where it is associated with structures strongly reminiscent of male cycadean cones.

Archaeocycas Mamay, typified by $A$. whitei Mamay, is approximately contemporary with Phasmatocycas kansana, occurring at two localities in the Belle Plains Formation of Texas. It resembles Phasmatocycas in having a basal seedbearing area and a sterile distal lamina. In Archaeocycas, however, the seeds are attached to the basal lamina, which is inrolled and at least partly encloses the seed. Archaeocycas probably represents a form intermediate between Spermopteris and Phasmatocycas. Alternatively, Archaeocycas might be a fertile appendage evolving in the direction of a carpellike organ through proliferation and fusion of the laminar margins; this alternative, however, is not preferred.

Associated with the cycadean megasporophylls are a single specimen of Cycadospadix (C. yochelsoni Mamay, n. sp.) and various other plants. C. yochelsoni cannot be determined as cycadalean or bennettitalean, although it is possible that it is either and that the two orders may have been distinct as long ago as the Early Permian. Among other plant associates, only Taeniopteris is common to all the cycad-bearing assemblages; this strengthens the hypothesis that Taeniopteris was the leaf of primitive cycads, as indicated by Spermopteris.

Stratigraphic distribution of the plants supports the idea of derivation of the cycads from the Pennsylvanian spermopterids and of a lineage to the madern cycads through the Triassic genera Palaeocycas-Bjuvia and Dioonitocarpidium. Horizontal and vertical distribution of the Paleozoic taxa emphasize the importance of the lower Leonardian of the southwestern United States as a temporal and geographic locale for rapid and dramatic plant evolution.

Modern cycadean leaves are thought to be derived from taeniopterid stock in the Paleozoic and Mesozoic through progressive incision of the laminar margin. In one line of foliar evolution, shallow marginal dentation, in which each tooth receives only one vein, becomes progressively deeper, resulting in the cycadaceous leaf type in which each leaflet has a single vein; a parallel series of known forms involved several veins to a segment and could have produced the zamiaceous leaf type. The Stangeria leaf type could have arisen from a compound taeniopterid with little modification, whereas marginal incision of a compound taeniopterid might have produced the Bowenia type of leaf.

Cumulative evidence indicates that the cycads extend back into the Late Pennsylvanian instead of only the Late Triassic; thus they rival the conifers as the oldest extant seed plants.

\section{INTRODUCTION}

The tenor of this paper is appropriately established by reference to some of T. M. Harris' perceptive comments on the fossil history of the cycads. Harris $(1961$, p. 322) : wrote as follows:

The fossil Cycads consist of a good many genera of isolated organs classified on more or less good evidence as Cycadales, a very few genera with two known organs and one genus with more than two organs. If we are right in our synthesis of these plants with two or more organs, and also right in our present classification of, say, half of the isolated organs (and I think it unreasonable to hope for more), then we can say that by Jurassic times the family had probably completed its evolution. $* * *$ The known genera are no more primitive than the living ones and they do not help in linking the Cycadales with any other family, and for this link one looks first at the 
Pteriodosperms. If we are to find progressive evolution it must be before the Jurassic.

Harris' remarks succinctly outline a particularly enigmatic deficiency in the paleobotanical record, in regard to which considerable speculatory discussion has been published. A brief supplement to Harris' statements is in order here as background to the present article, which may advance the status of our knowledge of the evolution of the cycads.

The order Cycadales is a small group of gymnosperms; most authors regard it as consisting of only nine living genera, although Johnson (1959) recognized a tenth. The geologic history of the Cycadales is little known and perplexing, despite the abundant Mesozoic occurrences of fossil leaves generally attributed to the cycads. Intermixed and often closely associated with these fossils are leaves of the extinct Bennettitales or cycadeoids-plants that reached their zenith during the Jurassic and disappeared before the end of the Mesozoic. The distinction between the foliage of the two groups is based largely on features of the epidermis, and particularly on the stomatal characters. Otherwise, leaves of the cycadeoids and cycads are so similar that they are difficult to differentiate on the basis of gross external morphology.

Reproductive structures of the cycadeoids were preserved in some abundance and have been investigated in considerable detail (Delevoryas, 1968a, b). However, little is known of either the polleniferous or ovulate mechanisms of the fossil cycads; accordingly, their phylogeny is speculative. The often-cited Late Triassic genera Dioonitocarpidium von Lilienstern and Palaeocycas Florin ("Bjuvia" Florin) and the Jurassic Cycadospadix Schimper are the oldest fossils regarded to represent true cycadean ovulate appendages. Of much more significance is the Middle Jurassic genus Beania Carruthers, a lax conelike structure with biovulate, spirally disposed peltate appendages. Beania is consistently compared with female cones of the modern zamioid cycads (Arnold, 1953, p. 62). The Jurassic existence of cones with advanced morphologic features such as those found in Beania indicates a considerable pre-Jurassic evolutionary history for the cycads; clearly, Harris had this circumstance in mind while writing the comments quoted above. The Jurassic cycads, along with the sparse but significant evidence of Triassic relatives, nurture a reasonable speculation that true cycads existed during Paleozoic time.

Harris' designation of the pteridosperms as the probable source of a "link" between the Cycadales and other taxa expresses a long-established line of thought, but one that has been developed on tenuous evidence. I feel that concrete evidence of a late Paleozoic cycadalean stock may now be contributed to the paleobotanical record. The cycadalean stock indeed has its beginnings in the pteridosperms, as speculated, and more specifically, in the taeniopterid pteridosperms.

In 1960, Cridland and Morris described the genus Spermopteris (fig. 1), a taxonomic novelty based on fertile pteridospermous foliage from the Upper Pennsylvanian of Kansas. Spermopteris was shown to be the ovulate phase of a member of the formgenus Taeniopteris, representatives of which are common in upper Paleozoic rocks. The seed-bearing specimens were identified with Taeniopteris coriacea Goeppert, which became the basionym for the type species, Spermopteris coriacea (Goeppert) Cridland and Morris. Spermopteris is characterized by having "a row of seeds borne on the abaxial surface of each side of the midvein" (Cridland and Morris, 1960, p. 855 ) on what otherwise were normal-appearing appendages. The authors limited their discussion of the significance of their material to a few statements regarding the infrageneric relationships of certain taeniopterid forms and refrained from speculating on the possibly broader evolutionary implications of Spermopteris. It is my opinion, however, that Spermopteris is one of the earliest known elements of evidence bearing on the paleontologic history of the cycads from the standpoint of ovulate reproductive structures. This opinion is bolstered considerably by the characteristics of the Permian material dis-

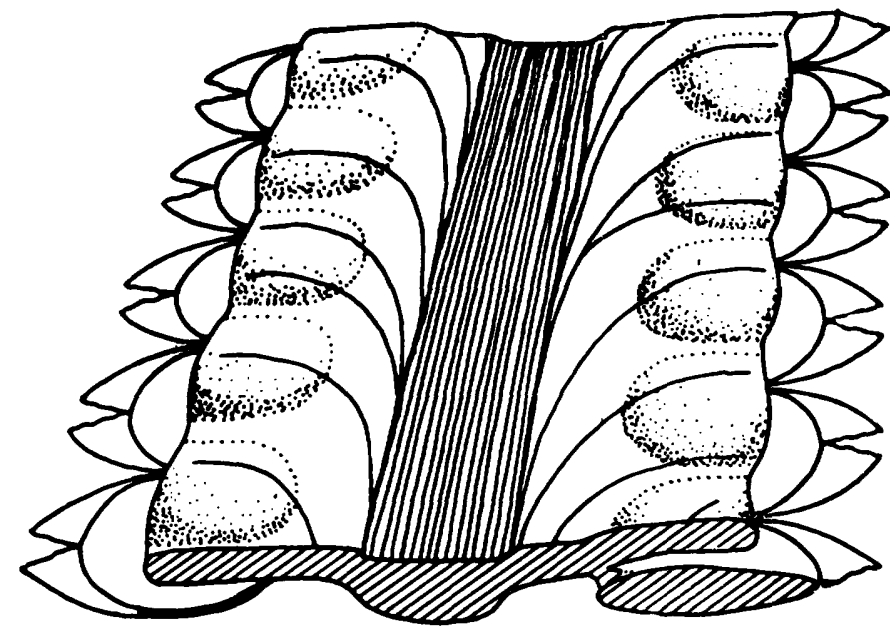

FIGURE 1.-Reconstruction of part of fertile leaf of Spermopteris coriacea, showing oblique view of upper (ventral) surface, and at lower right, mode of seed attachment to lamina (from Cridland and Morris, 1960, fig. 10). Approximately $\times 3$. 
cussed here, and considered with those of Spermopteris they form the basic theme of this paper.

The Paleozoic plant collections of the U.S. Geological Survey contain several Permian specimens of ovuliferous appendages that resemble Spermopteris in the general disposition of their seeds but differ conspicuously in details of the foliar lamination. Also present in the collections are other forms that may be related and are therefore included in this paper. Because of the stratigraphic and geographic relationships of the two suites of specimens, it seems reasonable that some of the morphological resemblances reflect phylogenetic alliances rather than fortuities or parallelisms. Thus this paper is intended as a sequel to the Cridland and Morris work on Spermopteris. All these specimens have been considered critically with the purpose of stressing certain morphological features that they have in common with each other, with other fossils regarded to represent true cycads, and with the modern Cycadales. A certain amount of speculation is entailed in this presentation, but the ensuing pages will also describe tangible evidence for the presence, in the late Paleozoic record, of plants directly related to the living recent cycads.

In the literature dealing with the modern cycads, evolutionary advancement of the various genera is usually interpreted in terms of comparative morphology of the female cones. The megasporophylls of Cycas are held to be the most primitive ovulate organs of the order, because they retain leaflike features indicative of foliar derivation and are produced like leaves in loose terminal crowns instead of in compact cones (fig. 2 ; Chamberlin, 1965, p. 145$150)$. Because they are produced like leaves they are also shed like leaves, as individual units rather than as more or less complete cones. Thus one would logically look for individual detached fossil megasporophylls in searching for primitive fossil cycads or their progenitors. This assumption is borne out here, inasmuch as the material on which this study is based consists entirely of single detached appendages that provide no evidence regarding modes of attachment to the parent plants. Fortunately the individual cycadalean megasporophyll, though simply constructed, is sufficiently diagnostic that the incomplete nature of the fossils treated here does not detract substantially from their phylogenetic significance.

\section{ACKNOWLEDGMENTS}

The late David White is in no small measure responsible for this paper, because he collected much

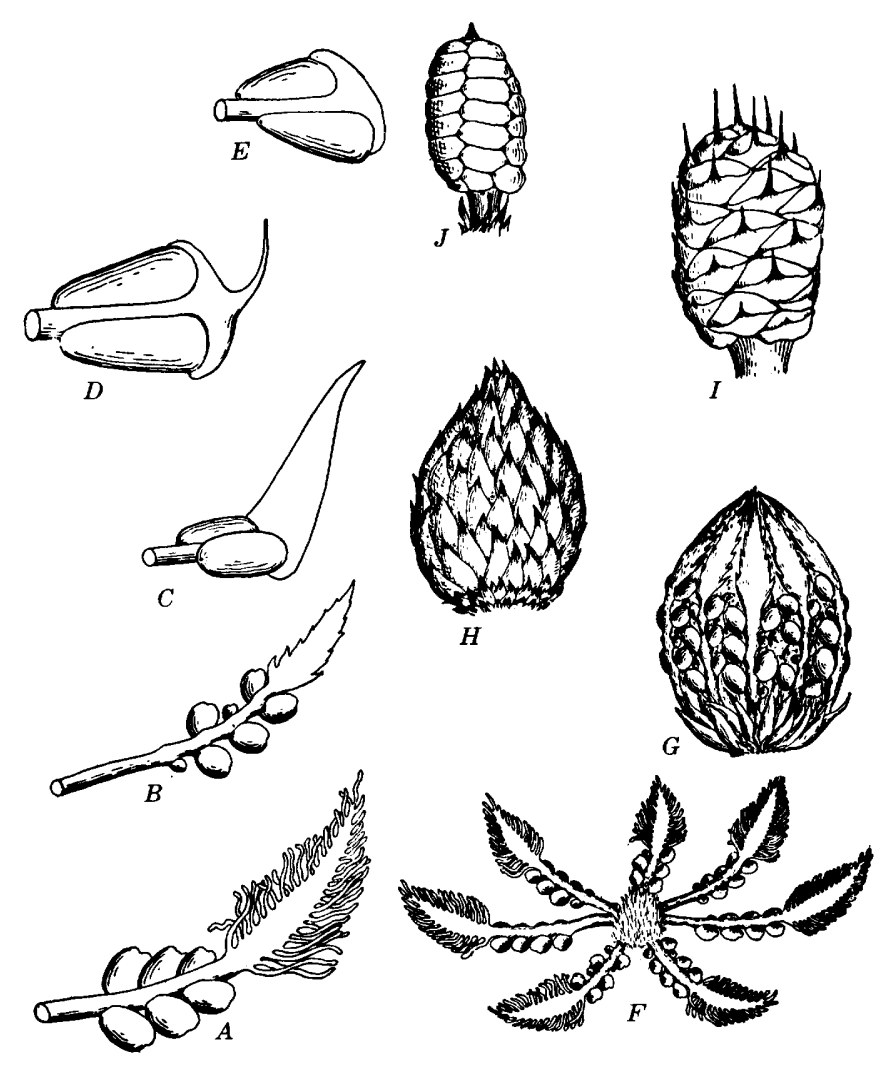

FIGURE 2.-Hypothetical reduction of the megasporophyll and evolution of the cone as implied by living cycads. $A$, Leaflike megasporophyll of Cycas revoluta; $F$, loose terminal crown of megasporophylls (C. revoluta), not compacted into a cone. $B$, Megasporophyll of Cycas media, the leaflets reduced to serrations; $G$, terminal aggregate of megasporphylls of same species, in a more conelike arrangement. $C$, Megasporophyll of Dioon edule, in which the lamina is entire-margined; $H$, loosely compacted cone of $D$. edule. $D$, Megasporophyll of Macrozamia miquelii, the lamina reduced to a spine; $I$, tightly compact cone of same species. $E$, Highly reduced megasporophyll of Zamia floridana, having no resemblance to a leaf; $J$, extremely compact cone of $Z$. floridana. (All from Chamberlain, 1930, p. 290, with slight modifications of figure explanations.)

of the critical material. Although he published nothing known to refer directly to this material, his curatorial markings on specimens and certain other kinds of evidence show that he was aware of the importance of some of the material described here and almost certainly suspected its cycadlike affinities. Thus White's considerable influence on the Paleozoic paleobotany of North America continues, even now, to exert itself.

Thanks are extended to Dr. J. A. Wilson, University of Texas, for information regarding the Patterson locality at Lawn, Tex., and to C. O. Patterson for permission to collect on his property. Ralph 
Howe and Mart Russell of Seymour, Tex., kindly permitted me to collect on the "Emily Irish" land during several field seasons. T. R. Tinsley of Stamford, Tex., gave me some of the specimens described and showed me the fossil plant deposit in Haskell County. A. D. Watt, U.S. Geological Survey, assisted me in the field in 1961, 1963, 1967 and 1974. During my first collecting trip to the Lawn locality, I was accompanied by C. B. Read and E. L. Yochelson, both of the U.S. Geological Survey. Read also gave me valuaable instruction in general procedures in locating fossiliferous deposits in the southwestern Permian red beds.

\section{TERMINOLOGY}

The literature dealing with cycadophytes is somewhat confusing with regard to the terminology applicable to the foliar organs. Some authors prefer the terms "leaf" and "leaflet," whereas, others use "front" and "pinna," or "frond-like leaf"; occasionally the alternative terms are even used interchangeably in the same publication. Thus, this area of terminology seems basically to involve a matter of personal choice, especially in routinely descriptive approaches. I prefer "leaf" to "frond," particularly because this study is fundamentally concerned with entire-margined taeniopterid foliar organs of unknown origins or homologies.

My use of the term "megasporophyll" for the fertile structures discussed here is commonly accepted usage, yet it invites a statement of qualification because of an article by Meeuse (1963), in which the traditional interpretation of the ovuliferous appendage of Cycas was challenged.

Sporne (1965, p. 111-112) presented a consensus on the evolutionary status of Cycas, reiterating the substance of Chamberlain's hypothesis as presented in figure 2 of this paper. Sporne wrote "It is widely accepted by morphologists that the Cycas sporophyll is the primitive type among cycads, and that, during the evolution of the group, there has been a reduction in the number of ovules to two ***." Meeuse (1963, p. 122), however, presented the interesting but improbable hypothesis that the ovulate appendage of Cycas is "an organ of dual nature combining axial and foliar characteristics" and the "socalled 'megasporophyll' represents an abnormally developed whole cycadalean strobilus." In attempting to demonstrate that "the conventional identification of the female reproduction organ of Cycas with a 'megasporophyll' (defined as a leaf homologue bearing marginal ovules) is fallacious," Meeuse in- voked unconvincing evidence, such as structural aberrancy or resemblance of the ovuliferous organ of Cycas to a teratological case. He furthermore rejected Palaeocycas Florin as a cycad, primarily on the basis of its entire-margined taeniopterid leaves.

Because of the taeniopterid form of the lamina of Spermopteris, its clearly megasporophyllar nature, and the evolutionarily simple processes of reduction of parts and incision of foliage necessary for derivation of the Cycas type of fertile appendage, Meeuse's hypothesis is herewith rejected in favor of traditional concepts. I regard the term "megasporophyll" as correctly applicable to Cycas and use it here accordingly.

The ovulelike bodies on the basal part of the lamina in Archaeocycas are described as attached to the lower (abaxial) surface of the megasporophyll, but the choice of this word-in preference to the contrasting term "upper" adaxial-is an arbitrary one, based on homology with the abaxial positons of the sporangia of most ferns. The few specimens available are detached, and thus it is impossible to determine their orientation in relation to the apex of the parent plant. Even though proof is lacking, however, the specimen shown in lateral view in plate 2 , figure 7, lends the strong impression of being oriented in its natural attitude, that is, with its adaxial surface toward the top of the illustration.

\section{SOURCES OF MATERIAL}

The specimens described here came from eight localities in Lower Permian outcrop areas, one in Oklahoma, three in Kansas, and four in Texas. The localities are described below, the numbers referring to U.S. Geological Survey paleobotany localities; quotation marks indicate parts of locality descriptions that were taken from the U.S. Geological Survey (USGS) locality register:

6233: "St. L. \& S. F. Ry. in cut $1 / 2$ mile west of station at Perry, Oklahoma. Coll. David White, Sept. 6, 7, 8, 1911. Permian." According to the geologic map of Oklahoma (Miser, 1954) this locality is within an undivided Permian rock interval indicated as "Pwa" (including the Admire Group through the Wellington Formation). As far as I am aware, no subsequent collections have been recorded from this locality.

8298: "Elmo limestone. Wellington formation,. Permian. Insect Hill, $3 \frac{1 / 2}{m i}$. SE of Elmo, Kansas, Barn lot on S. side of road, and adjacent localities. Coll. C. B. Read, 1931." The Elmo Limestone Member of Dunbar (1924) of the Wellington Formation is of Early Permian (Leonardian) age. I have not visited this area. 
8868: "Carleton, Kansas. Wade Sterling Ranch, 4 miles south of Carleton, Dickinson Co., Kansas (Wellington Fm.). D. White, 1909."

8869: " $3 \frac{1 / 2}{2}$ miles south of Banner, Kansas (Elmo ls.). Coll. by David White, 1909." This collection was probably made very close to locality 8298 , and almost certainly is from the same rock unit.

8877: "Wichita formation, $4 \frac{1}{4}$ miles south-east of Fulda, Texas. Collected by D. White." This locality is within the Lower Permian Belle Plains Formation (Romer, 1958, map facing p. 178), and although the locality register and specimen labels lack the date of the collection, a brief discussion of the collecting activities by White in his paper on Gigantopteris americana (1912, p. 495) indicates that the collection was made in 1910 . White wrote "the exact locality being the bank of the stream at the crossing of the old road, one-fourth miles south of the ford of the Little Wichita River, 4 miles southeast of Fulda, a station in Baylor County." In 1955 and 1957, I attempted to relocate this important fossil deposit, but the vague nature of the locality description and the lack of distinctive physiographic features in this badlands terrain made it impossible to be certain of one's position. Furthermore, the plant-bearing shale is easily eroded and the original deposit probably has been totally destroyed or obscured. A few nondescript fossil plant fragments were found in the supposed vicinity of White's locality, but none of these equaled White's material in quality of preservation.

8959: "Baylor County, Texas. East-central part of Emily Irish grant, south side of Salt Fork of Brazos River, 16 to $16 \frac{1}{2}$ miles scaled due S.E. of Seymour. Shale in upper part of Belle Plains Formation. Coll. Read and Ervin. October, 1940." This locality is on property now owned by Roland Howe, Fort Worth, Tex., and the plant deposit is by far the richest and most diversified one known in the Permian of the southwestern United States. I have collected from it on five different occasions, in 1955, 1957, 1961, 1963, 1967, and 1974. Actually, the plant deposit is at about the middle, rather than the upper part, of the Belle Plains Formation and is regarded as the approximate equivalent of the Valera Shale. A detailed locality description and a measured section of the "Emily Irish" exposure have been published (Mamay, 1968, p. I2-I3).

10057: C. O. Patterson property, Taylor County, Tex. The site is reached by starting at the theater in Lawn, Tex., going 1.5 miles $(2.4 \mathrm{~km})$ west, 2.9 miles $(4.8$ $\mathrm{km})$ south, $1.1(1.8 \mathrm{~km})$ miles west, and $0.5(0.9$ $\mathrm{km}$ ) mile south to the remains of the old home of C. O. Patterson. Fossils were found in a quarry and its vicinity, in a pasture against the east slope of a low hill as viewed west-southwest from the west side of the house. Fossil plants were especially abundant in a small lens of light gray shale about 100 yards $(915 \mathrm{~m})$ north of the quarry, and considerable material was collected in April 1955 by C. B. Read, E. L. Yochelson, and myself. According to Meyers and Morley (1929b), the Lawn deposits are in the lower part of the Vale Formation, in the
Lower Permian Clear Fork Group. (See Wilson, 1953 , p. 456-459 for further discussion of this locality.) In 1957 , A. D. Watt and I revisted this locality, hoping to obtain additional material. We found that the Patterson home had recently been destroyed by fire and was then in the process of being rebuilt on another site, and our collecting plans were completely thwarted because the pasture in which the fossil deposits occurred had been deep-plowed as part of a mesquite-eradication program. Small chips of the plant-bearing matrix and the underlying caliche bed were scattered over a fairly extensive area, but the plant beds may now be regarded as having been destroyed and lost to science.

10064: Haskell County, Tex. This locality is approximately 3 miles $(4.8 \mathrm{~km})$ north of Stamford, Tex., and just north of the Jones-Haskell County line. To reach the locality, go north and northwest on U.S. Highway 380 , starting at the city square in Stamford. After 2.25 miles $(3.7 \mathrm{~km})$ turn north on an unpaved crossroad; approximately 1 mile $(1.6 \mathrm{~km})$ north, plant fossils occur in red and gray, mediumto fine-grained sandstone which is exposed in the road shoulders and nearby pastures along both sides of the road. According to Meyers and Morley 1929a), exposures in this area are within the boundaries of the Vale Formation (Lower Permian Clear Fork Group), and their geographic proximity to other Vale exposures would suggest a high position in the Vale Formation. The presence of plant fossils in these beds was told to me by T. R. Tinsley of Stamford, and in his company, A. D. Watt and I collected plants there in 1961, 1963, and 1967.

\section{PREVIOUS WORK}

This study is limited to Paleozoic cycadean fructifications and their possible affinities with the early Mesozoic cycads, and because only a few examples are known, there is no need for an extensive review of past investigations of all fossil cycad parts. Several examples of petrified stems and other vegetative remains thought to have cycadean affinities are known from the Paleozoic. These are largely from the Old World, and their occurrences were summarized adequately by Arnold (1953, p. 61), who speculated that "There were probably some cycads in existence during the middle or late Carboniferous and by the end of the Paleozoic era they were fairly numerous."

The existence of true cycads in North America during Late Triassic time was demonstrated by Delevoryas and Hope (1971), who described the new genus Leptocycas from the Pekin Formation of North Carolina. The material consists of leaves and stem parts, both with typical cycadean cuticular characteristics; also found was a structure resembling a male cone, attached to a stem. Unfortunately, nothing is known of the ovulate parts. Delevoryas 
and Hope's reconstruction of Leptocycas gracilis shows a sparsely foliate plant with pinnate leaves and a slender trunk with long internodes. Stem features of Leptocycas differ from the modern cycad trunks which have dense armors of closely spaced persistent leaf bases.

Gould's (1971) anatomical study of petrified stem material from Upper Triassic beds of Arizona and New Mexico provided additional important evidence of cycads in the American Triassic. This investigation centered upon the taxon Lyssoxylon grigsbye Daughtery from the Chinle Formation. Lyssoxylon was originally regarded as a member of the Bennettitales (Daughtery, 1941), but various anatomical characters led Gould to reinterpret it as a true cycad.

The first recorded hint of Paleozoic cycads in North America appeared in a list of Permian plants published by White $(1912$, p. 508). White listed the taxon "Cycadospadix? sp." from a locality supposedly near Carlton, Kans. This listing was not substantiated by an illustration or description, but I found in White's collections a specimen that I believe to have been the basis for that identification; it is probably the most important specimen involved in this study.

In 1916, Bassler described a specimen of Plagiozamites planchardi (Renault) Zeiller from a coal seam in the Upper Pennsylvanian Conemaugh Group in West Virginia; this species is known from several Lower Permian localities in the old World but had not been reported previously in North America. Originally Plagiozamites was regarded as a true cycad leaf, although conclusive proof has never been found. Bassler's material neither substantiates nor refutes a cycadean affinity for the genus, but the Pennsylvanian occurrence is noteworthy.

The present paper culminates several years of study and six collecting trips. My interest was initially aroused by the presence of cycadlike specimens in White's Permian collections from the southwestern United States and was further stimulated by Cridland and Morris' (1960) description of Spermopteris. My ideas were announced in four brief publications (U.S. Geological Survey, 1968; Mamay, 1969a, 1971, 1973), in which the concept of late Paleozoic origin of cycads from Pennsylvanian spermopterids was set forth.

One of my articles (Mamay, 1969a) was immediately preceded in the same journal by an article by Taylor (1969a), in which a new type of polleniferous cone was described from Upper Pennsylvanian coal ball petrifications from Illinois. Taylor (p. 294) identified his material as Pennsylvanian cycads with the statement "The fossil record of true cycads is extended from the Upper Triassic to the Upper Pennsylvanian"; he (1969b) later reiterated this interpretation. In a subsequent publication, Taylor (1970) named the cones Lasiostrobus polysacci, at the same time modifying his interpretations so as to permit consideration of the possibility that the cones are coniferalean rather than cycadalean. Taylor's reason $(1970$, p. 682) for moderation of his originally unequivocal viewpoint was the discovery of additional specimens, some showing features of the apex.

Taylor's altered stance emphasizes the questionable taxonomic position of Lasiostrobus and the necessity for its reevaluation. I regard it as coniferophytic in the bulk of its characteristics and reject it as a cycad.

In my preliminary announcements (Mamay 1969a, b), I said that two new genera were recognized in this investigation. Formal names were not proposed; the genera were merely designated "new genus A" and "new genus B." Sporne (1971) discussed the new plants briefly, drawing attention to their as yet incomplete nomenclatural status; he also introduced an incorrect finality into some of my then-tentative ideas on angiosperm origins and accredited me with the discovery of "The origin of the carpel" (Sporne, 1971, p. 14). So that these possibly controversial fossils might be discussed with legitimate names, I proposed and validated the generic names Archaeocycas and Phasmatocycas (Mamay, 1973).

\section{SYSTEMATIC DESCRIPTIONS}

Four genera are recognized and discussed in this paper. Two of these-Spermopteris Cridland and Morris, 1960, and Cycadospadix Schimper, 1870are represented by one specimen each. The genus Archaeocycas Mamay, 1973, is represented by eight specimens; both counterparts of three of these are present. Phasmatocycas Mamay, 1973, is based on one specimen, both counterparts of which were found; a number of other specimens are provisionally assigned to this genus. Inasmuch as the formalization of the names Archaeocycas and Phasmatocycas in 1973 was an expedient designed to make names available while full descriptions and discussions were in preparation for this paper, the diagnoses are repeated here in the interest of completeness.

With the possible exception of Cycadospadix, the specimens above are clearly of megasporophyllar morphological nature. They are presented in the con- 
text of an evolutionarily interrelated complex of plants, which collectively appears to fill an important hiatus in the early history of the cycads. Two other plant structures, one foliar and one possibly a microsporangiate cone, are discussed because of their possible pertinence to the theme of this investigation.

\section{Division PTERIDOSPERMOPHYTA Order PTERIDOSPERMALES Genus SPERMOPTERIS Cridland and Morris, 1960 Spermopteris sp. \\ Plate 2, figure 2 DESCRIPTION}

This identification is based on one small specimen, poorly preserved on a chip of greenish fine-grained shale from the Perry, Okla., locality. The specimen represents a taeniopterid leaf fragment $3.0 \mathrm{~cm}$ long and $11.0 \mathrm{~mm}$ wide. It is preserved as an impression with only a few minor traces of adherent carbonaceous matter, which is restricted to the midrib. The midrib is conspicuously marked with parallel longitudinal striations and is very broad in proportion to the breadth of the lamina, measuring about $2.5 \mathrm{~mm}$ in width. The leaf fragment does not appreciably diminish in width from one end to the other.

The venation is poorly preserved, but the delicate ultimate veins may be seen by careful observation of a few small parts of the lamina. The veins are closely spaced, occasionally forked, and gently decurrent. Insofar as observable, the venation of this specimen is characteristically taeniopterid.

The chief significance of this specimen is in the presence of two uninterrupted rows of closely contiguous swellings that are roughly oblong or ovoid in shape and of very minor relief. One row lies along each side of the midrib, but the swellings are best seen along the right side of the specimen (pl. 2, fig. 2). The swellings average about $2.5 \mathrm{~mm}$ long and 1.5 $\mathrm{mm}$ wide. The basal ends of the swellings are not clearly separable from each other lengthwise and substantially coalesce to form a fairly conspicuous, uninterrupted but slightly undulating trough parallel to the midrib and about halfway out in the lamina on each side of the midrib. The sides of the swellings form shallow parallel depressions and generally follow the decurrence of the lateral veins. The swellings show no evidence of extending beyond the edges of the lamina; rather, they appear to be truncated at the leaf margins.

\section{DISCUSSION}

I am satisfied that this fossil represents a specimen of Spermopteris, probably preserved before the seeds had matured. Several features of the Oklahoma specimen suggest a congeneric relationship with material of Spermopteris that was regarded by Cridland and Morris to represent immature ontogenetic stages. In one of their specimens (Cridland and Morris, 1960, fig. 2), the positions of supposedly immature seeds are clearly shown, but the general proportions of the specimen are somewhat smaller than those of the Oklahoma specimen. Cridland and Morris illustrated a second specimen (Cridland and Morris, 1960 , fig. 9, p. 859), which they cited as a fertile leaf seen from the adaxial side, with "swellings which indicate the positions of immature seeds." This specimen and the Oklahoma specimen compare favorably in such characters as width of the leaf; proportional widths of lamina and midrib; density and attitude of the secondary veins; size, shape, and distribution of the seeds; and termination of the seeds apices exactly at the margins of their respective parent laminae. To judge from the indistinct seed outlines in the Oklahoma specimen, it may be assumed that the surface of this specimen represents the upper or adaxial surface of the leaf and, as in the case of Cridland's and Morris' specimen, the thickness of the foliar tissue obscured the details of the seeds in the fossils.

The Oklahoma specimen conforms with the generic diagnosis of Spermopteris in having a row of seeds or seedlike bodies on each side of the midrib of a taeniopterid leaf, but specific alliance cannot be attempted because of the limitations of material. However, a few remarks about specific identifications are added here because there is some evidence that this particular specimen was given more than passing attention by David White.

In discussing the relationships of Spermopteris, Cridland and Morris (1960, p. 859) commented on Von Gutbier's (1835, p. 73) original description of Taeniopteris abnormis, wherein he mentioned but did not illustrate specimens with shallow crosswrinkles ("flache Querfalten") toward the tips of the leaves. Apparently Cridland and Morris regarded this condition as a possible point of comparison with Spermopteris but did not pursue the idea further because of the unavailability of additional information. White $(1912$, p. 507) published a provisional list of plants from the Perry, Okla. locality. This list includes Taeniopteris multinervis Weiss and T. abnormis Gutbier, but no indication was given of the number of specimens of each that were present. The original collection contains just nine specimens of Taeniopteris, mostly very badly preserved. As the Oklahoma Spermopteris specimen is the only taeni- 
opterid in that suite that can be distinguished from the others on morphological grounds, it seems likely that White had studied this very specimen, equated its seedlike swellings with Gutbier's "flache Querfalten," and identified T. abnormis in the Oklahoma collection. In the same paper, White $(1912$, p. 506) also listed T. abnormis among the plants collected at the Fulda, Tex. locality (USGS locality 8877), but I have not been able to ascertain the basis for that identification.

This occurrence extends the known geographic range of Spermopteris from eastern Kansas to north-central Oklahoma. At the same time, the stratigraphic range of the genus is extended upward from the Upper Pennsylvanian (Virgilian) to the Lower Permian, where it is associated with Gigantopteris americana in flora zone 14 (Read and Mamay, 1964).

Occurrence.-USGS paleobotany locality 6233.

Figured specimen.-USGS 6233-1 (pl. 2, fig. 2).

\section{Division CYCADOPHYTA Order CYCADALES \\ Genus ARCHAEOCYCAS Mamay}

New genus B. Mamay, 1969b.

Archaeocycas Mamay, 1973.

Type species.-Archaeocycas whitei Mamay.

Generic diagnosis.-Bilaterally symmetrical fertile appendage (megasporophyll) with broad midrib; several pairs of apparently sessile, closely appressed ovules borne in two lateral rows on surface of reduced basal part of lamina; ovules closely invested by lamina, each with a small circular scar of attachment to lamina near midrib. Distal part of appendage expanded as flattened sterile foliar blade.

\section{Archaeocycas whitei Mamay}

Figure 3; plate 1; plate 2, figures 5-7

Archaeocycas whitei Mamay, 1973, p. 687, fig. 1, a-c.

Specific diagnosis.-Megasporophylls cuneiform, ovate, or lanceolate, $1.7-2.3 \mathrm{~cm}$ long, with greatest widths of $1.0 \mathrm{~cm}$. Midribs straight, flat, faintly marked with closely set parallel striations; midrib widths uniform or increasing distally from 1.0-1.3 $\mathrm{mm}$ at the bases to $3.0 \mathrm{~mm}$ at distal termini of fertile areas; midribs flaring out conspicuously or becoming obscure in distal, laminar parts of megasporophylls; sides of midribs more or less concavely scalloped through appression with ovule bases.

Proximal fertile area $1.2-1.6 \mathrm{~cm}$ long, $3.0-5.0 \mathrm{~mm}$ wide at base, nearly uniform in width or increasing distally to width of $9.0 \mathrm{~mm}$. Ovules produced in opposite pairs, four to six ovules in each row. Ovules oblong, oblanceolate, rhombic or rhomboidal, tightly appressed with each other, obliquely directed forward at broad angles to the rachis. Basalmost ovules proportionately shorter, broader than distal ones; ovules 1.5-3 mm long (measured along lines of appression between contiguous ovules), $1.5-3.0 \mathrm{~mm}$ wide (measured along outer free margins and along lines of appression with the rachis), reaching $5 \mathrm{~mm}$ in greatest (diagonal) dimension. Ovules each with a small circular shallow depression or attachment scar, $0.7-1.0 \mathrm{~mm}$ in diameter, uniformly placed on the upper surfaces of ovules near the center of area of ovular appression with the midrib. Upper (adaxial) surfaces of ovules closely invested by foliar lamina; extent of lamina over lower (abaxial) ovular surfaces unknown; laminar investment of ovules showing fine closely spaced parallel striations perpendiculan to midrib.

Megasporophylls abruptly modified into sterile laminar structures immediately distal to distal pair of ovules, and contiguous with ovules; extent, venation, and margination of distal laminae obscure.

Holotype.-USGS 8877-1 (pl. 1, fig. 5).

Paratypes.-USGS 8877-2, 3, 4 (pl. 1, fig. 3, 4; pl. 2, fig. 7) ; USGS 8959-1, 2 (pl. 1, fig. 1, 2; pl. 2, fig. 5, 6).

Occurrences.—USGS paleobotany localities 8877 , 8959.

\section{DESCRIPTION}

This description is based on eight specimens, six of which were collected by White at the Fulda locality (USGS paleobotany locality 8877) in 1910. Although I could not find White's locality, I was fortunate in discovering two additional specimens of Archaeocycas at the "Emily Irish" locality (USGS paleobotany locality 8959 ) in 1963 ; the two associated floras are substantially the same and presumably occupy the same stratigraphic position within the Belle Plains Formation. Although White never published an account of his specimens, it is obvious that he recognized them as unique or important, because I found them carefully trimmed, encircled in crayon marks, and segregated from the remainder of his Fulda collection in a separate tray.

The specimens are preserved as compressions with a moderate amount of relief that aids somewhat in their interpretation. Only small amounts of carbonaceous residue remain, but enough of this is present to provide some critical information. Three of the Fulda specimens are casts (pl. 1, figs. 4,$5 ; \mathrm{pl}$. 2, fig. 7), two are molds (pl. 1, figs. 1, 3), and the remaining one is available as both counterparts. 
Each of the two "Emily Irish" specimens consists of both counterparts; these are shown in plate 1 , figures 1 and 2, and plate 2, figures 5 and 6 . Unfortunately no cuticularized material is preserved; matrix samples from both localities were processed for palynological analyses, with negative results.

The specimens are each characterized by a fertile basal area, which is neatly and symmetrically "compartmented" (pl. 1, figs. 4, 5; pl. 2, fig. 7), and a distal, usually poorly preserved laminar extension. A superficial examination of this material might prompt the conclusion that the paired inflated objects borne along the basal extent of the midrib are vegetative pinnules, but close inspection necessitates another interpretation. If these were ordinary pinnules rather than casts and molds of expanded threedimensional bodies, the abrupt transition from a basal area of distinct pinnulation to the rather vague, poorly defined distal lamination would contrast markedly with the conventional type of pinnate foliar appendage. Again, if these were ordinary pinnules, one might expect some overlapping or other irregularities of attitude such as is found ordinarily in pinnate plant fossils. Instead, these bodies show no sign of overlapping but present the appearance of firmly attached solid objects of considerable depth; they abutted laterally against each other, with the result that contiguous sides were noticeably flattened (pl. 1, figs. 4,$5 ;$ pl. 2 , fig. 7 ). In the absence of compelling alternative evidence, these objects are regarded as the fillings of ovules, probably buried in an immature stage of development; consequently, the term "ovule" is applied herewith.

The casts are the most informative of the available specimens. Although most of the casts are lacking in carbonaceous residues, most of which adhered to the molds when the specimens were split, all the casts show remnants of a substantial thickness of coalified organic material separating contiguous ovules. These films, which average about $0.15 \mathrm{~mm}$ in thickness, are clearly seen on plate 1 , figures 4 and 5 , and plate 2, figures 6 and 7. The holotype (pl. 1, fig. 5) is particularly interesting in this respect. When tilted and viewed edgewise, the ovules are seen to reach thicknesses of $1.0 \mathrm{~mm}$ or slightly more, and the presence of coaly films beneath the edges of the ovules indicates that the ovules are actually the sedimentary casts or mud fillings of hollow bodies that were of sufficient substance to resist compaction. Most of the specimens were deposited with their flat surfaces normal to the surface of the enclosing sediment; the specimen shown in plate 2, figure 7, however, was deposited edgewise on the bedding surface and therefore gives some idea of the thickness of the ovules, which are seen nearly end-on in a side view of the sporophyll.

The coaly films separating the ovules from each other are interpreted as the organic residue of part of the investing lamina, which originally was deeply creased so as to intrude downward between the ovules. When the sporophylls were compressed, the foliar tissue was "pinched" between the flattening and laterally expanding ovules and is now preserved as a thin coalified film. The remainder of the foliar residue adhered to the counterparts, or molds ; there the grooves between ovules lack any coaly residue. This distribution of organic residue between counterparts of a given specimen is well demonstrated on plate 2, figures 5 and 6 .

The scalloped outlines of the midribs are also delimited by a thin coaly film that separates the ovules from the midribs (pl. 1, figs. 4, 5; pl. 2, fig. 6). Tilting and edgewise observation of these specimens show that the coaly film continues downward and toward the median axis of the midrib. Thus the midrib seems to have been compressed into a flangelike form, partly covering the upper surface of the foliar lamina in the fertile region of the sporophyll. Compression of the midrib probably caused an entrapment of foliar tissue between the rachis and ovules, similar to that between the ovules; the result is a gently curved longitudinal continuity of the coaly films separating contiguous ovules (pl. 2, figs. 5, 6).

These features favor the interpretation of these basal objects as originally distended tightly appressed bodies rather than flattened vegetative pinnules. They are emphasized in order to justify the diagnosis of the basal objects as ovules. Unfortunately, none of the specimens are exposed in bottom (abaxial) view, so that details of the opposite sides of the sporophylls and ovules are not known.

The ovules are arranged in opposite pairs. The specimen shown on plate 2 , figures 5 and 6 , has only four pairs, the smallest number of ovules observed. Some specimens have five pairs each (pl. 1, figs. 35 ), and others have six, the largest number observed (pl. 1, figs. 1, 2; pl. 2, fig. 7). The shape of the ovules varies somewhat, those at the basal end of the sporophyll being proportionately the longest in the direction parallel to the axis of the sporophyll; these variations in size and shape of ovules are shown on plate 1 , figure 5. The overall length of the fertile areas of the sporophylls ranges from about $1.2 \mathrm{~cm}$ in the smallest specimen (pl. 2, fig. 5) to $1.6 \mathrm{~cm}$ in the largest (pl. 2, fig. 7). The aggregate of ovules on a given sporophyll may be of an almost uniform width 
(pl. 1, fig. 3) or may show a wedgelike shape, the width increasing in the distal direction (pl. 1, figs. 4, 5).

Many of the ovules have a single small circular depression or scar; these range from 0.7 to $1.0 \mathrm{~mm}$ in diameter. Each of the eight ovules shown on plate 2 , figures 5 and 6 , has one of these marks; these are most clearly shown on the mold (pl. 2, fig. 5). The uppermost pair of ovules on plate 1, figure 4, shows these marks as distinct, fairly deep pits. Two others are seen on plate 2 , figure 7 , where they are partly filled with a carbonized residue. The scars are uniformly placed, next to the midrib at approximately the middle of the ovule. The scars on the specimen shown on plate 2 , figure 5, are of additional morphological interest because each one has a centrally located circular scar, approximately one-third of its own diameter.

Because of their occurrence, one to an ovule, these marks are interpreted as remnants of points of attachment to the lamina. There is no evidence of a stalk, so the ovules are regarded to have been sessile, with a small point of attachment; the subsidiary marks on the scars shown on plate 2 , figure 5, may represent points of entry of vascular strands into the bases of the ovules. The position of these marks, relative to the lamina and rachis, is essentially identical with the position of seed attachment in Spermopteris, as reconstructed by Cridland and Morris (1960, fig. 10).

Evidence of a laminar element in the ovuliferous area of the sporophyll is variously shown in the suite of specimens but is best seen on the specimens illustrated on plate 1 , figures 1 and 2 . These are counterparts of the same sporophyll; figure 1 shows the mold, figure 2 , the cast.

The mold has retained much of the coalified residue of the specimen, and many of its details are relatively obscure. However, the right half of the photograph shows not only the grooves separating the ovular impressions, but also a series of closely spaced parallel ridges and grooves, oriented at a broad angle decurrently to the midrib. These are indicative of a system of fine foliar venation.

The cast shows an important additional detail, indicated by the arrow in plate 1 , figure 2 . In this specimen, the grooves between contiguous ovules are clearly shown, but the most distal groove is incomplete; that is, it does not extend entirely to the margin of the lamina, as do all the others. This is evidently a function of the fact that this particular groove is beyond the most distal ovule, and the absence of the pressure of a contiguous ovule permitted the marginal part of the involute lamina to flatten out and merge with the distal sterile lamina. This demonstrates a continuity of lamina between fertile and sterile parts of the sporophyll.

On the basis of the foregoing, it is well established that the ovules of Archaeocycas were borne on a laminar blade, which seems to have at least partly enclosed the ovules. The evidence bearing on extent of the enclosure is incomplete, however.

All but one of the specimens show remnants of a distal foliar lamina immediately above the uppermost pair of ovules. The longest lamina is shown on plate 2, figure 7 , where it extends about $6 \mathrm{~mm}$ beyond the last ovule, and constitutes nearly one-third of the total length of the specimen. The complete extent of the lamina or features of its margination are not known. As shown on plate 1, figures 3-5, and plate 2 , figures $5-7$, it forms as a distal continuation of the midrib, which normally flares out rather abruptly; the striations of the midrib also diverge to present a vague suggestion of a fanlike system of fine veins.

The specimen shown on plate 2 , figures 5 and 6 , differs from the others in that the strong midrib essentially retains its identity as far as its broken distal end, and the lamina evidently decreases in width distally, instead of expanding as all the others do. The lamina shows faint striations, decurrently directed away from both the midrib and the ovules, so that the orientation of the photograph seems to be correct; that is, the morphologically proximal end of the specimen is directed downward on the plate. This conclusion is corroborated by comparisons of the shapes and decurrent attitudes of the ovules of this specimen with all the other specimens. The acute distal tapering of the lamina seems anomalous when compared with the other specimens; this, however is not an accident incurred when the matrix was split, because the laminar margin along the upper left of the photograph is entire and intact. Thus, in this particular specimen the distal laminar extension was significantly smaller than those seen in the other specimens ; and perhaps this one is nearly complete except for its very tip.

Another variation in the form of the distal lamina is seen in the holotype (pl. 1, fig. 5). In this specimen, the distal lamina is very broad in proportion to the widest part of the fertile area. This is indicated by a conspicuous folding of the lamina, which is seen in the photograph to begin in the middle of the midrib at a level approximately even with the uppermost pair of ovules. The resultant crease proceeds obliquely toward the upper right of the photograph, meanwhile deepening and continuing as far as the 


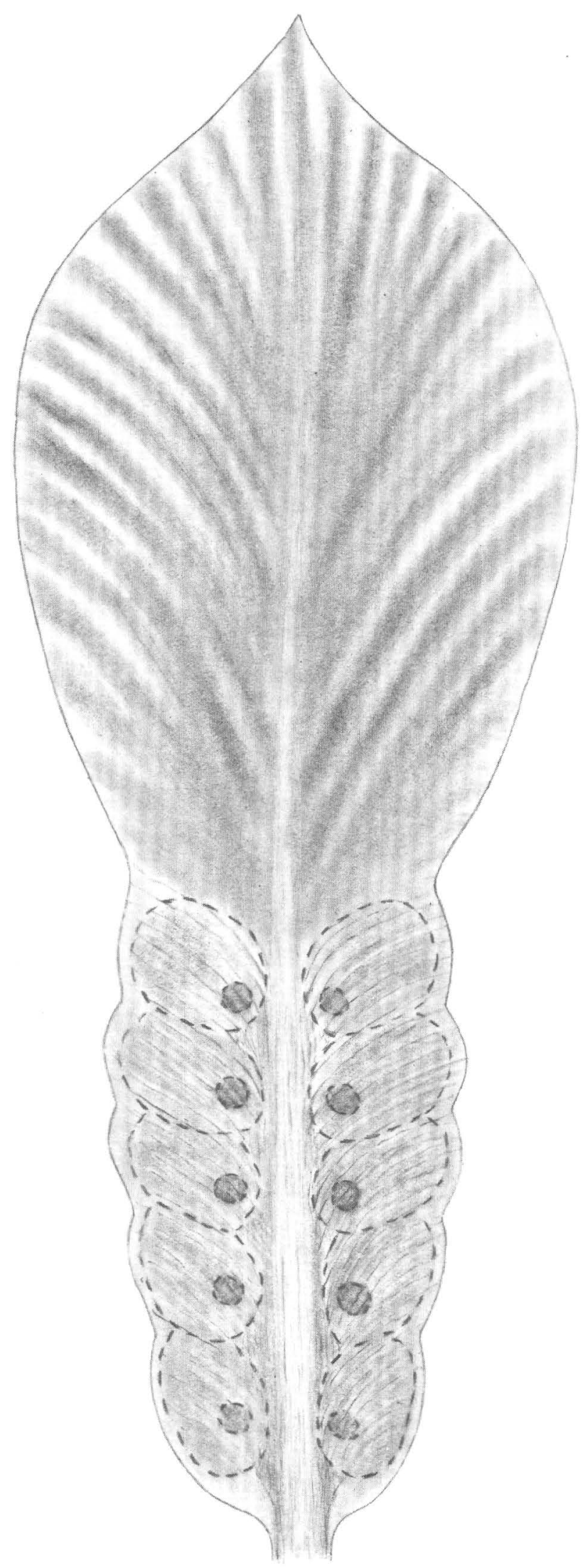

broken distal edge of the lamina. This folding or distortion had no noticeable effect on the symmetrical arrangement of the two rows of ovules below; the intactness of the symmetry may be interpreted to mean that the ovuliferous part of the appendage was quite rigid and capable of resisting distortion. The absence of the lowermost ovule on the right side of this specimen is due to breakage during splitting of the matrix, for when the specimen is tilted at a high angle and viewed from the side, remnants of the broken base of the missing ovule are evident.

There is no extensive information regarding the manner of attachment of Archaeocycas. A minor bit of evidence, however, is seen at the basal end of the specimen shown on plate 2, figure 7 . At the left end of the specimen, the broken end of the midrib increases abruptly in thickness, and remnants extend toward both the top and bottom of the figure. This indicates that the base of the sporophyll occurs immediately next to the proximal pair of ovules, and the sporophyll therefore had no extended stalk. It also suggests connection to a supporting axis whose orientation would parallel the left edge of the plate. In consideration of the fact that this particular specimen was laterally compressed in preservation, the basal enlargement of the rachis might be taken to indicate that the parent axis was perpendicular not only to the direction of the midrib but to the natural plane of the lamina as well. Thus the Archaeocycas specimen represents a lateral appendage equivalent to a leaf, rather than a subdivision of a compound leaf.

A partly diagrammatic restoration of a sporophyll of Archaeocycas is presented in figure 3.

\section{DISCUSSION}

Cycadean affinity of Archaeocycas.-Morphological interpretations and taxonomic assignment of Archaeocycas revolve about consideration of the following unique combination of structural features, which, insofar as I know, occurs in no other Paleozoic plant and validates the status of Archaeocycas as a new genus:

1. It is a bilaterally symmetrical flattened leaflike appendage.

FIGURE 3.-Reconstruction of megasporophyll of Archaeocycas whitei, showing upper (?adaxial) surface. Fertile basal part of megasporophyll rendered transparent to show ovules (broken lines); darkened circular areas represent points of attachment of ovules to lamina. Shape and extent of sterile distal lamina hypothetical. For view of lower surface of megasporophyll see figure $7 \mathrm{~A}$. 
2. It is clearly differentiated into two areas, the distal one which is sterile, and the basal one which is fertile. The basal or fertile part of the lamina is somewhat reduced, and on its lower surface it bears two lateral rows of large paired conspicuous bodies that are interpreted as ovules; the fertile lamina seems to have invested the ovules tightly and was involute so as to at least partly enclose the lower surfaces of the ovules. A simple small circular scar occupies the same relative position on each ovule.

The small circular scars on the fertile laminae are difficult to interpret in terms other than scars of attachment; likewise, the large size of the bodies attached thereto strongly suggests ovules. Additional evidence in support of their ovular nature is found in their resemblance to the seeds of Spermopteris and the manner in which the bodies were borne. The crowded closely appressed arrangement and shapes of the ovules of Archaeocycas are probably a function of immaturity at the time of preservation, and a function of the way in which the ovules were enclosed by the foliar lamina. When the plant matured, the fertile bașe of the sporophyll probably elongated rapidly to accommodate the increasing size of the ovules. The fertile lamina may have ceased to grow as the rachis and ovules enlarged, with the result that only inconspicuous distorted remnants of the fertile lamina remained to maintain the attachment of ovules to sporophyll. Thus, mature sporophylls, if found fossilized, could be difficult to recognize as later ontogenetic stages of the material upon which this description of Archaeocycas is based.

Phyllospermy-the condition in which seeds were borne directly upon more or less unmodified leaves (Sahni, 1920, p. 300) -is a phenomenon that became well established during late Paleozoic time. Several examples appear repeatedly in the literature as the result of important work by Halle (1929). Spermopteris is a clear example of phyllospermy; the Texas Permian has recently produced two distinctive but probably unrelated forms (Padgettia Mamay, 1960; Tinsleya Mamay, 1966), and now Archaeocycas may be added to the growing list. Archaeocycas stands apart from all other fossils of this general nature in having its ovules restricted to the basal part of the sporophyll. From the standpoint of symmetry of ovular insertion, striking comparisons may be drawn between Archaeocycas and Spermopteris, but the latter genus shows no evidence of sharp segregation of the reproductive function to the basal part of the sporophyll. The trend toward reduction of the basal part of the lamina, as demonstrated in Archaeocycas, is another important point of distinction between Archaeocycas and Spermopteris. A continuation of that trend obviously could result in a megasporophyll much like that of Cycas, and for this reason I regard Archaeocycas as an extremely significant stage in the evolution of the cycads. In recognition of these Permian fossils as representatives of a precursive cycadean stock, I have therefore applied the generic name Archaeocycas. The species A. whitei is named for David White, who found most of the specimens on which the description is based.

\section{Genus PHASMATOCYCAS Mamay}

New genus R. Mamay, 1969a.

Phasmatocycas Mamay, 1973.

Type species.-Phasmatocycas kansana Mamay.

Generic diagnosis.-Fertile axis with two lateral rows of sessile, broadly attached gymnospermous cvules; ovules simple, with blunt, funnel-shaped micropyles, two distinct cuticular layers, and a thick megaspore membrane; laminar tissue unknown, interseminal appendages lacking.

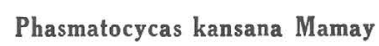

Phasmatocycas kansana Mamay, 1973, p. 689, fig. 1, d-g.

Specific diagnosis.-Axial fragment $2.5 \mathrm{~cm}$ long, relatively stout, $2.5-4.0 \mathrm{~mm}$ wide, rather abruptly broader at (?) basal end of specimen; surface of axis with obscure narrow longitudinal striations, lacking other characteristic markings.

Bilateral arrangement of ovules symmetrical; no evidence of ovules between lateral rows. Ovules inserted alternately to suboppositely, extending essentially perpendicularly to axis, closely arranged as to juxtapose against but not overlap each other. Ovules 2.8-4.0 $\mathrm{mm}$ long, $2.0-2.6 \mathrm{~mm}$ wide, ovoid to oblong, broadly attached with point of attachment to axis nearly as long as greatest width of ovule; ovular apices blunt, some specimens with a shallow apical cleft or notch.

Cuticular envelopes slightly smaller than impressions of ovules, lacking ornamentation; cuticles apparently complete except for micropylar openings; apices of cuticles gradually decreasing in diameter, without marked constriction, terminating in micropylar openings $0.2-0.5 \mathrm{~mm}$ wide; specialized chalazal features absent. Outer cuticle very thin, diaphanous, with elongate cells reaching 20 by $80 \mu \mathrm{m}$ (micrometres) in dimensions, parallel to long axis of ovule. Inner cuticle apparently thicker and separate from outer; cells thick walled, walls abruptly increasing 
in thickness toward the micropylar area; cells in micropylar area essentially isodiametric, averaging $10 \mu \mathrm{m}$ in diameter. Megaspore membrane essentially filling cavity within cuticles; membrane dense, lacking ornamentation.

Small $(0.25-0.33 \mathrm{~mm}$ in diameter) spherical sessile bodies with resinlike luster regularly alternating with ovules in each row; one such body partly imbedded in axial tissue at point between and approximately level with bases of two adjacent ovules.

Holotype._USGS 8869-1 (pls. 3, 4).

Occurrence._USGS paleobotany locality 8869 .

\section{DESCRIPTION}

Phasmatocycas kansana is based on one specimen from the Banner, Kans., locality. Fortunately, both counterparts of the specimen are available, and although only a short fragment of the axis was found, it is sufficiently well preserved that some important details are observable. The specimen is preserved in a matrix of very hard dark-gray limestone of poor fissibility and apparently not very rich in plant material.

Both counterparts of the specimen are shown on plate 3 (figs. 1,2). As the axis is broken at both ends, it is impossible to ascertain what the total length of the fertile structure was, but it may have been considerably more than the $2.5 \mathrm{~cm}$ preserved here.

The axis itself lacks any conspicuous morphological features, and only the fact that one end of the fragment is somewhat broader than the other gives one any basis for differentiating between the distal and proximal ends; I assume that the wider end $(4.0 \mathrm{~mm})$ is proximal and the narrow end $(2.5 \mathrm{~mm})$ is distal. Parts of each of the axial counterparts carry flecks of a fairly thick carbonaceous residue, but no traces of a cuticle are preserved.

Faint, closely spaced longitudinal striations appear in a few small areas on the axial surface; these are distributed over nearly the entire width of the axis and probably are best interpreted as striations caused by wrinkling of the original surface or as impressions of the vascular system of the axis. There are no traces of a foliar lamina between or projecting beyond the apices of the attached seeds, and, in consideration of the generally good preservation of the specimens, it may be concluded that this fragment is indeed lacking in any sort of foliar lamina. Indirect evidence regarding foliation of Phasmatocycas is presented on subsequent pages.

The most impressive feature of Phasmatocycas is its two lateral rows of seeds, the near-perfect aline- ment of which attests to the bilateral morphology of the appendage and precludes any interpretation of the seed insertion as a spiral system. Furthermore, the axial surface between the two rows of seeds shows no evidence whatsoever of scars of seed attachment that might provide a basis for challenging a bilateral interpretation for the seed arrangement of Phasmatocycas.

The seeds are mostly preserved as flattened molds, each of which contains a double seed cuticle and megaspore membrane on one or the other of its counterparts. The outlines of the molds are usually slightly wider and longer than the contained cuticles. This preservational feature is well shown in the detached seed at the left of figure 1 , plate 3 ; here the mold is about $2.5 \mathrm{~mm}$ wide and the enclosed cuticle is slightly less than $2.0 \mathrm{~mm}$ wide. The consistent presence of these flattened, slightly hollow seed cavities in the matrix surrounding the completely flattened cuticles suggests that the outermost layers of the seeds were fleshy integumental layers that were not adapted to fossilization. These integuments did resist compaction to a certain extent, however, and resulted in production of the slight cavities in the limestone, left there as molds when the integumental tissues disintegrated. Flakes of fairly thick coalified residue on the surfaces of some of the cuticles attest to the original presence of such an integumental layer.

In general proportions, most of the seed molds are less than twice as long as they are broad; their broad bases and blunt apices thus lend them a nearly oblong shape in most instances. Most of the seed bases are only slightly narrower than the widest parts of the seeds, and the actual point of attachment may even slightly exceed the width of the seed. The broadly sessile nature of the ovules is best seen on plate 3, figure 4 . The same figure shows another interesting, although perhaps not especially significant feature of the seed molds-a shallowly bifid or notched apex that appears in several of the specimens. These notches range form 0.2 to $0.3 \mathrm{~mm}$ in depth and tend to give one the initial impression that these are the molds of platyspermic seeds, because several previously described genera of supposedly platyspermic seeds have apical notches. Cridland and Morris (1960) described and illustrated similar apical notches in the seeds of Spermopteris. They speculated (Cridland and Morris, 1960, p. 857) that the apical cleft "may have been caused by fracture of the micropyle during compression or may be a natural feature of the seeds." In the case of Phasmatocycas, I prefer to interpret the apical clefts as a 
mechanical result of compression rather than a natural feature of the seeds. This seems to be a preferable interpretation because no consistent feature of the cuticles indicates a cleft micropyle in Phasmatocycas.

Associated with the axis are 21 seeds; one is detached but the others are preserved in their original positions of attachment. It is not possible to ascertain whether or not they were arranged in morphologically opposite pairs, because some are subopposite or slightly alternate to each other, perhaps as a result of slight preservational distortion of position. Nearly all the seeds, however, extend outward from the axis at right angles (pl. 3, figs. 1, 2) and give the impression that they were firmly attached. They are so close to each other that their sides are in physical contact with each other, but there is little overlapping. The seeds are essentially the same size and in the same condition of preservation from one end of the specimen to the other. Thus it would seem that all the ovules matured simultaneously.

All the seed cuticles are, in part, only loosely adherent to the limestone matrix. Consequently it was possible to remove three nearly complete cuticles and parts of two others. These were cleared of coalified remnants of integumental tissues and other humic components by the standard palynological clearing technique, using a mild Schultze's solution followed by washing and treatment with potassium hydroxide. This method cleared the specimens sufficiently for micruscopic examination. The cuticles were then mounted on glass slides in a synthetic resin mounting medium. Some of the specimens are shown on plate 4 . The evidence for an ovulate nature of the inflated bodies in Archaeocycas is partly inferential, but Phasmatocycas has genuine gymnospermous seeds. The description of the cuticles on the following pages leaves no room for doubt.

The best cuticular specimen, shown on plate 4 , figure 3 , is nearly complete except for the absence of a large patch of material within the almost-intact margin of the lower half of the seed. This specimen is $3.2 \mathrm{~mm}$ long and $1.8 \mathrm{~mm}$ wide. The broken specimen shown on plate 4 , figure 4 , is $3.3 \mathrm{~mm}$ long, and in its entirety it must have been at least $2.2 \mathrm{~mm}$ wide. Another nearly complete specimen, not illustrated, is $2.0 \mathrm{~mm}$ wide, but its length is not known. This one is the broadest of the cuticular specimens removed from the matrix; other larger specimens are still attached to the axis.

As shown on plate 4, figure 3 , the megaspore membrane is a heavily cutinized thick envelope. It is variously folded and wrinkled, as indicated by the dark stripes where two or more thicknesses of the membrane are involved. Thus, the light-colored patch below the middle of the seed shown on plate 4, figure 3 , represents a single layer of megaspore membrane; the darker area above it consists of a double layer, and the still darker stripes represent folded areas of four layers. Although the chalazal outlines of the megaspore membranes are quite plain, their apical contours are difficult to differentiate because of optical interference by the thickened surrounding cuticles in the micropylar areas of the seeds. On plate 4, figures 4 and 5, however, the dim outline of the apex of the megaspore is seen passing over the upper part of the seed approximately $0.5 \mathrm{~mm}$ below the seed apex, or the area that presumably constituted the bottom of the pollen chamber. Although the megaspores are heavily cutinized membranes, they do not have any conspicuous or characteristic ornamentation.

It is clear from the apical areas of the seeds that two distinct cuticles are present. This is shown in all of the photographs on plate 4 . The cuticles are difficult to differentiate through the entire length of the cleared specimens, however, and they may not have been sufficiently developed in the basal parts of the seeds to be preserved. In the specimen shown on plate 4 , figure 3 , the faint outlines of cuticular cells are observable down to about the midsection of the seed; in that area, only one layer is visible, however, and the differentiation into two layers is not apparent below approximately the apical $0.75 \mathrm{~mm}$ of the seed. The specimen shown on plate 4, figure 4, seems to be the best preserved from this standpoint, for cellular outlines of the isodiametric type that characterize the inner cuticular layer are visible proximally about as far as the median part of the seed.

At about the level of the "shoulders" of the seeds, or 0.7 to $0.8 \mathrm{~mm}$ below the seed apices, the inner cuticle thickens abruptly, whereas the outer cuticle remains very thin and barely visible in many places. Apparently the outer cuticle is separate from the inner; the distinction between the two layers is shown on plate 4, figures 1 and 5 . Most cells of the outer cuticle are elongate, reaching lengths of 50-80 $\mu \mathrm{m}$, and have widths of one-fourth or less of the length; these cells are oriented with their long axes parallel to the length of the seed. The isodiametric cells of the inner cuticle average about $10-15 \mu \mathrm{m}$ in any direction; their walls are very thick, particularly in the area immediately above the distal surface of the megaspore membrane. As shown on plate 4, figures 1 and 5, this wall thickening decreases abruptly in the terminal $0.2-0.3 \mathrm{~mm}$ of the micropyle. 
The micropylar narrowing of the cuticular envelope is shown on plate 4 . All the illustrated specimens show a gentle tapering of the apical "funnel." The actual openings of the micropylar canals range from 0.2 to $0.5 \mathrm{~mm}$ in width. The tips of the micropyles shown on plate 4 , figures 1,2 , and 3 , are slightly damaged, but the one shown on figures 4 and 5 is essentially intact and shows no evidence of a bifid tip. If any specialized pollen-receiving structures were within the seed apices, no evidence of such is preserved in the fossils. The present material permits only the assumption that the seeds of Phasma tocycas had a simple pollen chamber, accessible through a short, evidently unspecialized micropylar canal, which was delimited by the thick inner cuticle. The cleared specimens show no evidence of internal vasculature or pollen grains within the micropylar areas.

Interpretation of the morphological nature of the two cuticles of Phasmatocycas is aided by reference again to two of the preservational features of these seeds. First, the presence of flat cavities or seed molds in the matrix, somewhat larger than the cuticular outlines, indicates that a thick integument originally surrounded the seeds. This deduction is supported by the second pertinent feature, the presence of thick flecks of coalified organic residue on the outer surfaces of the cuticles. Thus, the absence of any trace of an outer integumental cuticle, which should have directly lined the seed molds, indicates that the thin outer cuticles of the cleared specimens represent the inner cuticular lining of the integument. Accordingly, the thickened inner cuticles are interpreted as the surface of the nucellus.

These interpretations are supported to some extent by Harris' (1941) study of the seeds of the Jurassic cycad Beania. Attention is directed to a comparison of the cleared specimens of Phasmatocycas (pl. 4) with Harris' (1941, pl. 5, fig. 14) preparation of the inner cuticles of a seed of Beania gracilis. In both instances, very similar sets of thickened membranes are preserved. The Beania contains a thick megaspore membrane surrounded by a relatively thick cuticle (nucellar), which in turn is enclosed by a thin inner integumental cuticle. The "apical spike" of Harris' Beania is not present in Phasmatocycas, nor does the nucellar cuticle of the Beania flare upward into the conelike projection present in Phasmatocycas. These differences in details of apical morphology of the two genera of seeds reduce the exactness of comparison, but the similarities point up the fact that the Phasmatocycas seeds are similar to those of the Jurassic cycads.
The excellent preservation of seed cuticles suggested the possibility that a palynological examination of the matrix might corroborate a cycadalean interpretation of Phasmatocycas. Chips of the limestone were submitted to R. A. Scott who reported (written commun., 1968) as follows:

The search for palynological evidence for the presence of cycadophytes was unsuccessful. Only a very few apparently monosulcate grains were seen; these were considered as unreliable because they 1) could be folded fern spores or 2) resembled the pollen of gingkophytes more closely than that of cycadophytes.

Because of poor preservation, these results do not in any way preclude the presence of cycadophyte pollen; they simply fail to establish it.

One other feature of Phasmatocycas invites close attention. Both counterparts of the holotype bear either the impressions or the actual substance of a number of tiny, almost perfectly spherical bodies, which measure $0.25-0.33 \mathrm{~mm}$ in diameter. Where the actual spherule is present on one counterpart, the impression is usually visible on the opposite counterpart. These bodies do not seem to have been compressed or distorted from a spherical shape during the process of preservation. The spherules are dark brown to black, and although most have lustrous surtrous surfaces, faint rugosity is evident on some specimens. Some are translucent and reddish brown suggestive of a resinoid composition.

One might first be tempted to interpret these spherules as a fortuitous concentration of foreign objects not related to Phasmatocycas. However, their distribution indicates that they are not all randomly placed, which necessitates the conclusion that the spherules are a natural part of the fertile axis.

A few of the spherules are present on the axis in random positions, whereas a few others are in the matrix a short distance away from the specimen. The most significant aspect of their distribution, however, is the fact that many of the spherules occur on the axis at the bases of the seeds, and most of these occupy positions exactly between two adjacent seeds; none occur directly on the seeds. This regular arrangement is shown on plate 3 , figures 3,4 , and 5. Plate 3, figure 3, shows this feature particularly well. Such a positional relationship between the seeds and spherules can hardly be accidental. Rather, it indicates that the spherules are a natural feature of Phasmatocycas and, inasmuch as they are intercalated between adjacent seeds, they should be approximately equal in number to the 21 seeds found on the type specimen. By actual count, the specimen contains the remains or impressions of 24 spherules. 
The slight disparity between numbers of spherules and seeds may reflect an originally weak attachment of spherules to the axis, some having been displaced from their natural positions and shifted to other locations during burial of the specimen.

If one accepts the distributional pattern of the spherules as evidence that they were originally attached to the axis of Phasmatocycas in two rows like the rows of seeds, one spherule placed between each two successive seeds, one then faces the problem of interpretation of these objects.

Because of their uniformity in size, shape, and distribution, the spherules are best interpreted as the remnants of regularly placed glands; the spherules represent the coagulated acellular contents. These hardened before burial and retained their naturally spherical shapes during induration of the matrix. Regardless of their functions, the glands constitute a point of comparison with associated leaf remains; this comparison warrants further elaboration because of its inferential bearing on the morphological identity and systematic placement of Phasmatocycas.

DISCUSSION

Evidence for a megasporophyllar interpretation of Phasmatocycas.-Phasmatocycas kansana shows no direct evidence of attachment to a foliar lamina. Because of the strikingly cycadlike nature of this fertile organ, however, it is well to examine closely whatever evidence is available in the direction of establishing or refuting a megasporophyllar character for Phasmatocycas. Certain compelling evidence is indeed present in the form of associated taeniopterid leaves bearing resinoid spherules that seem identical with those on the ovuliferous axis of Phasmatocycas.

The small assemblage of plants associated with the holotype of Phasmatocycas kansana contains seven fragments of narrow taeniopterid leaves, most of which are poorly preserved; the largest specimen is about $10 \mathrm{~cm}$ long. All these specimens bear either the impressions or the actual substance of small spherules, which compare closely in size with those of the fruiting axis. Their preservation is mostly inferior to preservation of the glandular remains on Phasmatocycas, but in two of the leaves, the spherules are identical with those of the fertile specimen in color and surface features. Distribution of the spherules or glands varies; in some of the leaves, the glands are more or less evenly scattered over the surfaces, but in one specimen they are concentrated near the margins of the lamina. Only a few of the glands appear directly on the midribs.
Another small collection from a nearby site also has taeniopterid material containing resinoid spherules. This collection (USGS paleobotany locality 8298) was made " $31 / 2$ mi. SE of Elmo"; the sources of this material and of the holotype of Phasmatocycas (USGS paleobotany locality $8869 ;$ " $31 \frac{1}{2} \mathrm{mi}$. S. of Banner") are probably the same outcrop, because Dunbar (1924, p. 174) pointed out that Elmo was "at one time called Banner City." Lithologic comparisons suggest that the two collections were made from the same rock unit.

This collection contains nine fragments of taeniopterid foliage, which is not distinguishable from the leaves from locality 8869. Most of these leaves are poorly preserved, but some show evidence of at least a few of the spherical bodies. One of these specimens, by contrast, is quite well preserved and is remarkable because of the large number of resinoid glandular remains or hemispherical impressions borne on its surface. This specimen is shown on plate 5 (figs. 5-7).

Plate 5, figure 5, shows the entire specimen, which is $6.5 \mathrm{~cm}$ long and $1.4 \mathrm{~cm}$ wide at its broadest point. The basal part of the specimen is missing, but the fragment clearly shows a stout midrib and simple typically taeniopterid venation.

Plate 5, figure 6, a higher magnification, shows the many small spherical bodies, more or less evenly distributed over the entire lamina. A small part of the lamina is shown at 20 magnifications on plate 5 , figure 7. The glands average about $0.25 \mathrm{~mm}$ in diameter and are so abundant that most of them are within $0.5 \mathrm{~mm}$ of another. They are restricted to the narrow laminar areas between the closely set veins, and the midrib itself is devoid of glands. The spherules are easily removed from the matrix, and many of them were detached, presumably when the specimen was collected. The positions of missing spherules, however, are clearly indicated by hemispherical depressions in the intercoastal areas. Most of the glandular bodies are virtually uncompressed, and in their general physical characteristics they are remarkably similar to those attached to Phasmatocycas kansana.

Excellent examples of the glandular remains also appear on taeniopterid foliage contained in USGS collection 8868 , from a locality near Carleton, Kans.

Attention was originaly directed to spherical bodies on taeniopterid foliage by Sellards $(1901,1908)$. In 1901, Sellards described some Permian taeniopterid material from the Banner City locality; this included specimens identified as Taeniopteris coriacea Goeppert, T. coriacea var. linearis, Sellards 
var., T. newberriana Fontaine and I. G. White, and $T$. sp. Much of that paper was devoted to description of "interneural bodies" and "scars on or near the rachis" on the foliage. The scars were compared with insect damage and fungal remains, but no definite interpretations were adopted.

The "interneural bodies" were described (Sellards, 1901, p. 5) as being "small, oval, resistant bodies, situated between the veins, half immersed in the epidermis of the frond, nearly globular in shape, some smooth on top, but more often showing a slit across the top." To judge from Sellards' illustrations, those bodies are identical with the spherules described here, with the exception of the distal slits; I have not observed such slits in the material at my disposal. Sellards briefly compared these bodies with dots on other genera from other localities. In attempting to analyze them in terms of morphology and function, he appeared to favor interpretation of the bodies as sporangia or a new type of fructification; in his subsequent paper (Sellards, 1908, p. 447), however, he regarded the question of function of the objects as an equivocal matter. Cridland and Morris (1960, p. 859) commented that the bodies "have never been shown to be anything but globules of iron oxide."

Much of Sellards' paper of 1901 was incorporated without alteration in his subsequent summary article on the late Paleozoic plants of Kansas (Sellards, 1908). Although no new or supplemental information regarding the taeniopterid complex or the "interneural bodies" was presented, that paper provided important information regarding the biological significance of the spheres. Sellards described 26 species (among nine genera) of plants represented by foliar organs, from the Banner City locality. "Interneural bodies" were discussed only in connection with the taeniopterids in the Banner City flora; comparable objects were not noted on any of the associated taxa. This consistency of association is borne out by my observations. The genera Callipteris, Glenopteris, and Odontopteris are present in the material I have examined from the vicinity of Banner City, but these show no evidence of spherical bodies.

From the foregoing discussion, one can scarcely avoid the deduction that the spherical objects are a natural biological attribute of the taeniopterid leaves from the Elmo Limestone Member of Dunbar (1924) at or near the Banner City plant locality. Their consistency of size, shape, and placement on the lamina between veins militates against their origin as accidents of mineralization or organic degradation. They are most likely glandular in origin, and their restricted occurrences on just one foliar form genus in a rather diverse generic assemblage demand scrutiny of possible relationships between these leaves and any associated plant remains on which similar glandular bodies occur.

The resemblances between the glands of Phasmatocycas kansana and those of the associated taeniopterid leaves lead to examination of the obvious inference, that is, that the fruiting axis and the leaves are parts of the same species of plant, if not the same morphological unit. Several circumstances add support to this inference; these and previously noted evidence are summarized here:

1. The glands are not found on any of several associated genera, although many of the associated taeniopterid leaf specimens show evidence of their presence.

2. Neither the occurrence nor distribution of the glands on Phasmatocycas and the associated taeniopterid leaves is reasonably ascribable to accident; these objects are doubtless a biologically controlled phenomenon.

3. The cycadlike fundamental morphology of Phasmatocycas requires only a terminal foliar part to complete the qualitative morphological requirements of a cycadean megasporophyll.

4. A seed-bearing taeniopterid leaf (Spermopteris Cridland and Morris) is already known; its geographic and stratigraphic occurrences and morphologic details make it a logical predecessor for a Phasmatocycas-like appendage with terminal taeniopterid foliation.

5. The putative Triassic cycads Dioonitocarpidium Lilienstern and Bjuvia Florin both have been supposed to have had taeniopterid foliage.

Viewed as an aggregate, these points of circumstantial evidence provide the basis for a tentative reconstruction, in which Phasmatocycas is presented as a cycadalean megasporophyll with a taeniopterid foliar lamina distal to the basal seeds. This is shown in figure 4.

Cycadean affinity of Phasmatocycas.-Phasmatocycas and Archaeocycas resemble each other fundamentally in their bilateral symmetry, each bearing two lateral rows of paired seedlike objects. In the case of Archaeocycas, substantial indirect evidence indicates that these objects are the remains of seeds, partly enclosed by a reduced lamina and attached to it a short distance from the rachis. In Phasmatocycas, on the other hand, the bilaterally paired objects are unequivocably the remains of gymnospermous seeds, as established by their well-preserved megaspore membranes and double cuticles. 


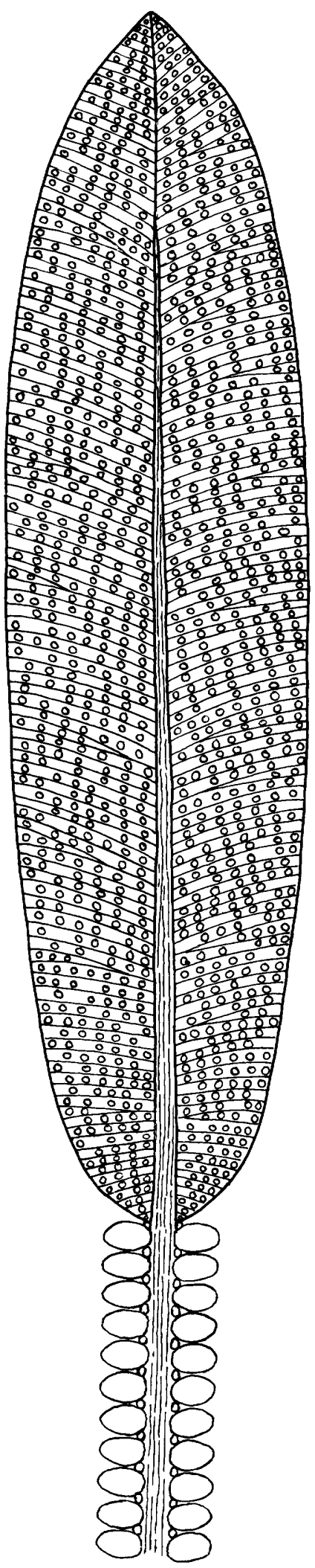

Phasmatocycas shows no development of a lamina in the ovuliferous region, so that if it is considered in the light of a reduction series, Spermopteris being the hypothetical ancestor, it would represent the ultimate stage in elimination of a foliar element in the fertile area of the appendage; the result would entail direct attachment of the seeds to a naked midrib. Only one specimen of Phasmatocycas is available, and absolute proof of attachment of a terminal foliar lamina is lacking. However, if my appraisal of indirect evidence and my resultant reconstruction of Phasmatocycas are correct, then Phasmatocycas may be regarded as the perfect fulfillment of a theoretical reduction series, beginning with the completely laminar Spermopteris and possibly involving Archaeocycas as an intermediate form. (See fig. 6).

Detailed comparisons of Phasmatocycas with other fossil gymnosperms in order to derive taxonomic conclusions would be pointless because no close similarities exist among the fossils. The seed-bearing groups known to exist in the Permian include the pteridosperms, the early conifers (cordaiteans and walchians), and the ginkgophytes, none of which constitutes a logical taxonomic receptacle for Phasmatocycas. This fossil shows no evidence of the cupular seed investment, complex pollen-receiving mechanism, or other critical features of the pteridosperms. A pteridospermous alliance for Phasmatocycas may be dispensed with, except in the sense that it was probably derived from the pteridospermous Spermopteris.

It is equally obvious that Phasmatocycas is no cordaitean or conifer. It lacks any evidence of the complex investiture of spirally arranged bracteate appendages that appear in cordaitean cones. It has no resemblance to the short shoots involved in the evolution of coniferous cone scales or of Ginkgo-like fructifications. There likewise appears to be no reason to postulate a Bennettitalean alliance for Phasmatocycas; Harris' (1954, p. 290) observations on the absence of a cutinized megaspore membrane in the cycadeoids, considered against the well-developed membrane in Phasmatocycas, weigh heavily against an already remote point of possible speculation.

The remaining approach lies in comparisons of qualitative features of Phasmatocycas with other gymnosperms, irrespective of relative ages. Such an

FigURE 4.-Reconstruction of megasporophyll of Phasmatocycas, showing bilaterally arranged basal ovules, alternating glands, and taeniopterid distal lamina. Relative length of distal lamina reduced; venation and glands on lamina shown less dense than in actual specimens. From Mamay, 1969a, figure $1 \mathrm{~A}$. 
examination reveals that, in points of fundamental morphology, Phasmatocycas is more like a megasporophyll of the modern genus Cycas than any other gymnospermous fructification, living or fossil. In all the living cycads, the ovules (usually only two) are bilaterally arranged, but Cycas usually has two or more pairs of ovules, indicating a multiovulate ancestral megasporophyll. Phasmatocycas at least hypothetically performs that role.

The seeds of Phasmatocycas were apparently of simple construction and are more like those of the cycads than of the pteridosperms or cordaites. The cuticular details of Phasmatocycas are sufficiently similar to those of the Jurassic cycad Beania to warrant increased emphasis of the other cycadlike features of Phasmatocycas.

In its overall qualitative aspects, then, the one extant specimen of Phasmatocycas is remarkably like a megasporophyll of Cycas. Only the terminal leaflike proliferation of the Cycas megasporophyll is missing from Phasmatocycas, but evidence for its presence, already discussed, is substantial. Conversely, such a terminal proliferation is indeed present in Archaeocycas, which I believe to represent an evolutionary form just one step below Phasmatocycas in this primitive cycadalean lineage.

The name Phasmatocycas derives from the modern generic name Cycas and the Greek "phasma," meaning apparition or specter.

In connection with a cycadean interpretation of Phasmatocycas, it is of interest that White's (1912 p. 508) list of provisional plant identifications from the Permian of Kansas includes reference to " $C y$ cadospadix? sp., C," the "C" referring to Carlton, Kans. (according to the USGS paleobotany locality register, this is locality 8868 , " 4 miles south of Carlton"). The Carlton collection contains nothing that might suggest a cycadean structure; conversely, Phasmatocycas is the only cycadlike specimen in the Banner collection, but White's list indicated nothing cycadlike from Banner. In attempting to determine the exact location of the Banner plant beds, certain facts have been found that may explain the above inconsistency and that consequently may identify White's "Cycadospadix? sp." as the specimen described here as the holotype of Phasmatocycas.

The town of Banner no longer exists under that name; its site is now occupied by the town of Elmo, which formerly was less than a mile west of Banner on the Missouri Pacific Railroad. Carlton still exists and is about 3 miles west of the former town of Banner. Collection 8868 was made " 4 miles south of Carlton," and collection 8869 was made " $31 / 2$ miles south of Banner." As Banner was just 3 miles east of Carlton, the two fossil localities were less than 4 miles apart. The collections could have been, and probably were, made the same day (collecting dates for the two localities are given only as " 1909 " in the USGS locality register). Parts of the two collections are lithologically indistinguishable, and it thus is possible that the two collections were mixed and mislabeled, and that White consequently identified a cycadlike fossil from Carlton instead of Banner. The two collections are very similar, and I am reasonably certain that White had in hand the holotype of Phasmatocycas when he made the identification of " $\mathrm{Cy}$ cadospadix ? sp.". If this analysis is not correct, then an important part of the Carlton collection was lost and White failed to notice this important specimen in the Banner collection. Either alternative seems unlikely, and the combination of circumstances is even more difficult to envisage.

Function of the glands. - The glandular bodies are so regularly placed between the seeds of Phasmatocycas and so abundant on the associated taeniopterid leaves-putatively the distal laminae of megasporophylls-that speculative teleological comments are in order. The function of the glands will likely remain conjectural at best, but the important biologic process of entomophily is indeed suggested by certain indirect evidence.

The presence of glandlike bodies on taeniopterid leaves is not a new idea, for Halle's (1927) memoir on Paleozoic plants from Shansi, China, included descriptions of two species of Taeniopteris that had "black dots" between the veins. Halle (1927, pl. 37, fig. 1) also showed similar bodies on the type specimen of T. multinervis from the Permian of Saxony. Halle regarded the dots as probably glandular but made no comments on their possible functions. In a later paper, however, Halle (1929) presented a lengthy and pertinent discussion of that possibility of entomophily in the Paleozoic; his argument was based largely on the presence of glandular bodies on other kinds of foliage, but it may be applied to Taeniopteris as well.

Halle's discussion (1929, p. 18-23) aimed primarily at trends in seed position in the pteridosperms, but modes of pollination were also considered. He wrote as follows:

There remains the possibility of insect pollination. Oliver and Scott, in their famous memoir 'On the structure of the Palaeozoic seed Lagenostoma Lomaxi etc.' draw attention in this connection to the capitate glands found on the cupule of Lagenostoma Lomaxi and on various parts of Lyginopteris oldhamia. Following a suggestion of the late Sir Joseph Hooker, 
the authors briefly discuss the possibility of insect pollination in the Lagenostoma seeds *** Insect pollination is not peculiar to the Angiosperms, since it has been found to occur in several genera of living Cycads (cf. Seward, Fossil Plants, vol. 3, 1917, p. 28). Several groups of insects being known to have existed in Carboniferous times, the possibility of entomophily in Paleozoic plants cannot be denied. The frequent accurrence of structures which seem to represent external glands is, indeed, a striking feature in the seed-bearing leaves of Pteridosperms known at present. ... But the relative frequency of these gland-like structures among plants which were certainly or probably Pteridosperms, coupled with the appearance at about the same time of a rich insect-life is suggestive. Additional knowledge of their distribution in different groups of Paleozoic plants is therefore desirable.

Thus there is evidence of a marked trend toward production of glandiferous foliage and accessory parts among late Paleozoic seed plants, and Phasmatocycas provides an excellent additional example.

The variety of insect life in the Paleozoic was pointed out by Carpenter (1952, p. 16) who listed nine orders of insects known from Permian strata and two orders from older rocks. Carpenter commented "Altogether, the lower Permian insect fauna was very diverse-more so, in fact, than any other insect fauna known."

Not only was the Paleozoic insect fauna taxonomically diverse, but according to Carpenter (1971), it showed significant adaptive modification of mouth parts. Carpenter commented as follows (1971, p. 1238, 1240, 1241) :

A very interesting feature of the Palaeodictyoptera, Megasecoptera and Diaphanopterodea that has been discovered in recent years is the presence of piercing-sucking mouthparts.

There can be no question that beaks in the Paleodictyoptera and the other two orders mentioned were used for piercing and for sucking liquid nutriment. What the types of food were, we have no way of knowing; presumably they were of plant origin. The most likely sources were probably some of the succulent lycopods that were extensive and abundant during the Carboniferous and Permian. ${ }^{1}$

Carpenter (1971, p. 1241) continued thusly:

The significance of this large array of hemipterous insects in the Paleozoic is obvious: there must have been abundant sources of liquid plant food available. With the Palaeodictyoptera, Megasecoptera and Diaphanopterodea also present, it is perhaps no exaggeration to state that nearly half the species of Paleozoic insects had piercing-sucking mouthparts.

I It is doubtful that the lycopods, although abundant in the Paleozoic, constituted an important source of food for herbivorous insects because of certain anatomical features of the lycopods. Their structural strength derived mainly from a thick outer periderm layer which was nonconductive and therefore not very succulent. Likewise, the thick hypodermal layers of the leaves probably discouraged foraging insects. Possibly some soft-skinned amphibians were plagued by these sharpbeaked insects, just as man suffers mosquito bites today. If one adheres to the idea of an herbivorous habit for these Paleozoic insects, however, alternative sources of food other than the lycopods deserve consideration. There seems to have been a compatibility of size between the sucking beaks of some of the Paleozoic insects and the micropylar canals of some of the pteridospermous seeds. Perhars the contents of the pollen chambers were attractive to the insects, who used their beaks to obtain these substances, but it is very doubtful that enough seeds were prothe plants seem to constitute a logical source of insect nutriment.
Considering the sizable number of Paleozoic insects that had specialized-feeding mouthparts and their coexistence with many kinds of seed plants, it seems reasonable to assume that the feeding habits of at least some of these insects were involved in the pollination of seed ferns and precursive cycads. The contents of the external glands were possibly attractive to insects and thus served the function of nectaries. It is intriguing to imagine pollen-dusted insects, having previously been attracted to the polleniferous organs by odor or other stimuli, visiting the putative taeniopterid distal lamina of Phasmatocycas for the food contained within the abundant glands. Thence, they would descend along the seed bearing axis, feeding on the interseminal glands and meanwhile depositing pollen on the micropyles or pollen drops of the ovules. The regular placement of the glands of Phasmatocycas would render each ovule equally attractive to the pollen-bearing insects, thus assuring pollination of all.

A mechanism for initial visual attraction of insects to a female infructescence of Phasmatocycas could conceivably have been one similar to that postulated by Leppik (1971, p. 172) for the Triassic Palaeocycas integer. This plant supposedly had a central crown of megasporophylls surrounded by a closely set group of leaves. According to Leppik,

Such patterns must have been clearly distinctive to the foodsearching phytophagous insects $* * *$ the adaptive form and arrangement of these clusters of sporophylls must have made them characteristic attractants to food searching insects, allowing them to distinguish these from the less palatable ferns and horse tails.

The question of insect pollination among the cycads is variously argued. Seward $(1917$, p. 28) wrote:

Recent observations point to the probability that insects play a part in the pollination of cycadean ovules. Kraus drew attention to the strong smell emitted by the microstrobili of Dioon edule and noticed that small bees were attracted to the ripe strobili of Macrozamia, while odourless cones of a neighboring Ceratozamia received no attention. Pearson and Rattray have obtained evidence that beetles and weevils act as pollinators to species of Encephalartos.

The reports of insect pollination in Encephalartos are interesting, but Coulter and Chamberlain (1910, p. 141) observed that "It is generally accepted that the cycads are wind-pollinated." Both Chamberlain (1935, p. 127-128) and Gaussen (1944, p. 56) pointed out that the supposedly pollinating beetle actually bores into the female gametophyte of $E n$ cephalartos, and the gametophyte is destroyed either in the process or by the hatching larvae. In this inefficient procedure, the ovules, although possibly 
pollinated, can mature only if the boring ovipositing process is not extensively damaging or if the beetle eggs fail to hatch. Crepet (1972, p. 1055) further discussed this interaction in presenting conjectures on the possibility of animal pollination of the Mesozoic cycadeoids.

Even though there is significant skepticism toward entomophily among the cycads, an affinity of sorts exists between certain modern cycads and certain insects. Perhaps this is the distant reflection of a dubiously successful experiment that began with Phasmatocycas, other Paleozoic plants, and insect pollinators unknown.

\section{?Phasmatocycas sp. \\ Plate 2, figure 1 \\ DESCRIPTION}

This account is based on a single specimen from the Haskell County, Tex., locality; it was found by Mr. T. R. Tinsley, who presented it to me for study. The specimen consists only of an impression in red siltstone; it lacks any organic matter but shows sufficient character to warrant discussion relative to Phasmatocycas and perhaps Spermopteris.

The specimen consists of a fragment of a stout straight axis, which bears the impressions of two lateral rows of oval objects that probably represent seeds. The axial fragment is $5 \mathrm{~cm}$ long, about $5.0 \mathrm{~mm}$ wide at its broadest point, and shows little tapering throughout its length.

Along either side of the axis is a row of shallow oval impressions closely resembling the symmetrical system of placement of the seeds in Phasmatocycas kansana. Toward what I presume to be the top of the axis, the impressions are evenly paired, but the positional relationships between the units in the two rows become somewhat obscure toward the opposite end of the axis where preservation is less complete. There are 24 impressions in all, 14 on the right and 10 on the left side, part of which is missing. It is evident that one row contained approximately the same number of impressions as the other.

The impressions are those of small round to oval bodies, 3.0-4.0 mm long and $2.0-3.0 \mathrm{~mm}$ wide. They show no tapering or beaklike apices, but evidently reflect broad attachments to the central axis by bases nearly as wide as their greatest widths, like seeds of Phasmatocycas kansana. The impressions are closely arranged but neither abut upon nor overlap each other; there are intervals of $1.0-1.5 \mathrm{~mm}$ between adjacent impressions. No evidence of accessory structures or scars of attachment of additional seed- like bodies is present on the surface of the axis between the lateral rows.

One additional feature of this specimen remains for comment. A slightly elevated ridge almost completely surrounds the specimen except for the basal area where preservation is extremely obscure. This ridge more or less outlines the axis at a distance of approximately $3 \mathrm{~mm}$ beyond the apices of the seedlike impressions. It is best seen at the presumed apex of the specimen, where it passes over the tip of the axis and lends a tonguelike outline to the organ (pl. 2, fig. 1). The rounded apical outline resembles the tip of a leaf or pinna, but if the ridge does in fact represent the margin of a laminar appendage, there are no impressions of veins to confirm this.

Figured specimen.-USGS 10064-1 (pl. 2, fig. 1) .

Occurrence.-USGS paleobotany locality 10064.

\section{DISCUSSION}

This specimen is only provisionally assigned to Phasmatocycas because of its preservational deficiencies. Nonetheless it merits attention because its symmetrical bilateral construction conforms with the cycadlike pattern of the other fossils under consideration. Its central axis is more robust than that of Phasmatocycas kansana in proportion to the size of the seedlike impressions; although the seedlike impressions are not as closely arranged as the seeds of $P$. kansana, this specimen is, in most respects, almost exactly what one might expect to see if the holotype of Phasmatocycas kansana had been preserved in the same manner as the specimen from the Vale Formation. I thus have no reservations in regarding the Vale specimen as a seed-bearing axis, and further, as a representative of some taxon in the Permian complex of ancestral cycads.

If we could establish beyond doubt that the Vale specimen is correctly assignable to Phasmatocycas, then the question of specific status would pose difficulties because only one specimen is available from each of the two localities concerned. The size and other differences between Phasmatocycas kansana sp. may fall within a reasonable range of specific variation, but until more material becomes available this problem must remain unanswered.

Of more moment is the matter of the generic assignment of the Vale specimen. Were it not for the vague suggestion of the outline of a foliar lamina surrounding the axis and its complement of presumed seeds, there would be a rather stronger case for assigning the specimen to an unnamed species of Phasmatocycas without the provisional question mark. This outline must be considered, however. If 
it actually represents the margin of a leaf blade rather than an anomalous sedimentary feature of the rock, then the Vale specimen cannot be regarded as a Phasmatocycas but as something more akin to Spermopteris. The seedlike bodies of the Vale specimen appear to have been attached directly to the axis; in this respect, the specimen differs from Spermopteris, whose seeds were attached to the lamina. Conversely, the mode of seed attachment relates the specimen to Phasmatocycas. If we assume that a lamina was present and the seeds were attached directly to the axis, then we may speculatively regard the Vale specimen as a derivative of Spermopteris, in which the foliar lamina retained its identity but in which the seeds had undergone a "phyletic slide" in the direction of the axis, to the extent of actually being attached to the latter. This possibility is interesting in the light of relative ages of material considered here. The Vale specimen is the youngest of the entire complex, but if it indeed retains the Spermopteris-like foliar lamina, it may represent a conservative line of cycad evolution, as opposed to the older Phasmatocycas, which has lost the foliar blade in the fertile area.

?Phasmatocycas spectabilis Mamay, new species

Plate 5, figures 1-4

Specific diagnosis.-Fertile axes large, robust, as long as $20 \mathrm{~cm}$ or more; widths as much as $1.0 \mathrm{~cm}$ or slightly more, distally tapering very gradually. Bilaterally inserted rows of seeds conspicuous, the seeds as long as $7.0 \mathrm{~mm}$, as wide as $5.0 \mathrm{~mm}$; seeds oval or ovoid with blunt or slightly pointed apices, broadly attached by bases $2.0-3.0 \mathrm{~mm}$ wide, oppositely paired or slightly alternating in position, perpendicular to the axis or slightly ascending in attitude, crowded so as to abut against one another or more laxly arranged with intervening spaces 1.0$2.0 \mathrm{~mm}$ wide.

Holotype.-USGS 8959-3 (pl. 5, fig. 1).

Paratypes._USGS 8877-5, 6, 7 (pl. 5, fig. 2, 3, 4).

Occurrences._USGS paleobotany localities 8877 , 8959.

\section{DESCRIPTION}

As was the case with Archaeocycas, my attention was originally directed toward the existence of this large fertile structure by a suite of specimens collected by David White at the locality south of Fulda, Tex. (USGS paleobotany locality 8877), where he also found the first specimens of Archaeocycas. Like Archaeocycas, these 10 specimens were found segregated in a separate tray, and some had been marked with crayon; thus it is obvious that White had noted these as fossils of special interest and probably had intended ultimately to describe them. In retrospect of these events, it is rather strange that he made no reference to them in his list of plants from the Fulda beds, published in his paper on Gigantopteris americana (1912).

In 1963, I found one small specimen of ?P. spectabilis, at the "Emily Irish" locality (USGS paleobotany locality 8959), and in 1967, I found several more specimens at the same place. The specimens from White's locality are better preserved and have more of a carbonaceous residue in a somewhat more durable matrix. There is no doubt, however, that the two suites of material represent the same taxon.

None of the axial surfaces between the lateral rows of seeds show any features that would aid in characterizing this species. Some of the specimens, particularly those from the Fulda locality, retain thin films of coalified plant residue and show vaguely defined longitudinal striations (pl. 5, fig. 4), but these may be shrinkage phenomena and probably are meaningless. The longitudinal striations are also seen in a few small areas on the holotype (pl. 5, fig. 1). Attention is directed to the "Emily Irish" specimen shown on plate 5 , figure 4 , because it has a rather thick film of coalified material adherent to the interseminal surface of the axis. This film is fragmented into many small, nearly cubical pieces but is particularly significant in that it shows no conspicuous points of interruption or discontinuity that would indicate places of attachment of seeds or accessory structures. This and all other observable features of this suite of specimens show that in ?P. spectabilis we are again dealing with a bilaterally symmetrical organ. Unfortunately the seeds are poorly preserved and contain no cutinized parts ; pollen analyses were attempted with samples from both localities, but results were negative. Nonetheless, the arrangement of the seeds conforms closely with the patterns seen in the other materials discussed in this paper.

The outstanding morphological feature of ?Phasmatocycas spectabilis is its large size. Some indication of this is provided by the holotype, shown on plate 5, figure 1 . This incomplete specimen is broken at both ends, measures $20 \mathrm{~cm}$ in length, and has the attached remains of about 60 seeds. As there is scarcely any diminution in its width from one end to the other, one has little basis for estimating the complete length of this specimen; it could have been considerably longer than $20 \mathrm{~cm}$, however. Approximately 20 smaller fragments were found closely associ- 
ated with the holotype, but these cannot be established as parts of the same specimen. None of the shorter fragments exceeds the width of the axis of the holotype (approximately $1.0 \mathrm{~cm}$ ) ; probably this was the maximum width attained by this species. White's specimens from Fulda, one of which is shown on plate 5 , figure 2 , substantially confirm a maximum axial width of approximately $1.0 \mathrm{~cm}$.

The best Fulda specimen, shown on plate 5, figure 2 , is $10.8 \mathrm{~cm}$ long and has a maximum width of 2.3 $\mathrm{cm}$; the latter measurement embraces the two lateral rows of seed. The longest specimen in this suite (pl. 5, fig. 4) is $11.5 \mathrm{~cm}$ long, and the remaining 10 are considerably shorter. Among the "Emily Irish" specimens, none approaches the holotype in total length. None of the other "Emily Irish" specimens show any unusual dimensions. The specimen shown on plate 5, figure 3 , however, shows a definite decrease (from 3.5 to $2.0 \mathrm{~mm}$ ) in width of the central axis and may represent the terminal part of the fruiting region.

The seeds are oval or ovoid, and those of the Fulda specimens generally appear to be somewhat more pointed than those from the "Emily Irish" locality. Exact dimensions are difficult to ascertain because the specimens are generally poorly preserved, but their size ranges from 5.0 to $9.0 \mathrm{~mm}$ in length and 4.0 to $7.0 \mathrm{~mm}$ in width. The largest seeds present in the collection are attached to the specimen shown on plate 5, figure 4 ; the fifth seed from the bottom in the right-hand row, for example, is $9.0 \mathrm{~mm}$ long and $7.5 \mathrm{~mm}$ wide, and others on this specimen are of comparable sizes. Some of the seeds on the holotype are considerably smaller and seem disproportionately small in relationship to the size of the axis.

Some of the seeds show vague suggestions of bifid apices, but such structures are not a consistent feature and may merely be the result of splitting of the integuments at the apices during compression. The presence of a thick integument is indicated by the "Emily Irish" specimens shown on plate 5, figures 2 and 3. A few of the seeds are represented only by flattened coalified films. Others, however, are more or less completely delimited by deep cavities in the matrix; these are evidently cavities left behind by the decay of the seed integuments, and the extent of the cavities is indicative of some considerable bulk to the original seed coats.

The seeds are uniformly sessile, being attached by very broad bases. In other features there is a certain degree of variation, all of which could be attributable to different relative positions on the parent axes. In most specimens the seeds are so closely inserted as to abut against each other (pl. 5, fig. 2), but in others they are considerably more widely spaced (pl. 5, fig. 1). Most of the seeds extend away from the axis perpendicularly, but in a few specimens they are directed forward at broad angles; the latter condition is most prevalent in specimens where the seeds are loosely arranged, as in the holotype (pl. 5, fig. 1). In some specimens, the seeds seem to be arranged in distinctly opposite pairs, but most commonly they appear to alternate with each other.

In none of the seeds is there any indication of cupular or bracteate investment; some seeds show irregular outlines and have erratic projections from their overall oval shapes, but I attribute these to preservational distortions. Furthermore, this species shows no remnants of the interseminal resinoid spheroids that appear on Phasmatocycas kansana. A final important feature of ?P. spectabilis is the absence of evidence of a foliar lamina. Because a complete specimen is not available, the presence or absence of a distal foliar lamina cannot be established.

\section{DISCUSSION}

?Phasmatocycas spectabilis is of considerable morphological interest because of its large size, the limits of which are yet unknown. More importantly, it establishes the presence in the Permian of still another representative of the cycadalean complex with which this paper is concerned. ?P. spectabilis repeats with remarkable clarity the bilateral symmetry and other qualitative features of the fruiting organs under study and thereby emphasizes the probability of phylogenetic derivation from Spermopteris. or a similar ancestral form.

The absence of cuticularization is unfortunate; because of this absence, I refer this species to Phasmatocycas with the provisory question mark. Were cuticles present, I am reasonably confident that an unqualified generic assignment to Phasmatocycas could be justified.

The specific name spectabilis refers to the overall showiness of these large fructifications.

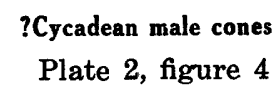

DESCRIPTION

An interesting element in the Haskell County flora is represented by 20-odd impressions or molds of axial fragments which were collected and given to me by Mr. Tinsley. The specimens are stout and unbranched, with no evidence of the apical or basal 
organization. The specimen shown on plate 2 , figure 4 , is the most informative of the lot.

The axes have surface patterns of closely imbricated, spirally arranged rhomboidal impressions with considerable depth; in most specimens the impressions are elongate transversly to the axis. The impressions range from 7.0 to $10.0 \mathrm{~mm}$ in width and average about $5.0 \mathrm{~mm}$ in height. Extending away from most of the axial specimens and ascending upward in gently curved attitudes are molds of spinelike appendages, $2.0-3.0 \mathrm{~cm}$ long ; these extend across bedding planes in a manner suggesting that the appendages were stiff and rigid at the time of burial and resisted compaction. Several are seen clearly in the illustrated specimen.

Figured specimen.-USGS 10064-2 (pl. 2, fig. 4).

Occurrence._USGS Paleobotany locality 10064.

DISCUSSION

These robust axes resemble to a certain extent the impressions of the characteristic bark patterns of the arborescent lycopods. However, the depth of the prominent surface impressions is much greater than that of fossil lycopod leaf cushions, which ordinarily show only a moderate amount of relief; these are more like the impressions that would be made by the distal faces of cycadean microsporophylls. If the Texas specimens are to be regarded as lycopod remains, this isolated appearance is anomalous with the known history of arborescent lycopods in North America. I am aware of no representatives of that complex in American rocks younger than those of the Belle Plains Formation, where lycopod remains occur rarely in an otherwise rich plant assemblage. It is therefore highly probable that the giant lycopods became extinct on this continent before the end of Belle Plains time, and identification of the Texas specimens with the lycopods seems unwarranted.

The preferred alternative of tentatively treating these specimens as cycadean male cones is encouraged by their geographic and stratigraphic proximity to Phasmatocycas and its putative foliage, Taeniopteris. That indirect evidence finds support in the resemblance of the Texas material to the specimen of the Jurassic Androstrobus zamioides figured by Schimper (1870-1872, pl. 72, fig. 1), especially in size, general proportions of the specimens, and the overall appearance of their surface markings. The cycadlike aspects of the Texas specimens is further accentuated by the molds of spinelike, apparently rigid extensions of the individual members. These may well represent the attenuated termini of microsporophylls, like those produced in the male cones of
Cycas circinalis (Schuster, 1932, fig. 10A) or of Macrozamia (Johnson, 1959). All factors taken into consideration then, I prefer at least provisionally to regard the Texas specimens as the essentially modern-appearing male cones of an early cycad rather than as representatives of a lingering remnant of the giant lycopod lineage. Only the absence of evidence of microsporangia on the individual units of these strobiloid structures restrains me from applying a formal binomial indicative of cycadean affinity.

Several kinds of presumably male strobiloid fructifications are present in other Permian collections under study; some are apparently new, but none can be identified as cycadean. Among these, those most like fossil cycadean male cones are the strobiloid structures from Fulda, Tex., described by White (1912, p. 500-501) as the "supposed polleniferous strobili" of Gigantopteris americana. These were composed of reniform bracts inserted in distichous rows, with "oval, pendant sacs" on the lower surfaces of the bracts. A few reniform bractlike organs are indeed present in the Fulda collection, but my examination of the original specimens does not substantiate either White's interpretation of these bracts as the actual appendicular components of the strobili, or his observation that the cone scales are distichously arranged. Furthermore, the material is too poorly preserved to allow observation of any details of sporangial structure or disposition. Nonetheless, the Fulda specimens present the overall appearance of rather loosely constructed cones, probably with spirally arranged appendages. The specimens illustrated by White $(1912$, pl. 48 , figs. 3, 4) are remarkably similar to some of the Jurassic male cycadean cones, Androstrobus wonnacotti Harris, illustrated by Thomas and Harris (1960, pl. 2, figs. $8-13)$; the similarity is most marked if one turns White's illustrations upside down and compares his figure 4 with Thomas and Harris' figure 10 or 12 . The absence of epidermal details or in situ pollen in the Fulda specimens, however, renders further comment on this similarity pointless.

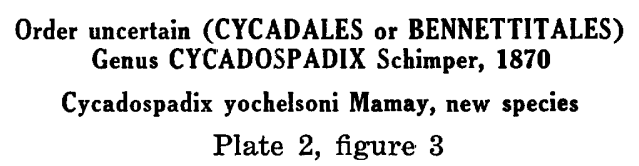

Specific diagnosis.-Appendage with short, broad peduncle and lanceolate lamina. Margin of lamina entire from broadest point to base, deeply pinnatifid distally; lamina with heavy, unbranched ribs, several to the undissected part, one each to the distal lobes. 
Appendage $21 \mathrm{~mm}$ long, $12 \mathrm{~mm}$ broad at widest part of lamina. Peduncle $5 \mathrm{~mm}$ wide, $4 \mathrm{~mm}$ or more long. Incised part of lamina with eight teeth along each margin; teeth as much as $3 \mathrm{~mm}$ long, the longest about halfway towards the sharply pointed tip. Teeth directed obliquely forward at broad angles.

Holotype.-USGS 10057-1.

Occurrence.-USGS paleobotany locality 10057.

\section{DESCRIPTION}

Only one specimen of this species has been found; the better of its counterparts is shown on plate 2, figure 3 . The incompletely preserved peduncle is a very broad and flat structure, the distal end of which extends as a broad wedge up into the base of the lamina and appears to have formed a slight ridge or suture at the line of juncture with the lamina. There is no indication of the nature of the vascular system of the peduncle other than a series of fine, closely spaced parallel surface striations that continue distally as far as the tip of the lamina.

The lamina flares out abruptly and at a broad angle from its point of confluence with the peduncle, soon reaching its maximum width of $12 \mathrm{~mm}$. Between the base of the lamina and its widest point the margin remains entire. The broad, parallel, distally directed ribs probably represent the original venation of this appendage. Each side of the undissected part of the lamina contains six such ribs, which depart from the distal end of the peduncle in a pseudopalmate fashion. Those that enter the margin lobes of the remaining two-thirds of the lamina, however, are arranged in a more typically pinnate manner. A distinct midrib is not evident in the lamina; the only indication of structural differentiation in the median part of the appendage is the weak parallel striations that extend into the lamina from the peduncle and continue to the tip.

The lobes of the dissected part of the lamina vary in angles of departure, the more proximal ones being directed forward at about $45^{\circ}$ and the distal ones extending out at right angles from the median line of the appendage. The lobes number eight or nine to each margin. The longest ones are about $3 \mathrm{~mm}$ long and less than $1 \mathrm{~mm}$ wide; they decrease in length so that the last one or two directly beneath the spicate tip of the lamina are slightly less than $1 \mathrm{~mm}$ long.

\section{DISCUSSION}

Cycadospadix Schimper is an artificial genus of isolated bractlike or megasporophyll-like organs, known from only a few occurrences, mostly of Mesozoic age. As stated by Harris $(1932 b$, p. 96), it is characterized by "a stalk expanded distally and bearing several fingerlike branches; the fossils resemble in miniature the megasporophylls of Cycas." The resemblance to Cycas led Schimper (1870-1872, p. 207) to express the opinion that there could be no doubt as to a cycadean affinity for his material. Schimper referred two species to Cycadospadix: $C$. Hennocquei (Pomel) Schimper and C. Moraeanus (Pomel) Schimper. In his diagnosis of the genus, Schimper drew attention to scars on the sides of the petiole which he interpreted as indications of points of seed attachment; this was purely speculative, and Schimper's illustration of C. Hennocquei shows no seeds attached. Emberger (1944, fig. 346) published a drawing of a specimen of that species that had a seed attached to the petiole, but Harris (1961, p. 316) stated that "no seed is known attached."

Harris (1932b, p. 97-98) described Cycadospadix dactylota on the basis of three specimens from the Rhaetic of Greenland. The cuticles were preserved in his material, and on the strength of stomata of the bennettitalean type, Harris emended the generic diagnosis of the genus, thus inferentially assigning all species of Cycadospadix to the Bennettitales; Harris interpreted his specimens as the basal scales of a bennettitalean "flower" rather than megasporophylls. Florin (1933, p. 34) rejected Harris' emendation of Cycadospadix and proposed a new genus, Bennettitolepis, for the Greenland material, typified by the recombination $B$. dactylota (Harris) Florin. Harris evidently prefers his original designation, because in 1961 (p. 316-317) he referred to the Greenland material only as Cycadospadix and made no mention of Bennettitolepis.

In his extensive article on the Mesozoic cycads, Florin (1933) restudied Nathorst's original material of Cycadospadix integer from the Rhaetic of Sweden. Florin was able to determine the cuticular details, and on the basis of epidermal structure, he concluded that the organs were in no way related to the Bennettitales but instead showed close affinity with the modern Cycadales. He proposed a new genus, Palaeocycas, typified by the species of $P$. integer (Nathorst) Florin, and reconstructed an entire plant. Florin's (1933, p. 91) often-reproduced reconstruction shows a plant with a dense aggregate of terminal megasporophylls of the Palaeocycas integer type and taeniopteroid leaves called Bjuvia simplex Florin. A single megasporophyll is shown as having a broad entire-margined lamina and two pairs of seeds attached to the sides of a thick stalk. Harris (1961, p. 315) remarked that none of the figured specimens has seeds attached, although bulges on the stalks of 
Palaeocycas are suggestive of points of seed attach ment.

The Texas specimen conforms well with the general concept of Cycadospadix but, as is the case with all other taxa heretofore assigned to Schimper's genus, there is no evidence of seed attachment. The broad stalk of $C$. yochelsoni suggests a stout seed-bearing axis, but no evidence of scars of attachment is visible; less than $5 \mathrm{~mm}$ of the stalk is preserved, however, and the possibility that more complete specimens would demonstrate evidence of seed attachment cannot be discounted. The distal laminar part of the appendage is remarkably similar to the top of a Cycas megasporophyll. This resemblance is such, in fact, that if C. yochelsoni had been found attached to any of the seed-bearing organs described here, there would scarcely be room for doubt as to a cycadalean affinity.

The cuticle of $C$. yochelsoni is not preserved; thus, no evidence of stomatal or other epidermal features is available to aid in interpreting relationships of the specimen. Furthermore, laminar form is of little assistance. With its distally laciniate and basally entire lamina, C. yochelsoni is intermediate between Bennettitolepis, a presumed cycadeoid, and Palaeocycas, a presumed cycad. A short while before Florin reassigned Cycadospadix integer to the new genus Palaeocycas because of epidermal characteristics, Harris (1932b, p. 96) suggested that the undissected margin of the lamina of $C$. integer probably was sufficient basis for its reference to another genus. Similarly, additional material from the Vale Formation may necessitate a reassessment of the generic status of $C$. yochelsoni.

Regardless of the taxonomic histories of organs originally assigned to Cycadospadix but later reassigned as the result of discovery of anatomical characteristics more definitive than gross external form, the original name Cycadospadix retains a considerable degree of utility as an ordinally noncommittal receptacle for structures that could be either cycadeoidean bracts or cycadalean megasporophylls. Consequently, the Texas specimen is appropriately retained in Cycadospadix. The question of its true systematic position-bennettitalean or cycadaleanmay, for the time being, be examined principally in the light of indirect evidence, some of it negative but all of it significant. The stratigraphic and geographic relationships between Cycadospadix yochelsoni and the other materials considered here are overwhelmingly indicative of a cycadalean alliance for $C$. yochelsoni. Conversely, the absence of credible evidence of bennettitalean plants in the Paleozoic of
North America militates against a bennettitalean interpretation of the Texas specimen. If $C$. yochelsoni is indeed a bennettitalean appendage, it stands strangely isolated-biotically, chronologically, and geographically. If its resemblance to the distal lamina of a Cycas megasporophyll is taken at face value, however, it assumes a harmonious niche in an assemblage of fossils whose collective impact is to extend the known history of the cycads downward through the greater part of two geologic systems.

Cycadospadix yochelsoni is named after E. L. Yochelson, who found the specimen.

\section{ASSOCIATED PLANTS}

The following summary enumerates the plants associated with the fossils described here. It is presented to emphasize that the cycadlike fossils share little in the way of floral associates that could be considered pertinent to questions of taxonomic affinity. The overall effect of this résumé is to strengthen the circumstantial evidence that the sporophyll of Phasmatocycas kansana had a taeniopterid lamina.

The Perry, Okla., flora (USGS paleobotany locality 6233), of which the specimen of Spermopteris is part, was discussed briefly by White $(1912$, p. 506507) in connection with occurrences of Gigantopteris americana. He listed the following seven genera: Pecopteris, Gigantopteris, Taeniopteris, Annularia, Sphenophyllum, Walchia, and Araucarites. I have confirmed the presence of all of those genera except the two arthrophytes; if present, they are too poorly preserved for positive identification. The identification of Araucarites is doubtful, but the collection contains a few small seeds that may have been the basis for White's identification; two are partly cutinized and resemble somewhat the seeds of Phasmatocycas kansana. Two specimens of the asymmetrically winged seeds attributed by White to Gigantopteris are present, and I have identified Odontopteris and Callipteris. This is a typical lower Permian assemblage, referable to Zone 14 of Read and Mamay (1964).

-The Banner, Kans., flora, supposedly the source of the holotype of Phasmatocycas kansana (USGS paleobotany locality 8869) was indicated by White (1912, p. 507-509) to contain the following six genera: Callipteris, Glenopteris, Taeniopteris, Sphenophyllum, Noeggerathia?, and Carpolithes. The collection also contains specimens of cordaitean leaves and several small undetermined sporangia, but I am hesitant to verify a noeggerathialean element in the collection. This is a sparse assemblage, but by virtue 
of the presence of the genus Glenopteris it is also assignable to Zone 14. The small collection from Insect Hill (USGS paleobotany locality 8298) contains no elements that are not present in the Banner assemblage. Sellards (1908), however, described the following additional genera from the vicinity of "Banner City" in his review of the Permian flora of Kansas: Pecopteris, Aphlebia, Neuropteris, Odontopteris, Sigillaria, Cordaites, Cordaianthus?, Rhabdocarpos, Cardiocarpon, and Aspidiopsis.

White (1912, p. 505-506) recognized 14 genera associated with Gigantopteris americana at the Fulda, Tex., plant beds (USGS paleobotany locality 8877). These are Diplothmema, Pecopteris, Odontopteris, Neuropteris, Taeniopteris, Annularia?, Sphenophyllum, Sigillaria, Cordaites, Poacordaites, Walchia, Gomphostrobus?, Aspidiopsis, and Araucarites. Names of plants from a nearby locality, 21/2 miles south of Fulda ("Castle Hollow," locality unnumbered) were incorporated in the same list because of the presumable identical stratigraphic positions of the two deposits. The "Castle Hollow" beds apparently contained most of the genera present in the Fulda beds, as well as the two additional genera Aphlebia and Sigillariostrobus. Thus the total number of genera from the two localities, as noted by White, is 17 .

My examination of White's Fulda collection substantiates his identifications with the exceptions of Sigillaria, Poacordaites, and Diplothmema. Conversely, this collection contains Stigmaria, Aphlebia, Annularia, Discinites (Mamay, 1954), and a curious apparently new peltate structure that in some features resembles the genus Daubreeia Zeiller. I have not located White's original "Castle Hollow" collection and must assume that it has been lost. Its absence, however, only reduces the total list of genera known from that area by one, Sigillariostrobus. The overall aspect of this flora is unusual only from the standpoint of the presence of the Daubreeia-like structure, Discinites, Archaeocycas, and ?Phasmatocycas. The flora is recognized as an assemblage typical of Zone 14.

The most diverse flora involved in this study is that of the "Emily Irish" deposit (USGS paleobotany locality 8959). These beds are regarded as the approximate stratigraphic equivalent of the Fulda beds; they contain all the genera recognized in White's collection with the exception of the Daubreeia-like organ. The "Emily Irish" flora is richer than the Fulda flora, however, in numbers of species as well as genera. It contains an unusually diverse spectrum of callipterids in addition to Lobatannularia, Sphenopteris, and the curious genus Russell- ites (Mamay, 1968). Also present are several types of undescribed microsporangiate fructifications. $G i$ gantopteris americana is a conspicuous element in this flora, which is referable to Zone 14 .

The Taylor County, Tex., flora (USGS paleobotany locality 10057) in which the specimen of Cycadospadix yochelsoni was found, is somewhat younger than the Fulda and "Emily Irish" assemblages and has been assigned to the youngest of the recognizable upper Paleozoic floral zones, Zone 15. It contains essentially the same generic association as the older flora but is distinguishable from it on the basis of several notable specific differences; the most striking of these differences is the appearance in the Lawn flora of a new, as-yet-undescribed species of Gigantopteris (G. n. sp. B ; Read and Mamay, 1964, pl. 19, fig. 2). In addition to Gigantopteris and Cycadospadix, the flora contains Annularia, Aphlebia, Taeniopteris, Sphenophyllum, Pecopteris, Gomphostrobus, Walchia, Callipteris, Odontopteris, and several taxa of unidentified seeds. Some of the odontopterids are of an extremely large-pinnulled type reminiscent of certain elements in the Siberian Angara flora, also of Permian age. The flora also contains some curious hooked appendages of unknown alliance, two specimens that resemble liverworts, and what appears to be a new genus of conifers. A description of this flora and related assemblages from other parts of the Vale Formation is being prepared.

The Haskell County, Tex., exposures (USGS paleobotany locality 10064) are higher in the Vale Formation than the Lawn deposit, and, accordingly, they contain the youngest flora involved in this study. This flora is also the simplest in terms of generic composition, although its taxonomically limited aspect is not regarded as a function of limited material. The known plant association consists only of the single specimen of ?Phasmatocycas sp., Taeniopteris, walchian conifers, an undescribed new species of Gigantopteris, and the axial specimens described as ?cycadean male cones. This sparse list of plant types is the result of not only my personal examination of literally hundreds of specimens scattered over an area of several acres, but it also reflects the careful collecting activities, over a period of many years, of Mr. T. R. Tinsley, who gave me the specimen of ?Phasmatocycas sp. as well as my choice of any other specimens in his collection. Mr. Tinsley had searched the site and immediate environs frequently, in the hope of finding "new" fossils. On my first visit there, I was astonished by not only the great numbers of specimens lying loose on the surface, but also by the predominance of specimens of Gigantopteris 
n. sp. This taxon constituted possibly all but 1 percent of the total number of specimens examined; walchian conifers were next in frequency. Only a few specimens of Taeniopteris have been found at this site. By virtue of the numbers of specimens examined, I believe that a reasonable representation of the original flora is preserved at the fossil site.

After elimination of the obviously pteridophytic or coniferous elements in the preceding assemblages, only seven pteridophyllous genera (Callipteris, Gigantopteris, Glenopteris, Neuropteris, Odontopteris, Russellites, and Taeniopteris) remain for consideration as possible foliar components of the plants that bore the cycadlike structures under investigation. From the standpoint of its pinnately compound morphology and parallel-veined foliar segments, Russellites is the most cycadlike of these genera. The possibility of cycadean affinity for Russellites has been considered briefly (Mamay, 1968, p. I10), but as it is known from only one site (USGS paleobotany locality 8959), it is ineligible for consideration as a common ancestral form for both Phasmatocycas and Archaeocycas.

Odontopteris, Callipteris, and Neuropteris are all regarded as pteridosperms; although they are stratigraphically and geographically widespread, none appears in the Haskell County flora. Although Gigantopteris is abundant at the Haskell County site and in other parts of Texas and Oklahoma, the genus is not known in Kansas; likewise Glenopteris, abundant in a small area of Kansas, is not known outside of that State. The distributions of Glenopteris and Gigantopteris, viewed in terms of paleophysiography and other physical factors, led Read and Mamay (1964) to present some conclusions regarding limited geographic provinciality of certain Permian plants in North America.

The conclusions from the foregoing remarks are that Taeniopteris is the least common botanical denominator; it is the only foliar element present at all the localities where the cycadlike remains have been found. Although inconclusive in itself, the evidence of consistent association must always be given careful consideration in drawing general conclusions; in this instance it is particularly germane because of the convincing evidence of the known seed-bearing habit of Spermopteris and the accessory evidence provided by the resinoid spherules of Phasmatocycas and associated taeniopterids.

\section{DISTRIBUTION OF THE FOSSILS}

Stratigraphic positions of the fossils are shown in figure 5 . The limited vertical distribution of the plants adds substantially to the distinctiveness of the guide assemblages that characterize floral zones 11 to 15 of Read and Mamay (1964). The scarcity of taxa in the Wolfcampian interval is clearly a function of limited collections. Wolfcampian beds have not yet yielded large amounts of good fossil plant material, and the few collections on hand have cast no light on the cycadean complex under investigation.

Geographically, the plants are distributed over a small part of the southwestern United States, extending only from north-central Texas to east-central Kansas. Although a very small area is involved, in terms of general geographic distribution of Paleozoic floras, the distribution of these plants may be significant from the standpoints of ecologic tolerances and evolutionary plasticity.

Read and Mamay (1964, p. K16-K18) recognized three Permian floral provinces in Leonardian rocks of the southwestern United States; these provinces were based on lateral distributions of the genera $G i$ gantopteris, Glenopteris, and Supaia, as related to paleophysiography, paleoedaphics, floristic characteristics, and other factors. The Glenopteris flora is restricted to a small province in eastern Kansas, and because of its consistently close association with saline rocks, the flora was presumed to have evolved in a physiologically xeric environment. Immediately south and southwest, the Glenopteris flora is displaced, without evidence of overlap, by the Gigantopteris flora, which occupied a rather less limited geographic province having presumably less rigorous environmental conditions. A third province, that of the Supaia flora, existed west of the ancestral Rocky Mountains; this province seems to have been characterized by harsh ecologic conditions which produced an impoverished flora.

The plants described in this paper were not restricted to any one of the three Permian floral provinces, but collectively they occupied all three. Although Spermopteris probably evolved before the beginning of the differentiation of upper Paleozoic floral provinces, it first appeared on the eastern margin of the area later to become the province of Glenopteris, then migrated southwest, and eventually was found in north-central Oklahoma in the Gigantopteris province. Phasmatocycas appears in the Glenopteris province and, assuming that my identifications are correct, in the Gigantopteris province as well. Only Archaeocycas and Cycadospadix are presently limited to one province-that of Gigantopteris. Taeniopteris, however, the one floral element in common association with all the others, is found in all 


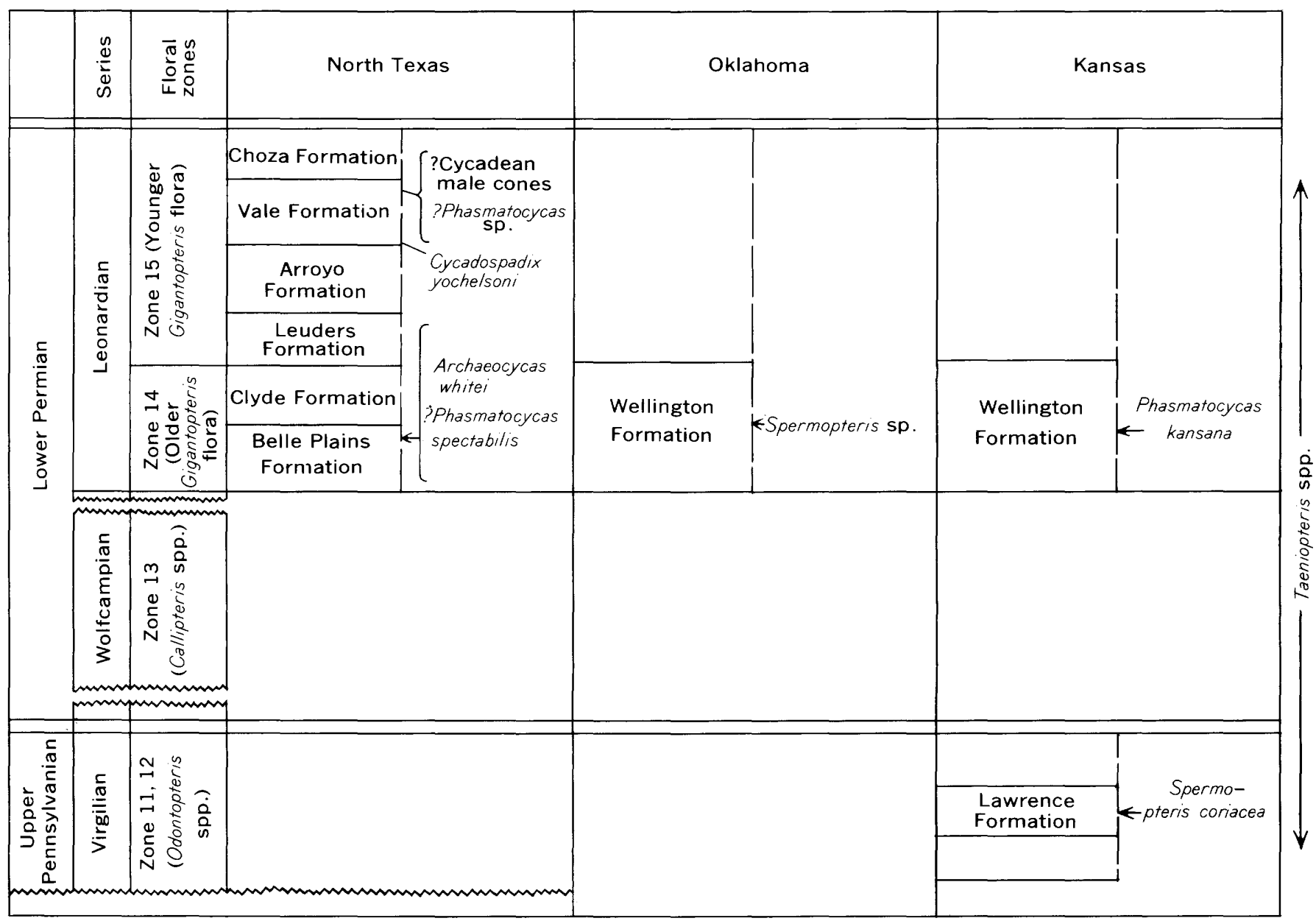

FIgURE 5.-Vertical distribution of late Paleozoic cycads and related plants. Modified from Dunbar and others (1960), Moore and others (1944), and Read and Mamay (1964).

three provinces; it is a conspicuous element in the Supaia flora, three species having been described from the Hermit Shale of the Grand Canyon, Ariz. (White, 1929). Thus Taeniopteris was chronologically persistent, geographically adventuresome, and ecologically resilient. If those qualities reflect a genetically robust constitution for the taeniopterids, the phylogenetic acquisition of such traits would equip any Paleozoic derivatives of the taeniopterids advantageously for worldwide dispersal during the Mesozoic.

\section{MORPHOLOGIC AND EVOLUTIONARY CONSIDERATIONS}

\section{INTERRELATIONSHIPS OF THE AMERICAN FOSSILS}

Appraisal of the evolutionary significance of these fossils is best begun by an attempt to weigh their relationships with each other. If their stratigraphic positions were such that a vertically linear sequence of forms could be used as a framework for phylogenetic analyses, those interpretations would be a relatively simple matter. As shown in figure 5, however, a linear phylogeny is not apparent among these plants because two of the principal forms, Phasmatocycas and Archaeocycas, are clearly representative of different evolutionary stages; in their earliest appearances, however, they occur in essentially synchronous deposits. Thus they probably represent separate evolutionary tangents, derived from a common spermopterid ancestor.

The simplest phyletic facet of this association is in the relationship between Spermopteris and Phasmatocycas. The role of Spermopteris as the morphologic equivalent of, if not the actual archetypic plant from which Phasmatocycas kansana arose, becomes apparent upon examination of all the pertinent facts. The stratigraphic relations fit the demands for such a phylogenetic affinity, for Spermopteris, the ancestor, is considerably older than Phasmatocycas, the descendant. The geographic proximity of known occurrences of the two genera adds substance to a hypothetical genetic relationship. Seeds of the two, 
as far as they are known, are similar. The intimate association of the genera with sterile taeniopterid foliage emphasizes the probability of physical identity. This probability is virtually converted into reality by the presence of the regularly distributed resinoid spheroids on the axis of Phasmatocycas kansana and of similar bodies on only taeniopterid foliage; only the actual organic continuity between Taeniopteris and Phasmatocycas remains to be found. The total effect of the foregoing lines of evidence is to promote acceptance of Phasmatocycas as a cycadean megasporophyll with basal ovules and a taeniopterid distal lamina, as reconstructed in figure 4.

Phyletic derivation of Phasmatocycas from Spermopteris would involve the morphogenetic processes of migration of seed positions, partial sterilization of the megasporophyll, and reduction of the lamina. According to Cridland and Morris (1960, p. 855), the seeds were confined to the terminal regions of the megasporophyll of Spermopteris but in all the cycads and in the reconstruction of Phasmatocycas the seeds were basal. As seed position varies considerably among the pteridosperms that have simple, noncupular phyllospermy, there is no compelling reason to believe that terminal seed positions need have been phyletically immutable among the spermopterids. If some spermopterid megasporophylls originally were only basally fertile, or became basally fertile through distal sterilization of completely fertile megasporophylls or through basal migration of originally terminal seeds, one has found a phyletically immediate antecedent for Phasmatocycas. Eventual organogenetic elimination of the basal fertile part of the lamina would then effect a migration of the points of seed attachment from laminally superficial positions to positions along the sides of the foliar midrib, which would thus become the fertile peduncle of the megasporophyll. This process would preserve the original bilateral disposition of the laminally borne seeds of Spermopteris and would be reflected in the bilateral ovuliferous habit of all cycadean megasporophylls, living and fossil.

This hypothetical series of modifications is shown diagrammatically in figure 6 . The ultimate derivative form (fig. $E$ ), representing Phasmatocycas kansana, is essentially a modern Cycas-type of megasporophyll, except for certain minor morphologic divergences such as its relatively large number of ovules and its entire-margined lamina. Inasmuch as it epitomizes a cycadean megasporophyllar form that had substantially completed the important qualitative phases of its evolution by the onset of Leonardian time, closely related taxa might reasonably be expected to be found ultimately in any post-Paleozoic rock unit. Even though a certain amount of doubt attends the identity of the Haskell County specimen from the Vale Formation, the presence there of Phasmatocycas may well be expected. Considered in relation to other pertinent material, the Vale specimen would more logically be a true Phasmatocycas than an intermediate form with Spermopteris-like foliation; nonetheless, the possibility of affinity with Spermopteris cannot be discounted without more satisfactorily preserved material.

With the exception of Archaeocycas, which probably represents an evolutionary stage similar to that shown in figure $6 D$, the age relationships of the known elements in this evolutionary series suggest that forms intermediate between Spermopteris and Phasmatocycas must be sought in Wolfcampian rocks, where evidence of cycadean fossils is yet absent (fig. 5).

The specimens of ?Phasmatocycas spectabilis are impressive because of the large size of the sporophylls and the great numbers of seeds. These features make it difficult to assess possible affinities between ?P. spectabilis and its contemporary, $P$. kansana, which is known from only one small specimen. Although the bilateral distribution of the seeds of the Texas specimens strongly suggests their assignment to Phasmatocycas, the absence of information regarding ovular details precludes the positive generic identification. Organic evidence for correlation of the fertile axes with a given foliar type, such as presented by the resinoid spherules in the Kansas material, is not available in the Texas specimens. However, some of the associated Texas taeniopterid leaves are so large (laminae as much as $10.0 \mathrm{~cm}$ wide and midribs as broad as $15.0 \mathrm{~mm}$ ) that their establishment as distal laminae of the large fructifications of ?P. spectabilis would not seem disproportionate.

Accepting the probability that ?P. spectabilis and $P$. kansana are congenerically related, the impressive quantitative differences and essentially contemporaneous stratigraphic relationships of the two taxa would seem to discourage the concept of a linear phylogenetic alliance. More likely they are coordinate descendents of a common spermopterid ancestor, ?P. spectabilis having undergone reduction of a considerable length of foliar lamina while retaining a large complement of seeds. In the latter respect, $P$. spectabilis is to be regarded as the most prolific megasporophyllar type yet discovered among the cycads. It is also to be regarded as primitive, if the concept of reduction of numbers of parts is to be 

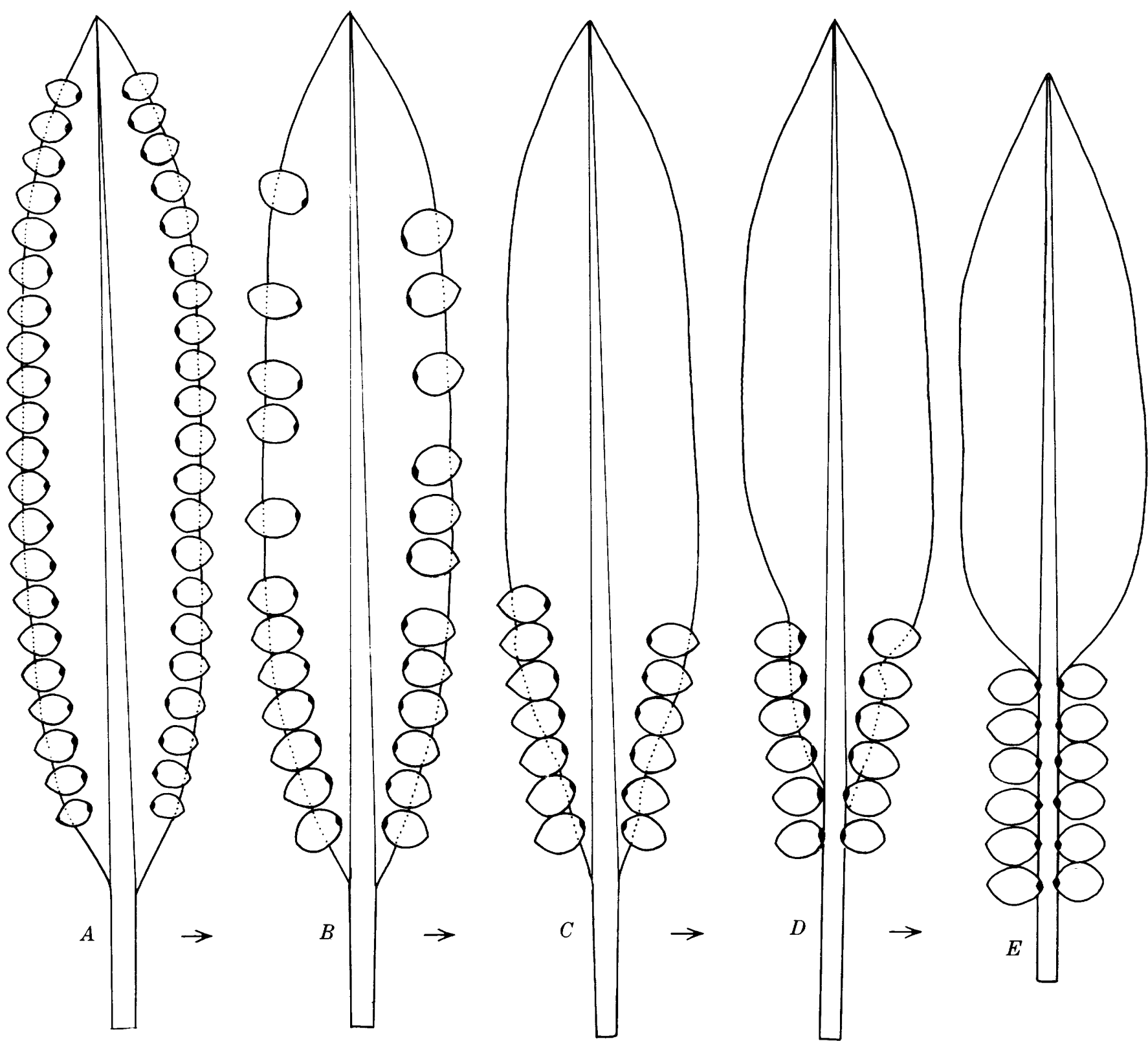

FIGURE 6.-Hypothetical evolutionary development of primitive Cycas-like megasporophyll from Spermopteris-like pteridosperm. $A$, Dorsal view of ancestral spermopteroid megasporophyll with taeniopterid lamina and superficial seeds (small solid-black areas at seed bases indicate points of attachment to lamina). $B$, Derivative form with reduced numbers of seeds. $C$, Further reduction, with seeds restricted to basal area of lamina. $D$, Form with seed production essentially constant, but basal part of lamina reduced, with basalmost seeds attached directly to stalk of megasporophyll. $E$, Ultimate Cycas-like derivative (=Phasmatocycas), with basal part of lamina completely reduced and all seeds attached to megasporophyll stalk.

retained as indicative of a trend in the direction of evolutionary advancement.

Because of its morphologic intermediacy, Archaeocycas whitei stands out as the most intriguing and phylogenetically important taxon found in this study. It is a curious mixture of both primitive and advanced features; thus the nature of its morphologic origins and the direction of its phyletic destiny seem apparent. The critical characteristics of this plant are consistently observable in such a large suite of specimens that they cannot be coincidental; thus, an obvious set of interpretations may be set forth with confidence,

The spacing of the small circular scars of seed attachment is remarkably regular in Archaeocycas, showing that the seeds were attached to the lamina 
only a short distance away from the midrib. This method of seed attachment is very much like that in Spermopteris, as diagrammatically shown at the lower right of Cridland and Morris' (1960) figure 10 (fig. 1 of this paper). Thus Archaeocycas retains the primitive feature of laminally borne seeds; by virtue of this characteristic, Archaeocycas may be regarded as a primitive megasporophyll, derived from Spermopteris or a Spermopteris-like ancestor.

Judged on its laminar morphology, Archaeocycas is distinctly intermediate between Spermopteris and the Cycas-type of megasporophyll. Although its lamina was still essentially complete, the basal part had become sharply modified and partly reduced, forming a closely fitting indusiumlike covering for the ovules. The sterile distal part of the lamina is known to have been abruptly expanded immediately above the fertile area. Its distal details are incompletely known, but there is no reason to doubt its foliar nature; the specimens shown on plate 1 , figures 1,2 , and plate 2, figures 5, 6 , show hints of a taeniopterid type of venation. The extent to which the ovules were enclosed by the laminar "indusium," is unknown, but, in keeping with the cycadean theme of this paper, I would venture to guess that the lower surfaces of the ovules were largely exposed.

Judged next on the basis of positions and numbers of seeds, Archaeocycas contrarily demonstrates a distinctly advanced morphological level, particularly in comparison with Spermopteris. Although the seeds of Spermopteris are said to be restricted to terminal parts of the sporophyll, those of Archaeocycas are definitely basal and therefore of substantially modern Cycas-like appearance. Furthermore, the number of ovules of Archaeocycas is not known to range beyond the extremes of 8 and 12 on a given sporophyll, with an average of 10 . This modest level of ovule production is again an essentially modern feature; inasmuch as it is consistent among a handful of specimens from two different localities, this seems to have been a stable genetic feature of at least the type species, Archaeocycas whitei. Comparison of this characteristic would seem to indicate a higher level of advancement for Archaeocycas than either Spermopteris or Phasmatocycas. In Spermopteris, the number of seeds on a given sporophyll is not evident from Cridland and Morris' (1960) account, but evidently the seeds were produced in large numbers; the type specimen of Phasmatocycas kansana had 21 or more seeds, ?P. sp. had 24 or more, and ?P. spectabilis produced 60 or more.

All morphologic features considered, then, Archaeocycas must be the derivative of some plant with the salient attributes of Spermopteris. It needed only to undergo morphogenetic reduction of the basal indusiumlike covering of the ovules and migration of the points of seed attachment to the midrib to attain the morphologic equivalence of a modern Cycas megasporophyll. Archaeocycas is, in fact, a classic example of evolutionary intermediacy; it is the type of fossil that would eventually have been predicted on a paper diagram, had it not been discovered in actual substance. In the vernacular, it is a critical "missing link."

In terms of the hypothetical evolutionary sequence diagrammed in figure 6, Archaeocycas would most closely approximate the stage depicted in $6 C$ or $6 D$; the chief qualitative difference is that the laminar "indusium" extending around the ovules is not shown in the diagram. A more complete representation of my visual concept of Archaeocycas and its evolutionary development into a Cycas-like megasporophyll is given in figure 7 . The progressively deeper marginal incision of the distal lamina, as shown in forms $C$ and $D$, represents a necessary step in the derivation of a pinnate appendage from an entire-margined one; certain fossil evidence for such a process is discussed below.

The kinds or degrees of natural affinity that existed between Archaeocycas and Phasmatocycas are difficult to weigh, primarily because both genera appeared at approximately the same time. Were it chronologically intermediate, Archaeocycas might be regarded as phylogenetically intermediate between Spermopteris and Phasmatocycas, in much the same manner that it seems intermediate between Spermopteris and Cycas; it might even be construed as a common ancestor of both Phasmatocycas and Cycas. The essentially comparable ages of the two Permian fossils, however, introduces the need for caution in reading their relationships in terms of a simple linear phylogeny. This picture is further beclouded by the fact that ?Phasmatocycas spectabilis occurs at the same two localities and in the same beds in which Archaeocycas has been found. A clearer understanding of the affinities between $P$. kansana and ?P. spectabilis would be helpful because, as previously stated, their phylogeny probably is not a linear one. If one is not derived from the other, it is possible that a common ancestor, intermediate between Spermopteris and those two Permian species, exists in older Permian rocks, and that the same taxon was ancestral to Archaeocycas as well. In the light of age relationships of the fosils, then, it seems preferable to regard Archaeocycas as the result of a 

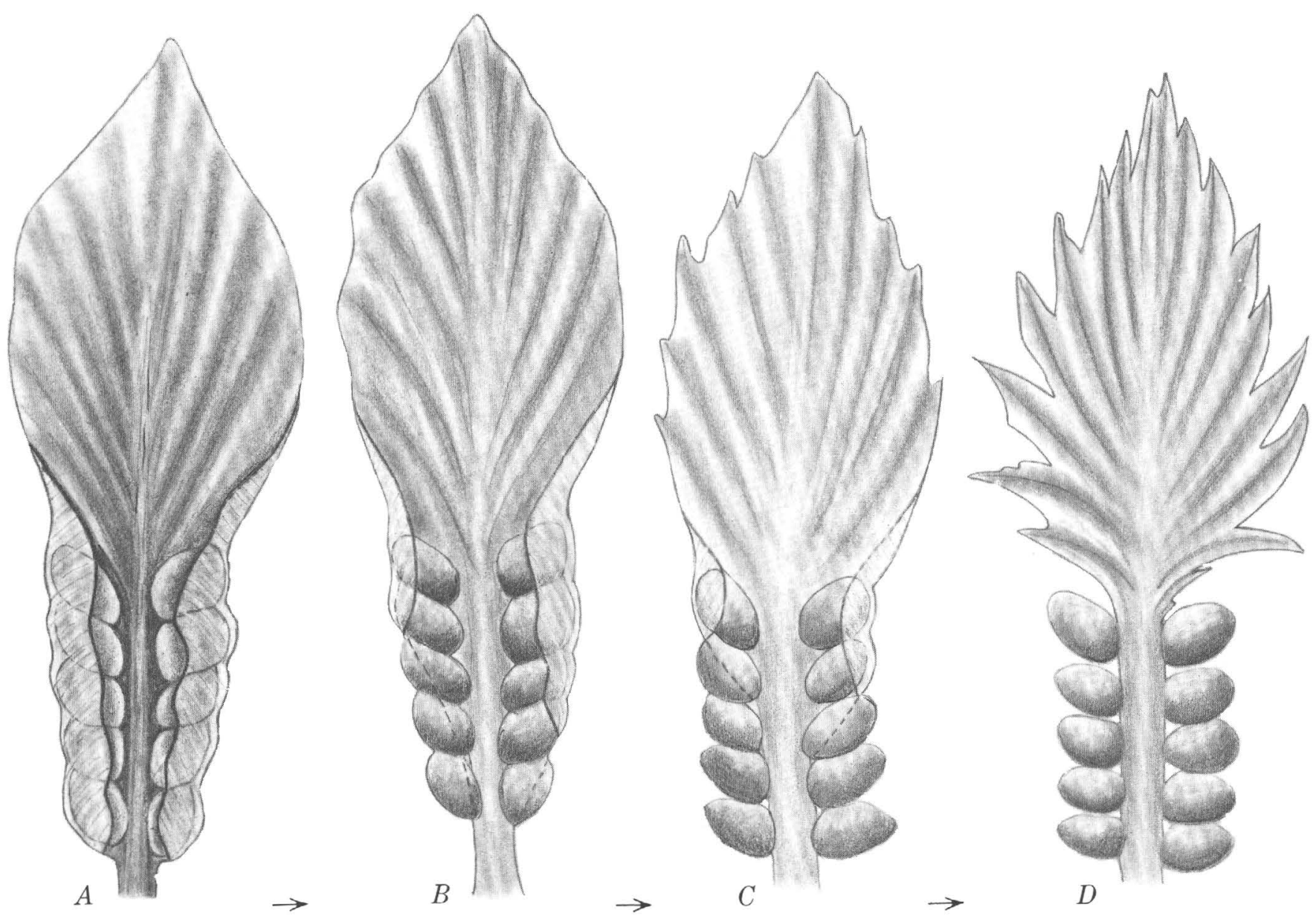

FIGURE 7.-Hypothetical evolution of Cycas-like megasporophyll from Archaeocycas (modified from Mamay, 1969a, tig. 1). $A$, Presumed dorsal view of megasporophyll, showing partial enclosure of paired basal seeds by sporophyllar lamina (extent of enclosure conjectural). B, C, Hypothetical derivatives, showing progressive reduction of basal lamina and resultant attachment of basalmost seeds to midrib, or stalk, of sporophyll; margin of distal lamina of form depicted in $C$ has become slightly incised. $D$, Cycas-like ultimate form, with basal lamina completely reduced and all seeds attached directly to stalk of sporophyll; distal lamina deeply pinnatifid, substantially as in Cycas revoluta.

line of descent independent from that which produced Phasmatocycas.

Cycadospadix yochelsoni is difficult to interpret from the standpoint of phyletic position. Almost any of the necessarily indirect bases for assaying its natural relationships to the other fossils discussed here are obscured by the possibility that this species is actually a cycadeoidean bract rather than part of a cycadean megasporophyll. Nonetheless, be it cycadean or cycadeoidean, its presence in Lower Permian rocks is chronologically precocious, like that of its cycadean associates. Cycadospadix yochelsoni is further intriguing in that it would not appear biologically incongruous if it were established as the distal extension of one of the terminally incomplete fructifications described in preceding pages; rather, it would seem harmonious in such a position and would complete the portrayal of a Cycas-like megasporophyll in any of those instances.

\section{AN ALTERNATIVE INTERPRETATION OF ARCHAEOCYCAS}

The sketches presented in figure 7 were made on the premise that the ovules of Archaeocycas were incompletely enclosed by the fertile lamina. Placement of the margins of the lamina was rendered speculative because the few specimens available for this study were preserved only in lateral or ventral view, and delicacy of matrix and preservation limited mechanical preparation to a point just short of destruction of the specimens. Thus the lower or dorsal aspects of the megasporophyll of Archaeocycas 
are not known. The lack of evidence of constriction of foliar tissue immediately distal to the most distal pairs of ovules, however, suggests that at least that part of the lamina was incompletely inrolled and that the plant was therefore gymnospermous.

With the morphology of Spermopteris and other cycadalean entities in mind, then, I applied the most conservative interpretation of Archaeocycas and depicted it as a fertile leaf with superficial ovules and incompletely involute margins. As such it represents as uncomplicated as possible a theoretical derivative of a Spermopteris-like ancestor, yet with significant attributes of a primitive Cycas-like megasporophyl Only a modicum of morphogenetic reduction of the lamina was necessary to produce a Phasmatocycas or Cycas type of megasporophyll; thus Archaeocycas, if interpreted correctly, stands as an important Permian intermediate between the Pennsylvanian Spermopteris and the modern Cycas.

The uncertain extent of involution of the megasporophyll of Archaeocycas introduces the necessity for considering an alternate interpretation. It seems at least remotely possible that, even if not coalescent in the known specimens of Archaeocycas, the opposing margins of the fertile base of the lamina were in an initial stage of proliferation rather than reduction, so that they subsequently met and began phylogenetic fusion. Continuation of the process of fusion would eventually have resulted in an organ in which the ovules were completely enclosed. This structure would thus show basic characteristics of an angiospermous carpel; as illustrated in my preliminary article (Mamay, 1969a, fig. 1H), this hypothetical organ was said by Uhl and Moore $(1971$, p. 990) to resemble the carpel of the palm Nypa.

This theoretical process is illustrated in figure 8, adapted from the preliminary article (Mamay, 1969a, fig. 1). Its significance lies in the inference that plants having at least one important angiospermlike reproductive feature could have been derived on a more or less direct line from the late Paleozoic pteridosperms, and in the corollary evidence from the fossil record, that the carpel is indeed a modified seed-bearing leaf. Thus the suggestion emerges that possibly the angiosperms and cycads are closely related through a common ancestry - the spermopterid pteridosperms-or even that the angiosperms arose directly. from the cycads during the late Paleozoic. The latter idea could be particularly attractive to those who espouse the concept of Paleozoic angiospermy. (See Eames, 1959.) At the same time it would shed doubt on my arbitrarily delineated distinction between dorsal and ventral sides of Archaeocycas, because it is accepted that angiosperm ovules are produced on the adaxial (ventral) side of the megasporophyll (Eames, 1961, p. 186) ; thus, either the ovules of Archaeocycas were attached to the wrong side of the lamina or my terminology has been incorrectly applied.

The possibility that the specimen of Cycadospadix in the Texas flora is a Bennettitalean appendage resuscitates the question of relationships between the cycads and cycadeoids. Chamberlain (1935, p. 158, figs. 171, 172) proposed that both groups arose from a common ancestor among the Paleozoic pteridosperms and presented a series of drawings depicting two reduction series leading to the cycads and cycadeoids; the hypothetical ancestral megasporophyll had a terminal ovule and several lateral ones intercalated between foliar segments. In one series the terminal ovules aborted, and continued reduction of parts resulted in several of the modern types of cycadean megasporophylls; in the other series, some of the terminal ovules were retained, all others were aborted, and with the reduction of laminar tissue, the ovule-bearing stalks and sterile "interseminal scales" of Bennettites were produced. Neither the ancestral nor the intermediate forms have been discovered, so that Chamberlain's hypothesis remains unsubstantiated. Delevoryas (1968b) agreed that the pteridosperms are the most likely source of the cycadeoids, but he also pointed out that the cycads and cycadeoids have always been distinct orders. If a common ancestry is involved among the pteridosperms, one probably must look for it in prePennsylvanian sediments. Certainly the present study sheds no light on the question, and if the Texas specimen of Cycadospadix is indeed bennettitalean, it is more than ever apparent that the two orders were distinct entities for as long as either can be recognized.

It would be impractical to attempt to review here all the thoughts that have been published in regard to the ancestry of the angiosperms. Suffice it to say that all the various groups of gymnosperms-particularly the pteridosperms-have at one time or other been regarded as probable progenitors of the flowering plants. The cycads were especially favored as angiosperm ancestors by Chadefaud (1936) who interpreted the fertile megasporangiate organs as homologous and wrote (Chadefaud, 1936, p. 590591):

Or, la feuille carpellaire des Angiospermes est manifestement un feuille fertile à ovules lateraux $* * *$

On en devra évidenment conclure que les Angiospermes sont plus étroitement apparentées aux Cycadales qu'a aucun autre 


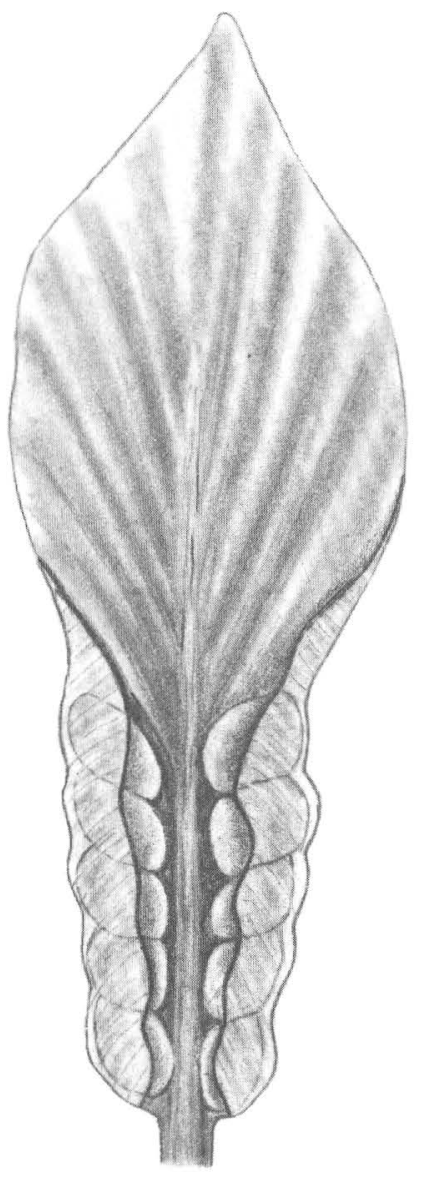

A

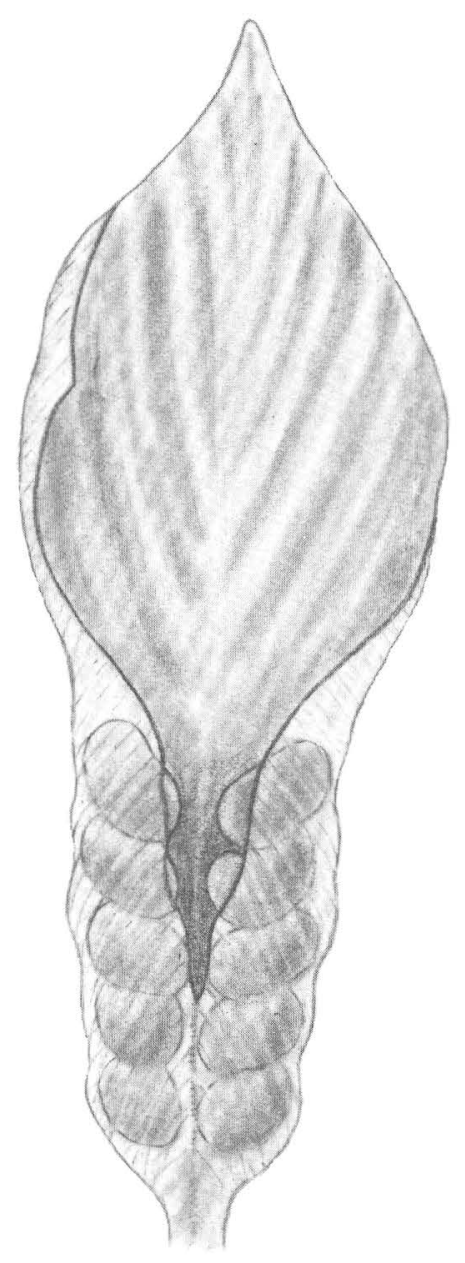

$B$

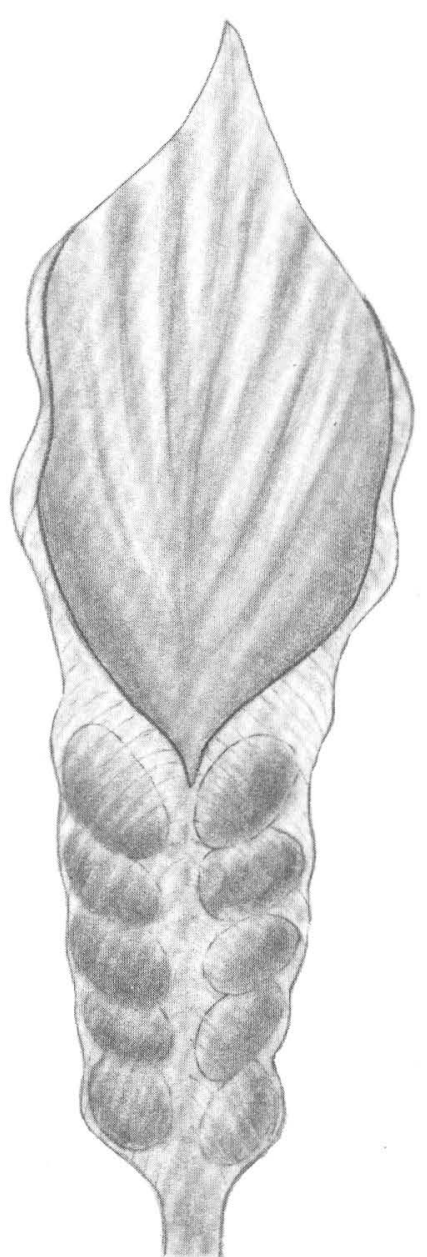

C

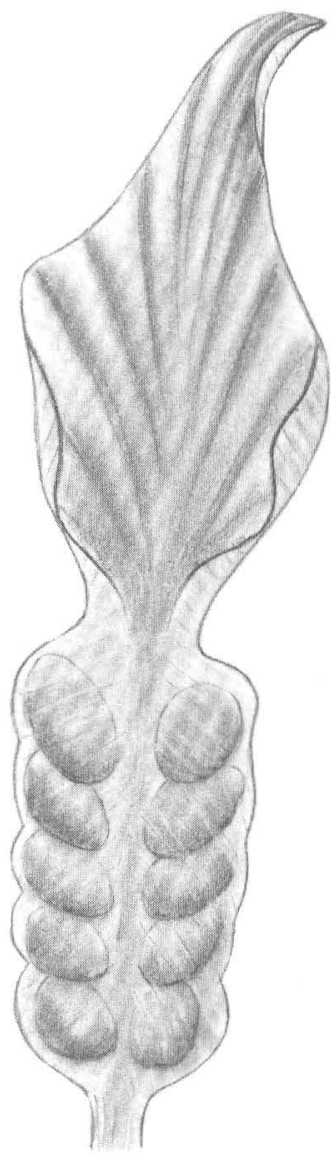

$D$

FIGURE 8.-Hypothetical evolution of carpellike organ from Archaeocycas (modified from Mamay, 1969a, fig. 1). A, Presumed dorsal view of megasporophyll, showing partial enclosure of ovules by sporophyllar lamina. $B-D$, Hypothetical derivatives, showing progressive proliferation and fusion of margins of lamina, resulting in complete enclosure of ovules $(D)$.

groupe de Gymnospermes. En particulier, c'est aux Cycadales et non aux Bennettitales qu'il faut les rattacher.

Chadefaud's ideas have not been widely accepted by subsequent writers. Eames (1961, p. 464-467) reviewed the possible origins of angiospermy and omitted the cycads from consideration. Cronquist (1968, p. 40-46) again considered the possibilities and eliminated all the gymnosperms except the pteridosperms (Lyginopteridales) as likely angiosperm forerunners, meanwhile urging caution toward acceptance of the lyginopterids in that capacity. Cronquist conceded, however, that the cycads probably arose from the pteridosperms; this view implicitly indicates a distant but common ancestry for the cycads and angiosperms.

Carlquist (1969, p. 353), in commenting on fossil evidence on floral theories, discounted any evidence that "Cordaitales, Ginkoales, Coniferales, Cycadeoidales or even Cycadales ever had leaf-like megasporophylls." Carlquist also commented that "The chance of finding a fossil that shows ancestral carpel form is vanishingly small-and would we recognize it if we saw it, or would we misidentify it because of preconceptions?"

Carlquist's comment on the "vanishingly small" chance seems incongruous with the steadily increasing ranks of paleobotanists, the attendant increase in collecting activities, and the fluid overall state of fossil botany. And perhaps an early "ancestral carpel form" may be represented by an Archaeocycaslike plant, and only better material is needed to establish its identity as such.

The foregoing discussion is not intended as my endorsement of the idea that Archaeocycas is a car- 
pel or even an early form in the evolution of the carpel; I regard the cycadalean interpretation as more consistent with the attendant facts and circumstances, and particularly with the morphology of Spermopteris. The discussion is rather intended to point up the increasingly evident fact that Permian time produced many botanical innovations (see Mamay, 1962, 1966, 1968; White, 1912), some of which may have involved carpellike seed enclosure and the beginnings of angiospermy.

\section{RELATIONSHIPS OF THE AMERICAN FOSSILS TO OTHER FOSSIL GYCADS}

Appraisal of the natural affinities between the American taxa and other fossil cycad fructifications ish not substantially more complicated than that of the interrelationships of the American fossils themselves. The problem is that so few points of comparison exist; only a few post-Paleozoic ovuliferous cycadean fructifications are recorded, and recently Harris (1961) has reviewed reasons for doubting the validity of some of those.

The most thoroughly understood of the Mesozoic ovuliferous cycad fructifications is the genus Beania Carruthers from the Jurassic of Yorkshire, England; our knowledge of Beania is the result principally of the many contributions of T. M. Harris and $\mathrm{H}$. H. Thomas. Beania is commonly regarded as the most advanced of the known Mesozoic cycads, for its seeds are of essentially modern aspect and the female infructescence, although long, lax and not very conelike, is composed of simple biovulate sporophylls of zamioid construction. Thus Beania does not bear any significant morphological resemblance to any of the American fossils and is probably not as closely related to Phasmatocycas or Archaeocycas as it is to the modern genera; if related within a simple infrafamilial phylesis, Beania is certainly closer to Phasmatocycas than to Archaeocycas, because of the more modern aspects of Phasmatocycas. If Beania arose from a member of the spermopterid stock of which the American fossils are clearly the progeny, the evidence for such derivation has not begun to be recovered; when found, it may be difficult to recognize as such. Beania, then, is of little aid in interrelating the American fossils with fossils of the Old World or of the post-Paleozoic. Furthermore, the Jurassic Period was sufficiently younger than the Permian, and cycad evolution apparently so rapid, that even if a more complete spectrum of female fructifications were known from the Jurassic, probably none of those fossils would be very enlightening on the phylogenetic implications of the
American material. We must therefore consider the Triassic cycads.

Only two Triassic taxa need to be considered here: Dioonitocarpidium Lilienstern 1928 and Palaeocycas Florin 1933. Both genera have been widely cited as credible examples of Triassic cycads, but in each instance challenges have been directed at cycadean interpretations.

Rühle von Lilienstern described Dioonitocarpidi$u m$ on the basis of Upper Triassic (Keuper) material from Bavaria. It is a composite taxon, consisting of taeniopterid sterile foliage (Danaeopsis angustifolia Schenk) and pinnate sporophylls (Dioonites pennaeformis Schenk), each sporophyll supposedly bearing a basal pair of ovules. The type species is $D$. pennaeforme (Schenk) Lilienstern. Lilienstern's original reconstruction of the apical part of a plant is presented here in figure $9 \mathrm{~A}$. Although this reconstruction has been duplicated by various authors (Gothan and Weyland, 1954; Kräusel, 1950; Magdefrau, 1956), it has not been universally accepted. It was criticized by Florin (1933, p. 122), who expressed doubt that a plant with simple taeniopterioid leaves would produce pinnate sporophylls. Florin furthermore pointed out that the foliage (Danaeopsis angustifolia) may not even be gymnospermous and that the name Dioonitocarpidium possibly embraces two unrelated plants, one a fern, the other a cycadophyte.

An element of doubt as to morphological detail attends Lilienstern's reconstruction of the fertile base of a megasporophyll (fig. $9: B$ ). The drawing depicts a broad stalk with slender hairy pinnae and a pair of basal seeds. Within bounds of artistic license the reconstruction is reasonably acceptable, except for what appear to be anomalous subsidiary flanges of tissue extending from the sporophyll stalk below the attached ovules and continuing distally to the upper limits of the sketch. This improbable feature was not discussed in Lilienstern's text and is possibly attributable to a drafting error. The probability of an error gains support from the fact that the detailed reconstruction of the sporophyll base (see fig. $9 \mathrm{C}$ ) was modified in two textbooks by Gothan and Weyland $(1954$, p. $288 ; 1964$, p. 314$)$, so as to eliminate the superfluous flange, although Lilienstern's overall reconstruction of the plant is faithfully reproduced in both the cited instances.

Inasmuch as the Gothan and Weyland references included no explanation of the discrepancies between their reconstruction and the original, I inquired of Professor Weyland as to a possible reason. Weyland (written comm., 1968) advised me that "The illus- 

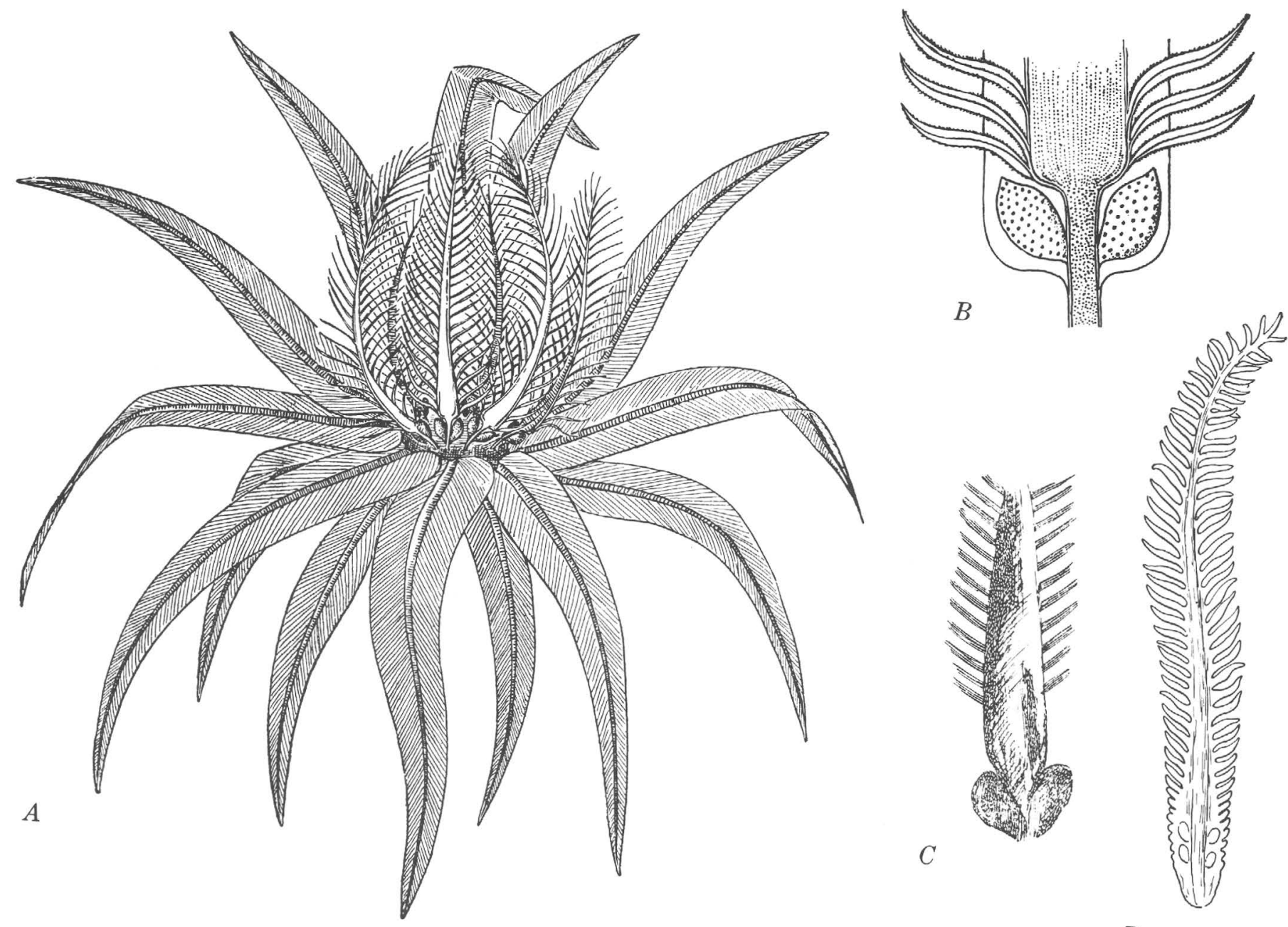

$D$

FIgURE 9.-Reconstructions of Dioonitocarpidium Lilienstern. A, Apical part of plant of D. pennaeforme, showing taeniopteroid sterile foliage and pinnate sporophylls (from Lilienstern, 1928, fig. 1). B, Lilienstern's reconstruction of basal part of megasporophyll, showing pair of seeds and peculiar subsidiary flangelike structure beneath the pinnae (from Lilienstern, 1928, pl. 6, fig. 4). C, Modified reconstruction of basal part of megasporophyll of D. pennaeforme (from Gothan and Weyland, 1964, fig. 208 a). D, Reconstruction of megasporophyll of D. keuperianum (Krasser) Kräusel, showing two pairs of basal seeds and pinnate lamina (from Kräusel, 1949, fig. 4).

tration of the sporophyll originated with Gothan and, so far as I know, it is not published elsewhere. Lilienstern's reconstruction probably seemed incorrect to him. However, I do not know where the specimen forming the basis of Gothan's illustration is located today." Whatever the exact basis of Gothan's illustration was, it is apparent that he disagreed with Lilienstern's depiction of the fertile base of a sporophyll, meanwhile accepting the overall reconstruction of Dioonitocarpidium as a plant with pinnate sporophylls and taeniopterid sterile leaves. The modifications introduced by Gothan into the reconstruction of the individual megasporophyll have resulted in a morphologically more reasonable form than the original of Lilienstern.
Two additional species of Dioonitocarpidium $-D$. keuperianum (Krasser) Kräusel, and D. liliensterni Kräusel-were subsequently described; these also are from the Upper Triassic Keuper beds of Bavaria. D. keuperianum (Kräusel, 1949) was reported as a megasporophyll with a pinnate distal part and a slightly pinnatifid basal flange of laminar tissue to the surface of which "several" seeds were allegedly attached; Kräusel published a reconstruction of the sporophyll, which appears here as fig. $9 D$. In a later publication, Kräusel (1953, p. 106) discussed additional material of D. keuperianum, which was said to "partly confirm, partly broaden and correct" his earlier description of that species. Kräusel (1953, p. 106) stated that seeds were plainly visible on one of 
the specimens, and that at least five were attached to one side of the sporophyll. Unfortunately, the photographic illustrations in both publications are of poor quality and do not permit verification of the critical details of Kräusel's reconstruction or of his diagnosis (Kräusel, 1949, p. 48) of D. keuperianum.

A similar circumstance concerns the third species, D. litiensterni. In 1953, Kräusel described D. liliensterni on the basis of a single sporophyll. This species differed from Kräusel's concept of D. keuperianum in that its basal, supposedly fertile part was much longer and broader than that of $D$. keuperianum and was entire-margined. Kräusel (1953, p. 107) stated that three seeds were attached to one side of this organ. Here again the photographic illustrations fall short of convincing demonstration of attached seeds. It may well be that the broad base of the leaf in question truly represents a reproductive specialization, but the requisite seeds remain in question. Thus, in consideration of the deficiencies of illustration, a certain amount of reservation appears necessary in drawing comparisons of $D$. keuperianum and D. liliensterni.

If one assumes that the descriptions and reconstructions of the three species of Dioonitocarpidium are accurate, then one must weigh the question of their taxonomic relationships, because their modes of seed attachment show as much difference, fundamentally, as the difference between the seed attachment of Archaeocycas and Phasmatocycas. In $D$. pennaeforme the seeds are sessile and supposedly are attached directly to a naked sporophyll stalk, as is the case with Phasmatocycas; conversely the seeds of $D$. liliensterni and D. keuperianum are supposedly attached to a basal laminar extension of the sporophyll, similar to the manner of seed attachment in Archaeocycas. Thus the Dioonitocarpidium concept may in fact consist of two genera, differentiable on the basis of characteristics of the fertile bases of the sporophylls. From this speculative standpoint, one might postulate two Permian-Triassic evolutionary lines of cycads, one leading from Phasmatocycas to Dioonitocarpidium pennaeforme and an attendant reduction in number of seeds, the other leading from Archaeocycas to $D$. liliensterni and $D$. keuperianum. Admittedly this is a tenuous approach to phyletic considerations because of the many deficiencies in the physical evidence on hand. The American and European taxa may very well not be related by way of a linear phylesis. However, they show approximately comparable morphological qualities and seem to express similar evolutionary trends. Both groups contain members with laminally produced seeds, a fact which, through conservative interpretation, suggests that both groups were derived from a spermopterid stock. Thus it is not entirely unrealistic to suppose that the two groups had a common ancestry, if not a lineal relationship. The evidence of common association with taeniopterid foliage seems to bear out the foregoing lines of thought.

The one Triassic taxon remaining for consideration is Palaeocycas-Bjuvia, a cycadean plant from the Rhaetian (Upper Triassic) of Sweden, which was described and reconstructed by Florin in 1933; his reconstructions appear here as figure 10. Like Dioonitocarpidium, Palaeocycas (for the sake of brevity of reference, Florin arbitrarily selected this as the name for the entire plant) is a composite genus. It consists of large taeniopterid leaves (Taeniopteris gigantea Nathorst), to which Florin applied the binomial Bjuvia simplex, and presumed megasporophylls with ovate entire-margined distal laminae; Florin named the latter Palaeocycas integer. No seeds were found attached to the megasporophylls, but the stalks of these organs each bore two pairs of prominent lateral protrusions. Florin interpreted the latter as points of seed attachment and reconstructed the sporophyll as a leaflike appendage with four basal seeds attached to the naked stalk. Because of their association in the same rock strata and similar epidermal anatomy in the leaves and sporophylls, Florin deduced that the two organs belonged to the same plants. The reconstruction of this plant shows a stout armored trunk and loose terminal crown of leaflike megasporophylls, which strikingly resemble those of the modern Cycas. The outstanding discrepancy between Palaeocycas and $C y$ cas is in the architecture of their respective fronds; those of Palaeocycas are simple, whereas those of Cycas are pinnate.

The circumstantial nature of the evidence for Florin's synthesis of Palaeocycas and Bjuvia into one plant was discussed fully by Harris (1961). Harris' comments were mildly skeptical; his emphasis was on the absence of seeds as an important negative factor. Notwithstanding this type of criticism, however, Florin's reconstruction continues to appear in recent textbooks (Sporne, 1965, p. 106; Emberger, 1968, p. 457) as an acceptable Mesozoic cycad. Indeed, this is possibly the most widely reproduced example of paleobotanical synthesis; Florin's reconstruction seems to have enjoyed classic status from the time of its original publication.

The relevance of Palaeocycas to the present study is in the important resemblances that are seen between this Triassic plant and my concept of Phas- 


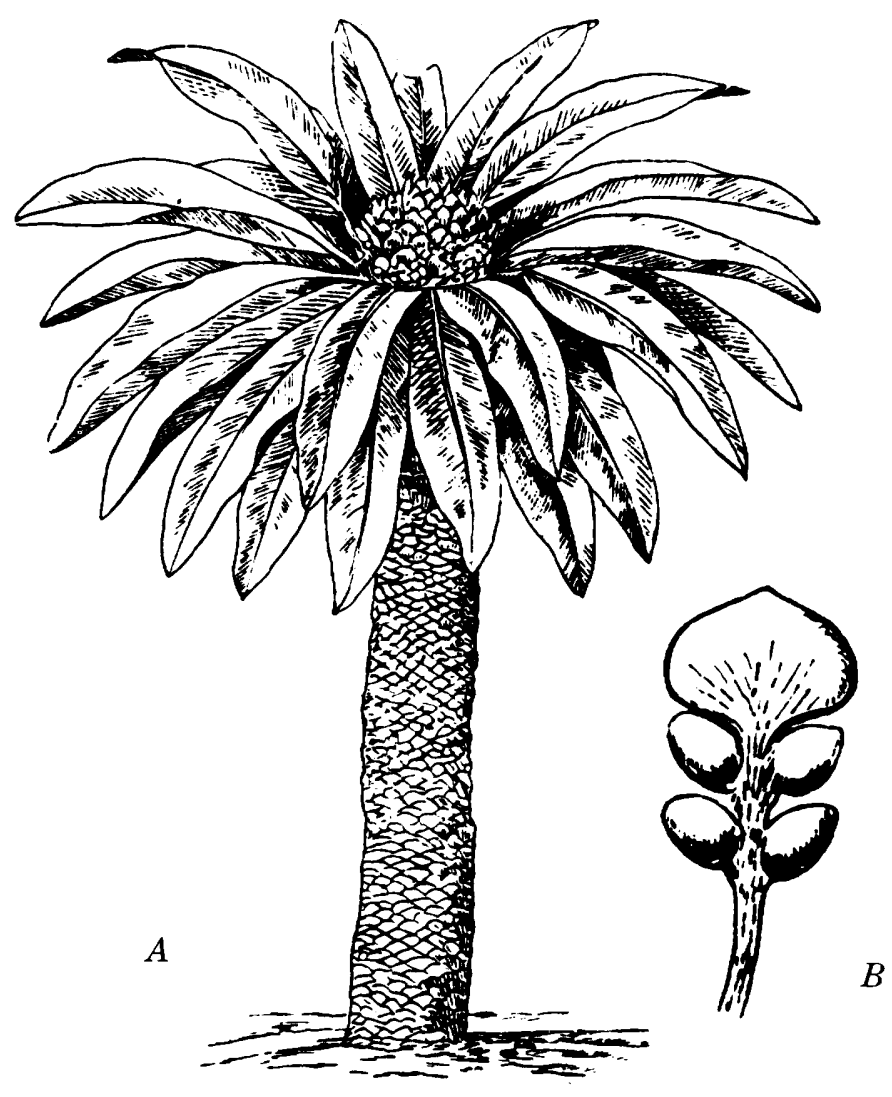

FIGURE 10.-Reconstructions of Palaeocycas-Bjuvia. A, $\mathrm{Hy}-$ pothetical reconstruction of entire plant. $B$, Single megasporophyll, reconstructed with two pairs of basal seeds. From Gothan and Weyland, 1964, fig. 209.

matocycas; a much more convincing set of arguments can be presented in support of direct phyletic relationships between Phasmatocycas and Palaeocycas than is possible in comparing Dioonitocarpidium with Archaeocycas and Phasmatocycas. Although Palaeocycas and Phasmatocycas are both incompletely known, the gaps in our knowledge, which appear in different areas of their diagnostic images, are considerably minimized by taxonomically significant similarities. Indeed, their reconstructions are mutually corroborative on the grounds of complementarily indirect evidences.

In both genera, sterile taeniopterid leaves and megasporophylls are regarded as attributable to a common parent on similar bases: (1) consistent association in the same strata, and (2) morphological features shared by both pairs of organs-epidermal characteristics in the case of Palaeocycas and glands in the case of Phasmatocycas. The seeds are absent from the sporophyll of Palaeocycas but its distal lamina is known, whereas the reverse is true for Phasmatocycas; its seeds are known but the distal lamina is not. Nonetheless, the evidence for correlation of parts in each instance points toward two plants with very similar ovulate sporophylls and both with taeniopterid foliage. Although my reconstruction of the megasporophyll of Phasmatocycas entails a longer, more leaflike distal lamina and more seeds than in Palaeocycas, I believe that the overall aspects of the two plants were probably very similar and that, with only minor modifications, Florin's habit reconstruction of Palaeocycas might represent Phasmatocycas as well. The sporophyllar differences between the two genera are of minor quantitative nature and may be ascribed to reductive evolution in the direction of Palaeocycas, the younger of the two genera. From the standpoint of all morphologic evidence as well as stratigraphic relationships, a Palaeocycas-like plant would be a credible derivative of Phasmatocycas. Therein lies the most apparent relationship between American and other fossil cycads. Archaeocycas must be related to Palaeocycas in much the same way as it is related to Phasmatocycas.

\section{EVOLUTION OF THE PINNATE HABIT IN CYCADALEAN FOLIAGE}

Considerable indirect evidence favors the assumption that all the known pre-Jurassic cycads, with the exception of the Upper Triassic Leptocycas, bore entire-margined taeniopterid foliage. One thus is prompted to seek fossil evidence of an evolutionary process leading from simple undivided laminae to pinnate leaves of the type that characterizes most of the modern cycads. Gradual incision or laciniation of an originally Taeniopteris-like foliar lamina seems the most logical theme. As hypothetically proposed on preceding pages, the taeniopterid distal lamina of the sporophyll of Archaeocycas or Phasmatocycas became incised to produce a Cycas-like megasporophyll, and there is no good reason to discount a coordinate modification of the sterile leaves as well. The essence of such an evolutionary sequence among the cycads was briefly touched upon by Gaussen (1944, p. 20), who wrote: "Pour passer de la feuille de Palaeocycas à celle des Cycadites ou du type $C y$ cas, il faut que le limbe se dechere en pinnules et que dans chacune la nervure fine se transforme en une épaisse."

Taeniopteris or closely allied forms are abundant in the late Paleozoic fossil record, and among these are some whose margination suggests, and would easily fit into, an evolutionary series that produced a Cycas-type of leaf in which each laminar division contains a single vein. Taeniopteris serrulata, from the Lower Shihhotse Series (Lower Permian) of 
Shansi, China (Halle, 1927, p. 160-161, pl. 42, figs. 13-18, pl. 64, fig. 13), is a species that well might represent an early evolutionary stage in such a series. $T$. serrulata has a simple leaf and is quite ordinary in most morphological aspects; however, it has a finely serrate margin. The marginal teeth are very small, but each one is occupied by a single vein ending (cf. fig. 11B).

A further step in this evolutionary process is exemplified by the lamina of Taeniopteris? koreanensis Cheong and Lee, 1970, from the upper part of the Sadong Formation in Korea. The associated plants indicate an Early Permian age for T.? koreanensis and place it in a harmonious stratigraphic light within this hypothetical evolutionary series. Previously given the new generic name Serratopteris (Cheong, 1969), this material consists of a "probably unipinnate" leaf, in which all but the basal part of the lamina is deeply divided into a series of essentially equal incipient "pinnules" that extend about halfway from the margin of the lamina to the midrib (cf. fig. $11 C$ ). As in T. serrulata, each division received a single vein. The illustrations suggest that $T$. ? koreanensis is a compound leaf and that the serrations represent incipient pinnules rather than pinnae, but this point is not entirely clear. It is also not known whether the deep serrations extend to the tips of the laminae, because the specimens are incomplete. Notwithstanding, this species is a near-perfect intermediate between a normal, entire-margined Taeniopteris and a Cycas leaf with its single-veined leaflets; $T$. serrulata would be the expectable starting point. Interpretation of these plants as an infallibly credible series is beclouded by the uncertainty whether T.? koreanensis is a simple or compound leaf, but certainly the two examples demonstrate the possibility of a regular increasing process of laminar laciniation in the Paleozoic, each resultant ultimate foliar division supplied by a single vein, as in the modern monotypic family Cycadaceae (classification of Johnson, 1959). Culmination of the process producing $T$. serrulata might be envisioned in the Jurassic genus Paracycas Harris. A natural segregate from the form-genus Cycadites, Paracycas has Cycas-like pinnation and venation and is grouped among the cycads by Harris $(1964$, p. 65) .

With the exception of Stangeria, all other genera of modern cycads are characterized by pinnae or pinnules that lack midribs and have several to many longitudinal dichotomous veins; those genera were placed by Johnson (1959) in the family Zamiaceae. Stangeria, monotypifying the family Stangeriaceae, differs markedly in that its pinnae each have a pro- nounced midvein with a dense system of transverse, parallel, dichotomously divided secondary veins.

Just as putatively early stages in the development of the Cycas type of leaf are present among the Paleozoic taeniopterids, there are known fossil forms that may be regarded as possibly early representatives of the zamioid type of foliage. Halle's Taeniopteris? serrata (Halle, 1927, p. 161, pl. 42, figs. 9-12), a pinnate form associated with $T$. serrulata in the Permian Shansi flora, has a lamina with an irregularly serrate margin. In this species, however, the marginal areas between adjacent teeth receive three or four veins, rather than one as in T. serrulata (cf. fig. 11E).

Taeniopteris pseudobrevis is a species described by Barnard (1967, p. 725, pl. 61, figs. $1-4 ; 1970$, p. 37-38, pl. 5, figs. 1, 4, text-figs. 3B, D) from Upper Triassic rocks of Afghanistan. In this plant, the foliar lamina is regularly corrugated at intervals of 2-3 $\mathrm{mm}$ and is incised to as much as one-sixth the total width of the blade (cf. fig. $11 F$ ). Each partial segment contains the ends of several simple veins. This leaf thus gives the impression of a simple taeniopterid leaf well on the way toward becoming a pinnate one; the multiple-veined segments would each correspond to a single leaflet of a Zamia-like leaf.

Zamioid foliage appears more fully blown in the Upper Triasic of North Carolina, in the genus Leptocycas Delevoryas and Hope. The leaves of Leptocycas were compared with the common Jurassic genus Pseudoctenis, which, according to Harris (1964, p. 71), "would include the leaves of more than one genus of Recent Cycads." The lamina in this case is completely divided into essentially equal linear segments, each containing several parallel veins. This leaf is interpreted here as a remarkably precocious end product of laminar dissection, and consonantly Leptocycas, if truly a zamioid cycad, represents the earliest known appearance of the zamioid lineage.

Jurassic time, during which explosive development of the cycadophytes took place, produced a broad variety of foliar types. Some forms are regularly pinnate and quite cycadlike in most aspects; others, however, show significant intermediate steps in the laciniation, or pinnation, of originally entiremargined taeniopterid laminae. The specimen illustrated by Seward (1917, fig. 615) as Pterophyllum (Anomozamites) Nilssoni from the Middle Jurassic beds of Yorkshire, England, is a particularly interesting form. It has a very irregular but basically taeniopterid lamina, some parts of which are divided as far as the midrib into unequal truncated 
segments; the apical one-third of the lamina is nearly entire, however. This species was later placed in Anomozamites by Harris $(1969$, p. 80$)$ and is regarded as bennettitalean. The other species of Anomozamites, $A$. thomasi Harris, has nearly uniform segmentation of the lamina.

The genus Nilssonia is especially pertinent to the rationale of this theory of cycadean foliar evolution, because Nilssonia species show extremes of variable laminar dissection that occur in no other contemporary plant. Harris' (1932b, p. 40-52) descriptions of the Lower Jurassic species of Nilssonia from East Greenland revealed interesting examples. In some, the lamina may be consistently entire $(N$. undulata Harris), but in others ( $N$. polymorpha Schenk; cf. fig. $11 G$ ) the lamina is entire or deeply incised into irregular segments. Usually the segments on one side of the leaf have no regular relationship to those on the other. In N. incisoserrata Harris, (1932a; p. 4952) the leaf is mostly "incisoserrate," uniform segmentation reaching only part of the distance to the midrib (cf. fig. 11F) ; this form resembles Taeniopteris pseudobrevis Barnard in the partial segmentation of the lamnia. N. obtusa (Nathorst) Harris usually has entire leaves, but some have deep incisions at long intervals. Asama (1968) pointed out a trend observed in some Japanese forms of Nilssonia in which the entire-margined Early Jurassic $N$. orientalis supposedly gave rise to the smaller Late Jurassic $N$. orientalis var. minor. Asama assumed the series to culminate in the still smaller, Early Cretaceous $N$. schaumburgensis, in which the lamina is dissected into irregular segments as in N. tenuinervis. Asama's article, however, was intended to demonstrate a decrease in laminar size with the passage of time, and did not express any ideas regarding cycadean leaf derivation from an entiremargined ancestral form.

Other examples of irregular segmentation in Nilssonia are widely documented, but only one more, $N$. tenuinervis Seward, need be discussed here because of its established cycadean affinity. Harris (1941) presented compelling evidence that Androstrobus, a cycadean male cone; Beania, a female cone; and the leaf Nilssonia are parts of the same plant and that the plant is certainly a cycad. Thomas and Harris (1960) defined specific relationships with the conclusion that Beania mamayi, Androstrobus wonnacotti and Nilssonia tenuinervis, all of Middle Jurassic age, belonged to the same plant. They (p. 147) stated that

the Nilssonia plant is to be classified as a member of the Cycadales, but though nearest to the Zamioideae in its female cones, it should not be included in the Zamioideae because the female cones and probably the male cones differ from the cones of all Zamioideae in their lax and open construction.

In the same article, Thomas and Harris (1960, p. 150) concluded that Androstrobus prisma Thomas and Harris and Pseudoctenis lanei Thomas emend. Harris, were male cone and leaf of the same plant. Unlike Nilssonia tenuinervis, Pseudoctenis lanei is in most aspects remarkably similar to leaves of Zamia or Encephalartos, and Thomas and Harris $(1960$, p. 153) remarked on the zamioid aspects of this combination of organs :

Taking the two fossils together the agreement with the Zamioideae is much enhanced, and without speculating about the unknown female cone, we can say that in Pseudoctenis lanei with Androstrobus prisma we have a plant which is so like them that it may prove to belong to one of these living genera.

Harris' conclusions regarding the relationships between Nilssonia tenuinervis, Androstrobus wonnacotti and Beania mamayi led him to publish a restoration of a cycad bearing those three organs (Harris, 1961, text-fig. 2). It shows the irregular construction of the taeniopterid leaves, with long laminar segments separated by clefts extending as far as the midribs.

The morphologic variability discussed here clearly expresses the manifestation of a trend involving evolutionary modification of leaves constructed on the simple taeniopterid pattern. The oldest taeniopterids are of late Paleozoic age and are mostly entiremargined; in the Permian, however, the early beginnings of marginal incision are seen. The trend progresses to the extent that, by Late Triassic time, laminar dissection was complete in at least one example; by Middle Jurassic time it was complete in several taxa, although resultant foliar segments were not always of uniform size. To be sure, certain anomalies appear in this trend: the apparent precocity in Leptocycas and the conservatism in Nilssonia. These express the vagaries of morphogenetic rates within a group of rapidly evolving organisms. Nonetheless, the degree of laminar dissection seems generally consistent with decreasing geologic age of materials. Furthermore, the evolutionary process involved stages leading to two of the basic types of cycadean foliage-the Cycas type having singleveined leaflets, and the Zamia type with multipleveined divisions. It is even feasible to postulate derivation of the Stangeria type of leaf from Paleozoic stock, for pinnately compound taeniopterids are known, and each leaflet of a Stangeria leaf is basically equivalent to a simple Taeniopteris leaf in overall 


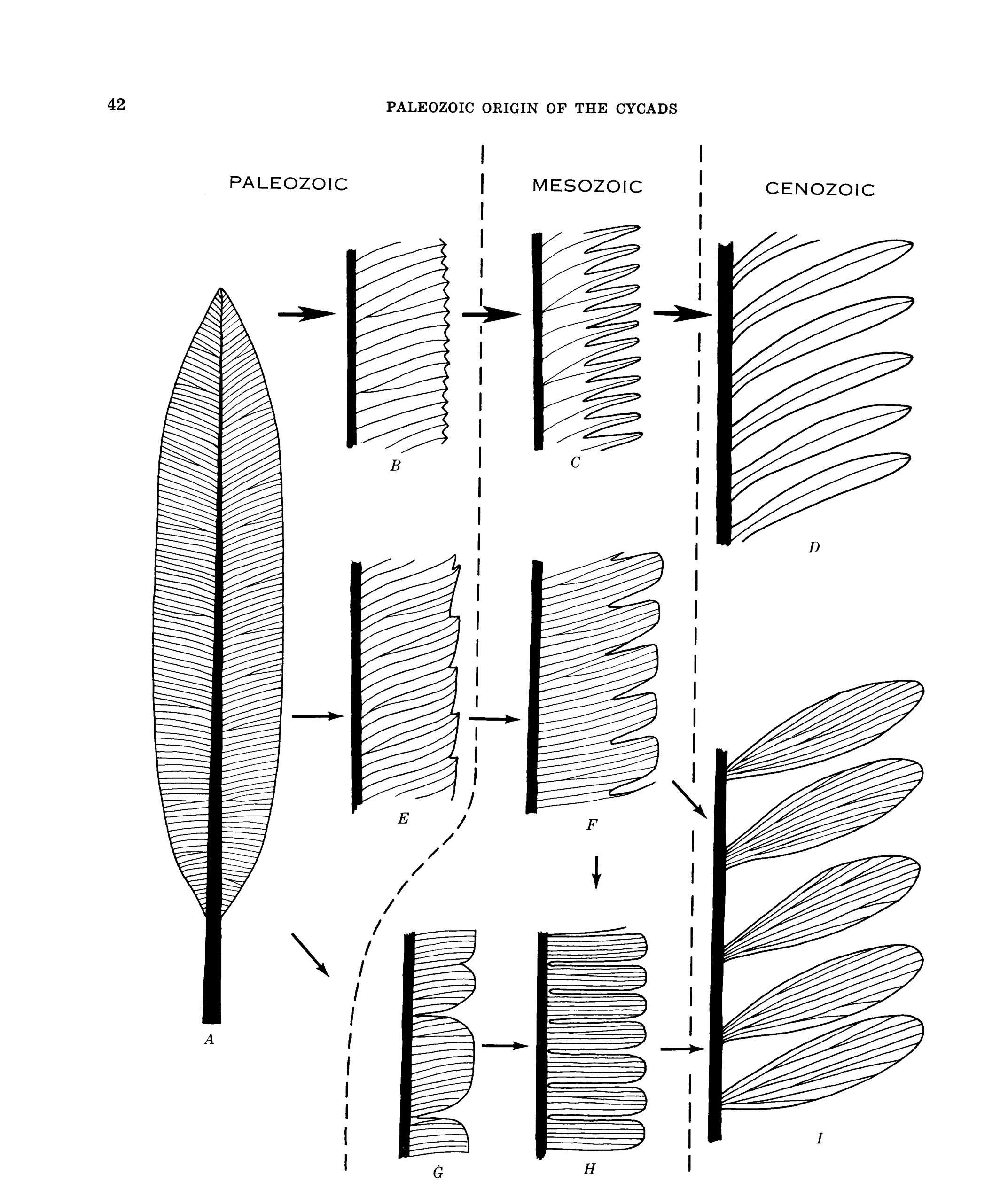


shape, venation, and margination. Thus, a pinnately compound taeniopterid leaf could evolve into a Stangeria leaf with only relatively minor modifications. Further, the bipinnate Bowenia type of leaf might have evolved from a pinnate taeniopterid ancestor through incision of the leaflets into multiveined segments.

Intimate association of leaves and fructifications has been of utmost importance in tracing the course of early cycadean evolution; cuticular comparisons, although not always possible, have also constituted critical evidence. In all instances where fossil leaves and reproductive parts have been suspected or demonstrated to represent the same plant and that plant has been interpreted as a cycad, the leaves have been taeniopterid or almost certainly of taeniopterid derivation. This circumstance strengthens the proposition that the cycads arose from taeniopterid pteridosperms and that modern cycad leaves have been derived from either simple or pinnate taeniopterid leaves through relatively little evolutionary modification, or through an evolutionary process no more complicated than laminar dissection.

Substantially the same statement may be made in regard to cycadeoid foliage. Taeniopteris has long been accepted as an artificial (form) genus representing Cycadales, Bennettitales, and Pentoxylales; nomenclatural and taxonomic adjustments have been made to accommodate the situation (Harris, 1969, p. 68; Sahni, 1948, p. 50). Although conclusions cannot yet be drawn relative to a possibly common ancestry between the Cycadales and Bennettitales or the age of the ancestral complex, it seems reasonable, on the basis of present knowledge of Bennettitalean leaves, to suppose that they too arose from a simple taeniop-

FIGURE 11.-Suggested evolution of cycadalean leaves beginning with $(A)$, an entire-margined ancestral taeniopterid leaf and, through progressively deeper incision of margins, resulting in two basic types of cycadalean leaves ( $D$, cycadaceous type; $I$, zamiaceous type). All diagrams are based on known fossil or modern forms. The cycadaceous lineage, indicated by heavy arrows, consists of forms in which marginal teeth and ultimate foliar segments involve a single vein each ( $B$, cf. Taeniopteris serrulata; $C$, cf. T.? koreanensis; $D$, cf. Cycas sp.). The zamiaceous lineage, indicated by light arrows, consists of forms in which marginal incisions and ultimate foliar segments involve several veins each ( $E$, cf. Taeniopteris? serrata; $F$, cf. T. pseudobrevis or Nilssonia incisoserrata; $G$, cf. Nilssonia tenuinervis or $N$. polymorpha; $H$, cf. $N$. tenuicaulis; $I$, cf. Zamia sp.) ; forms such as $E$ and $G$ might have been derived independently from $A$, whereas $H$ may have arisen from either $F$ or $G$. Both cycadaceous and zamiaceous lineages evolved substantially concurrently. Ages of forms: $A$, Pennsylvanian-Permian; $B, E$, Permian; $C$, Triassic; $F, G$, TriassicJurassic; $H$, Jurassic; $D, I$, Mesozoic-Cenozoic. terid leaf form through a process parallel to that proposed here for the cycads. The sum of presently available evidence, then, suggests that Taeniopteris constitutes a logical source of evolutional raw material for derivation of the open-veined cycadophytic leaf, be it bennettitalean or cycadalean.

\section{CONCLUSIONS}

The morphology, age, and geographic occurrences of the fossils discussed here combine to present a significant set of conclusions, bearing on various aspects of the history of some of the gymnosperms.

Archaeocycas and Phasmatocycas are sufficiently cycadlike to be classified among the cycads; Phasmatocycas is particularly convincing because of its twin-ranked, well-preserved seed cuticles. At the same time, these genera are so logically derivable from Spermopteris that the cycadean lineage is clearly extended to the Pennsylvanian pteridosperms; this conclusion corroborates the opinions of Harris (1961) and others and injects additional credence into the few known occurrences in the Paleozoic of petrified wood with cycadlike anatomical features (Cycadoxylon; Andrews, 1940). These fossils eminently represent the pre-Jurassic "progressive evolution" postulated by Harris (1961, p. 322). Thus, the stratigraphic continuity of the cycadalean lineage is extended from the Upper Triassic to the Upper Pennsylvanian, and the cycads join the conifers as one of the two oldest groups of extant seed plants.

On the basis of present information, we cannot know when the spermopterid ancestors of the cycads ceased to be pteridosperms and became cycads, even though the relationship between the two taxa seems clear. Concordantly, the possible impact of the Paleozoic fossils on the broad classification of the cycads cannot yet be assayed, and a revised system will not be attempted here; such a system will depend ultimately on the acquisition of knowledge of other parts of the Permian and Triassic cycads, such as the male organs and vascular anatomy. Nonetheless, Spermopteris, Phasmatocycas and Archaeocycas appear to uphold the concept that Cycas, with its leaflike megasporophylls, is the primitive genus among extant cycadales; this appraisal has been the popularly accepted one, although Thomas (1947, p. 250; 1953 , p. 582) held the contrasting view that Zamia, rather than Cycas, is the primitive member of the Cycadales.

The evidence for taeniopterid foliation among the early cycads and the indications that gradual lami- 
nar dissection of entire leaves produced the pinnate types of modern cycad foliage are an important facet of this study, but they also pose a perplexing problem-the origin of taeniopterid foliage-whose solution will necessitate extensive searches of prePennsylvanian rocks. Taeniopteris appears "suddenly" in Pennsylvanian rocks and gives no clues as to its ancestry; it is a conspicuous element in the Permian and Triassic floras. In keeping with his theories of leaf evolution, Asama (1960, p. 258) believes that the simple leaf of Taeniopteris is an example of an "enlarged leaf," formed from an originally pinnate form. Kon'no, Asama, and Rajah (1970, p. 559), however, stated that no substantial evidence yet exists in the Cathaysian flora for this opinion, and I know of none in the Angara. European, or American floras. It is conceivable, of course, that Asama's notions are correct and that intermediate forms ancestral to Taeniopteris simply have not been found.

Geologic age and geologic occurrence of the fossils discussed here are significant considerations, for they contribute to the ever-growing number of indications that the Lower Permian deposits of the southwestern United States contain proof that this area was an important center of botanical evolution and radiation. Late Pennsylvanian plants such as Spermopteris emphasize the importance of that time in respect to the beginnings of major innovations in plant form. Wolfcampian time produced the Permian guide fossil, Callipteris, but this genus has no more morphólogical significance than that of a younger type of seed-fern with a "marker" type of foliage.

Leonardian time, however, saw the introduction into the American botanical community of radically different forms, some of which leave no grounds for interpretation as to antecedents or progeny; Gigantopteris americana White and Russellites taeniata (Darrah) Mamay are prime examples. Reproductive methods of these two genera are yet speculative. They are probably seed plants, but this speculation is based only on their age and the otherwise demonstrated progress of plant evolution as shown by fossils.

Thus far, the advent of cycads is the most important botanical event attributable to the Leonardian or even to the Permian System. It emphasizes the importance of Leonardian rocks as the physical representation of a time interval worthy of close examination in the search for progressive evolution among higher plants.

\section{REFERENCES CITED}

Andrews, H. N., Jr., 1940, On the stelar anatomy of the pteridosperms, with particular reference to the secondary wood: Missouri Bot. Garden Annals, v. 27, no. 1, p. 51-118.

Arnold, C. A., 1953, Origin and relationships of the cycads: Phytomorphology, v. 3, nos. 1-2, p. 51-65.

Asama, Kazuo, 1960, Evolution of the leaf forms through the ages explained by the successive retardation and neoteny: Tohoku Univ. Sci. Repts., 2d ser. (Geology), spec. v., no. 4 (Shoshiro Hanzawa Memorial Volume), p. 252-280. 1968, The evolution of Nilssonia orientalis: Tokyo Nat. Sci. Mus. Mem., no. 1, p. 33-36. (In Japanese with English abstract and title.)

Barnard, P. D. W., 1967, Two new plants from the Upper Triassic of North East Afghanistan: Riv. Italiana Paleontologia Stratigrafia, v. 73 , no. 3, p. 723-728.

1970, Upper Triassic plants from the Kalawch River, North-East Afghanistan: Italian Exped. Karakorum $\left(\mathrm{K}^{2}\right)$ and Hindu Kush, Sci. Repts. 4, PaleontologyZoology-Botany, v. 2, Fossils of north-east Afghanistan, p. 25-40.

Bassler, Harvey, 1916, A cycadophyte from the North American coal measures: Am. Jour. Sci., 4th ser., v. 42, no. 247, p. 21-26.

Carlquist, Sherwin, 1969, Toward acceptable evolutionary interpretations of floral anatomy: Phytomorphology, v. 19, no. 4 , p. $332-362$.

Carpenter, F. M., 1952, Fossil insects, in U.S. Dept. Agriculture, Yearbook of Agriculture, 1952: Washington, D.C., U.S. Govt. Printing Office, p. 14-19.

1971, Adaptations among Paleozoic insects: North Am. Paleont. Convention Proc., pt. 1, 1236-1251.

Chadefaud, M., 1936, L'origine cycadéene des Angiospermes et la classification générale des Phanerogams: Soc. Botanique France Bull., v. 83, p. 586-592.

Chamberlain, C. J., 1930, Elements of plant science: New York, McGraw-Hill Book Co., 394 p.

1935, Gymnosperms: structure and evolution: Chicago, Univ. Chicago Press, $483 \mathrm{p}$.

1965, The living cycads: New York, Hafner Publishing Co., 172 p. (facsimile of 1919 ed.).

Cheong, C. H., 1969, Stratigraphy and paleontology of the Samcheog coalfield, Gangweondo, Korea (1): Geol. Soc. Korea, Jour., v. 5, no. 1, p. 13-56.

Cheong, Chang $\mathrm{Hi}$, and Lee, Ha Young, 1970, Some fossil plants from the Jangseong Formation of the Gangweon coal mine, Korea: Geol. Soc. Korea Jour., v. 6, no. 1, p. 13-27, pl. 1-4.

Coulter, J. M., and Chamberlain, C. J., 1910, Morphology of gymnosperms: Chicago, Univ. Chicago Press, $458 \mathrm{p}$.

Crepet, W. L., 1972, Investigations of North American cycadeoids: pollination mechanisms in Cycadeoidea: Am. Jour. Botany, v. 59, no. 10, p. 1048-1056.

Cridland, A. A., and Morris, J. E., 1960, Spermopteris, a new genus of pteridosperms from the Upper Pennsylvanian Series of Kansas: Am. Jour. Botany, v. 47, no. 10, p. 855-859.

Cronquist, Arthur, 1968: The evolution and classification of flowering plants: Boston and New York, Houghton Mifflin Co., 396 p. 
Daugherty, L. H., 1941, The Upper Triassic flora of Arizona, with a discussion of its geologic occurrence by $\mathrm{H}$. R. Stagner: Carnegie Inst. Washington Pub. 526, 108 p. $34 \mathrm{pl}$.

Delevoryas, Theodore, 1968a, Investigations of North American cycadeoids-structure, ontogeny and phylogenetic considerations of cones of Cycadeoidea: Palaeontographica, v. 121, Abt. B, Lief. 4-6, p. 122-133, pl. 34-38.

- 1968b, Some aspects of cycadeoid evolution: Linnean Soc. London Jour., Botany, v. 61, no. 384, p. 137-146; reprinted in K. L. Alvin and others, eds., Studies on fossil plants, London and New York, Academic Press.

Delevoryas, Theodore, and Hope, R. C., 1971, A new Triassic cycad and its phyletic implications: Postilla, no. 150, p. 1-21.

Dunbar, C. O., 1923, Kansas Permian insects, pt. 1. The geologic occurrence and the environment of the insects; with a description of a new paleodictyopterid, by R. J. Tillyard: Am. Jour. Sci., 5th ser., v. 7, no. 39, p. 171209,2 pls.

Dunbar, C. O., chm., and others, 1960, Correlation of the Permian formations of North America: Geol. Soc. America Bull., v. 71 , no. 12, pt. 1, p. 1763-1805, chart 7 .

Eames, A. J., 1959, The morphological basis for Paleozoic origin of the angiosperms: Internat. Bot. Cong., 9th, Montreal, 1959, Proc., v. 2, Abstracts, p. 100-101.

1961, Morphology of the angiosperms: New York, McGraw-Hill Rook Co., 518 p.

Emberger, Louis, 1944, Les plantes fossiles dans leurs rapports avec les végétaux vivants (éléments de paléobotanique et de morphologie comparée) : Paris, Masson et Cie, 492 p. (2d ed., 1968, 758 p.).

Florin, Rudolf, 1933, Studien über die Cycadales des Mesozoikums nebst Erörterungen über die Spaltöffnungsapparate der Bennettitales: Kgl. Svenska Vetenskapsakad. Handl., ser. 3, v. 12 , no. 5, 134 p., 16 pl.

Gaussen, Henri, 1944, Les Cycadales, Chap. 3 of Les gymnospermes actuelles et fossiles, fasc. 1-2: Toulouse, Fac. Sci., [106] p. (First part of a monographic study of fossil and living gymnosperms.)

Gothan, Walther, and Weyland, Hermann, 1954, Lehrbuch der Paläobotanik: Berlin, Akad.-Verlag, 535 p. (2d. ed., 1964, 594 p.).

Gould, R. E., 1971, Lyssoxylon grigsbyi, a cycad trunk from the Upper Triassic of Arizona and New Mexico: Am. Jour. Botany, v. 58, no. 3, p. 239-248.

Halle, T. G., 1927, Paleozoic plants from Central Shansi: Palaeontologia Sinica, ser. A, v. 2, pt. 1, 316 p., 64 pl.

1929, Scme seed-bearing pteridosperms from the Permian of China: Kgl. Svenska vetenskapsakad. Handl., ser. 3 , v. 6 , no. 8,24 p.

Harris, T. M., 1932a, The fossil flora of Scoresby Sound, East Greenland-Pt. 2, Description of seed plants incertae sedis, together with a discussion of certain cycadophyte cuticles: Medd. Grønland, v. 85, no. 3, 114 p. 9 , pls.

- 1932b, The fossil flora of Scoresby Sound, East Greenland-Pt. 3, Caytoniales and Bennettitales: Medd. Grønland, v. 85, no. 5,133 p., $19 \mathrm{pls}$.

- 1941, Cones of extinct Cycadales from the Jurassic rocks of Yorkshire: Royal Soc. London Philos. Trans., ser. B, v. 231 , no. 577 , p. $75-98,2$ pl.
1954, Mesozoic seed cuticles: Svensk Bot. Tidskr., v. 48 , no. 2, p. 281-291.

1961, The fossil cycads: Palaeontology, v. 4, pt. 3, p. 313-323.

1964, The Yorkshire Jurassic flora-Part 2, Caytoniales, Cycadales and pteridosperms: London, British Mus. (Nat. History), 191 p., 7 pl.

1969, The Yorkshire Jurassic flora-Part 3, Bennettitales: London, British Mus. (Nat. History), 186 p., 7 pl.

Johnson, L. A. S., 1959, The families of cycads and the Zamiaceae of Australia: Linn. Soc. New South Wales Proc., v. 84 , pt. 1 , no. 389 , p. 64-117.

Kon'no, Enzo, Asama, Kazuo, and Rajah, S. S., 1970, The Late Permian Linggiu flora from the Gunong Blumut area, Johore, Malaysia: Nat. Sci. Mus. [Tokyo] Bull., v. 13 , no. 3 , p. $491-580$.

Kräusel, Richard, 1949, Koniferen und andere Gymnospermen aus der Trias von Lunz, Nieder-Österreich: Palaeontographica, v. 89, Abt. B, lf. 1-3, p. 35-78, pl. 6-18.

1950, Versunkene Floren-eine Einführung in die Paläobotanik: Frankfurt am Main, Waldemar Kramer, 152 p., 63 pls.

- 1953, Ein neuses Dioonitocarpidium aus der Trias von Lunz: Senckenbergiana, v. 34, no. 1-3, p. 105-108, 1 pl.

Leppik, E. E., 1971, Paleontological evidence on the morphogenetic development of flower types: Phytomorphology, v. 21 , no. 2-3, p. $164-174$.

Lilienstern, H. R., 1928, Dioonites pennaeformis Schenk, eine fertile Cycadee aus der Lettenkohle: Paläont. Zeitschr., v. 10, p. 91-107, pl. 5-6.

Mägdefrau, Karl, 1956, Paläobiologie der Pflanzen: 3d ed., Jena, Gustav Fischer 443 p.

Mamay, S. H., 1954, A Permian Discinites cone: Washington Acad. Sci. Jour., v. 44, no. 1, p. 7-11.

1960 (1962), Padgettia, a new genus based on fertile neuropteroid foliage from the Permian of Texas: Paleobotanist, v. 9, no. 1-2, p. 53-57.

1966, Tinsleya, a new genus of seed-bearing callipterid plants from the Permian of north-central Texas: U.S. Geol. Survey Prof. Paper 523-E, p. E1-E15, pl. 1-3.

1968, Russellites, new genus, a problematical plant from the Lower Permian of Texas: U.S. Geol. Survey Prof. Paper 593-I, p. I1-I15, pl. 1-3.

1969a, Cycads-fossil evidence of late Paleozoic origin: Science, v. 164, no. 3877 , p. 295-296.

1969b, Fossil evidence of Late Paleozoic origin of the cycads: Internat. Bot. Cong., 11th, Seattle, 1969, p. 139 .

1971, Cycadales, in McGraw-Hill yearbook of science and technology: New York, McGraw-Hill Book Co., p. 158-160.

- 1973, Archaeocycas and Phasmatocycas-new genera of Permian cycads: U.S. Geol. Survey Jour. Research, v. 1, no. 6, p. $687-689$.

Meeuse, A. D. J, 1963, The so-called "megasporophyll" of Cycas-a morphological misconception. Its bearing on the phylogeny and the classification of the Cycadophyta: Acta Botanica Neerlandica, v. 12, p. 119-128.

Meyers, P. A., and Morley, H. T., 1929a, Geologic map of Jones County, Texas: Texas Univ. Bur. Econ. Geology map, scale 1:48,000; revised, 1937. 
1929b, Geologic map of Taylor County, Texas: Texas Univ. Bur. Econ. Geology map, scale 1:48,000; revised 1937.

Miser, H. D., 1954, Geologic map of Oklahoma: U.S. Geol. Survey in cooperation with Oklahoma Geol. Survey, scale 1:500,000.

Moore, R. C., chm., and others, 1944, Correlation of Pennsylvanian formations of North America: Geol. Soc. America Bull., v. 55, no. 6, p. 657-706, pl. 1 (chart 6 of series).

Read, C. B., and Mamay, S. H., 1964, Upper Paleozoic floral zones and floral provinces of the United States: U.S. Geol. Survey Prof. Paper 454-K, p. K1-K35.

Romer, A. S., 1958, The Texas Permian redbeds and their vertebrate fauna, in Westoll, T .S., ed., Studies on fossil vertebrates: London Univ., Athlone Press, p. 157-179.

Sahni, Birbal, 1920, On the structure and affinities of Acmopyle Pancheri, Pilger: Royal Soc. London Philos. Trans., ser. B, v. 210 , p. $253-310$, pl. 9-11.

1948, The Pentoxyleae: a new group of Jurassic gymnosperms from the Rajmahal Hills of India: Bot. Gaz., v. 110 , no. 1 , p. 47-80.

Schimper, W. P., 1870-1872, Traité de paléontólogie végétale ou la flore du monde primitif: Paris, J. B. Bailliére et Fils, 3 v., and atlas containing 110 pls.

Schuster, J., 1932, Cycadaceae, in Engler, Adolph, Das Pflanzenreich: Leipzig and Berlin, W. Engelmann, v. 4, pt. 1, p. 1-168.

Sellards, E. H., 1901, Permian plants-Taeniopteris of the Permian of Kansas: Kansas Univ. Quart., v. 10, no. 1, p. 1-12, pl. 1-4.

1908, Fossil plants of the Upper Paleozoic of Kansas: Kansas Univ. Geol. Survey, v. 9, p. 386-480, pls. 44-69.

Seward, A. C., 1917, Fossil plants: London, Cambridge Univ. Press, v. $3,656 \mathrm{p}$.
Sporne, K. R., 1965, The morphology of gymnosperms: London, Hutchinson Univ. Library, $216 \mathrm{p}$.

1971, The mysterious origin of flowering plants: London, Oxford Univ. Press, 16 p.

Taylor, T. N., 1969a, Cycads-evidence from the Upper Pennsylvanian: Science, v. 164 , no. 3877 , p. 294-295.

$1969 \mathrm{~b}$, Evidence for the presence of cycads in the Upper Pennsylvanian: Internat. Bot. Cong., 11th, Seattle, 1969, Abstracts, p. 216.

- 1970, Lasiostrobus gen. n., a staminate strobilus of gymnospermous affinity from the Pennsylvanian of North America: Am. Jour. Batany, v. 57, no. 6, pt. 1, p. 670690.

Thomas, H. H., 1947, The history of plant form: British Assoc. Adv. Sci. Reports, v. 4, no. 15, p. 243-254.

- 1953, The relationships between the Bennettitales and Cycadales: Internat. Bot. Cong., 7th, Stockholm, 1950, Proc., p. 581-582.

Thomas, H. H., and Harris, T. M., 1960, Cycadean cones of the Yorkshire Jurassic: Senckenbergiana Lethaea, v. 41, no. 1-6, p. 139-161, pl. 1-4.

Uhl, N. W., and Moore, H. E., 1971, The palm gynoecium: Am. Jour. Botany, v. 58, no. 10, p. 945-992.

U.S. Geological Survey, 1968, Geological Survey Research, 1968: U.S. Geol. Survey Prof. Paper 600-A, 371 p.

Von Gutbier, C. A., 835, Abdrücke und Versteinerungen des Zwickauer Schwarzkohlengebirges und seiner Umgebungen: Zwickau, G. Richter, 80 p., 11 pl.

White, C. D., 1912, The characters of the fossil plant Gigantopteris Schenk and its occurrence in North America: U.S. Natl. Mus. Proc., v. 41, no. 1873, p. 493-516.

1929, Flora of the Hermit shale, Grand Canyon, Arizona: Carnegie Inst. Washington Pub. 405, 221 p., 51 pl.

Wilson, J. A., 1953, Permian vertebrates from Taylor County, Texas: Jour. Paleontology, v. 27, no. 3, p. 456-470. 


\section{INDEX}

[Italic page numbers indicate descriptions and major references]

\section{$\mathbf{A}$ \\ Page}

abnormis, Taeniopteris _............ 7, 8 americana, Gigantopteris _-_ 5, 8, 24, 26, 27, 44 Androstrobus

wonnacotti 24,4

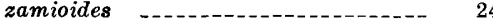

angustifolia, Danaeopsis ........... 36

Annularia - Danaeopsis

Anomozamites ........................ 41

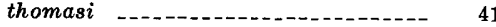

Nilssoni, Pterophyllum _.......... 40

(Anomozamites) Nilssoni, Pterophyllum 40 Aphlebia _............................ 27

Araucarites - -

Archaeocycas _- 4, 6, 8, 10,11, 12, 14, 17, 18, 19,

$22,27,28,29,30,31,32,33,34,35,36,38,39,43$ whitei _...... $8,11,12,31,32$; text-fig. 3 ; pls. 1, 2

Aspidiopsis

Beania $2,15,19,36,41$ $\begin{array}{lll}\text { gracilis } & \\ \text { mamayi } & & \end{array}$

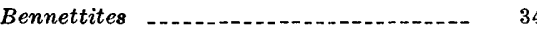

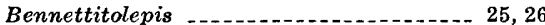
dactylota Bjuvia _... 2, 17, 38, 39 simplex _.................... 25, 38

Bowenia C

Callipteris $17,26,27,28,44$

Cardiocarpon

Carpolithes -

Ceratozamia -

circinalis, Cycas _......... 24

Cordaianthus

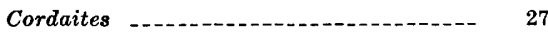

coriacea, Spermopteris _..._. 2

Taeniopteris _.................... 2, 16 linearis, Taeniopteris 16

Cycadites -

Cycadospadix _... 2, 6, 25, 26, 27, 28, 34 dactylota Hennocquei ..................... 25 integer Moraeanus yochelsoni _................ 26, 33; pl. 2 sp _....... 6, 19 Cycadoxylon _..................... 43

Cycas _........ 3, 4, 12, 19, 25, 26, 30, 31, 32, $33,34,38,40,43$ circinalis -....... 24 media - - 3 revoluta _. sp

D

dactylota, Bennettitolepis Cycadospadix

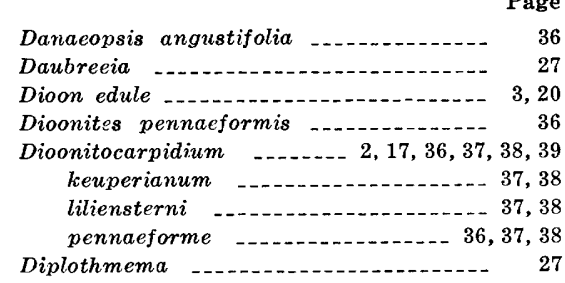

Discinites -

E

edule, Dioon

3,20

Encephalartos $-20,41$

\section{F}

floridana, Zamia 3

\section{G}

gigantea, Taeniopteris _..._._._._. 38 Gigantopteris ................... 26, 27, 28 americana _.......... 5, 8, 24, 26, 27, 44 n. sp --_-_- 27 Ginkgo -..-18 Glenopteris Gomphostrobus _. gracilis, Beania Leptocycas 6 grigsbye, Lyssoxylon

\section{H}

Hennocquei, Cycadospadix 25

incisoserrata, Nilssonia _..._........ 41, 43 integer, Cycadospadix Palaeocycas _._.

\section{K}

kansana, Phasmatocycas - 12, 21, 23, 26, 29, 30, 32; text-fig. 4 ; pls. 3,4

keuperianum, Dioonitocarpidium _..... 37, 38 koreanensis, Taeniopteris _._._.... 40,43

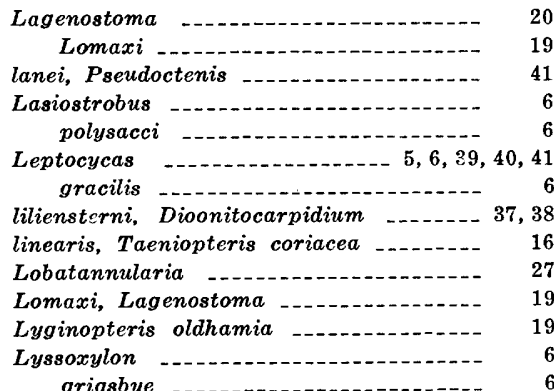

1

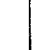

Macrozamia -_. 20,24

miquelii

mamayi, Beania -

media, Cycas

minor, Nilssonia orientalis .......... 41

miquelii, Macrozamia _....... 3

Moreanus, Cycadospadix

multinervis, Taeniopteris _. 7,19

\section{$\mathbf{N}$}

Neuropteris

newberriana, Taeniopteris

Nilssonia -...- 41

incisoserrata 41,43

obtusa -

orientalis

minor -

polymorpha

schaumburgensis -...-... 41

tenuicaulis ..... 43

tenuinervis _.................... 41, 43

undulata -

Noeggerathia -

Nypa

\section{o}

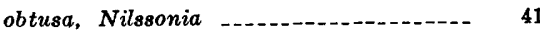
Odontopteris oldhamia, Lyginopteris _............ 19 orientalis, Nilssonia _...... 41 minor, Nilssonia

$\mathbf{P}$

Padgettia - -

Palaeocycas _._____ 2, 4, 25, 26, 36, 38, 39 integer

Paracycas - - 40

Pecopteris - Dioonitocarpidium -_ $36,37,38$ pennaeforme, Dioonitocarpidium -- 36, 37, 38
pennaeformis, Dioonites

Phasmatocycas _- $6,13,14,15,16,17,18,19,20$ $21,22,23,24,27,28,29,30$ $31,32,33,34,36,38,39,43$

kansana _...... 12, 21, 23, 26, 29, 30, 32 text-fig. $4 ;$ pls. 3,4

spectabilis _._. sp -

Plagiozamites -.... 6

planchardi _......... 6

planchardi, Plagiozamites -...... 6

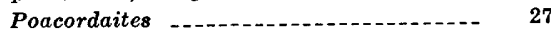

polymorpha, Nilssonia _._......... 41, 43

polysacci, Lasiostrobus _..._-_._. 6

prisma, Androstrobus _.............. 41

pseudobrcvis, Taeniopteris ....... 40,41,43

Pseudoctenis _...... 40 lanei -.... 41

Pterophyllum _. 40 


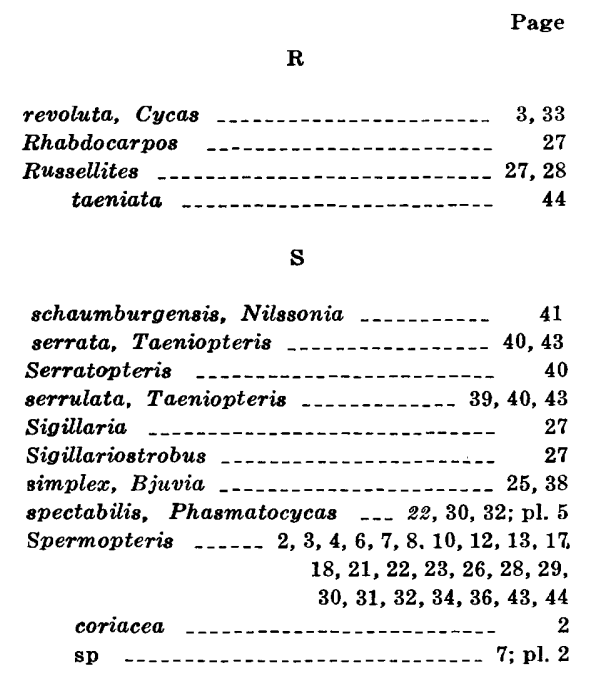

$\begin{array}{cr} & \text { Page } \\ \text { Sphenophyllum } & \\ \text { Sphenopteris } & 26 \\ \text { Stangeria } & \\ \text { Stigmaria } & \\ \text { Supaia } & \\ & \end{array}$

taeniata, Russellites

Taeniopteris $2,7,19,24,26,28,29,30,39$,

$41,43,44$

abnormis -

coriacea _._._.

linearis _... 16

gigantea

koreanensis -

multinervis -

newberriana _..._. 17

pseudobrevis _.......... 40, 41, 43

serrata - .

serrulata _..._.

sp _.......-

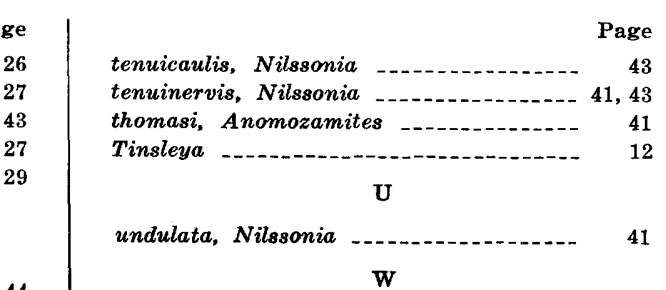

$\mathbf{W}$

Walchia whitei, Archaeocycas _...... 8,11, 12,31,32; wonnacotti, Androstrobus text-fig. 3; pls. 1,2 $\mathbf{Y}$

yochelsoni, Cycadospadix ____._-_ 26, 33; pl. 2 $\mathbf{z}$

Zamia floridana ...... 3

sp -1.-- 43

zamioides, Androstrobus 


\section{PLATES $1-5$}

Contact photographs of the plates in this report are available, at cost, from U.S. Geological Survey Library, Federal Center,

Denver, Colorado 80225 


\section{PLATE 1}

Figures 1-5. Archaeocycas whitei Mamay (p. 8).

1. Megasporophyll exposed in oblique-lateral position, showing carbonaceous remnants of original tissues, indusiumlike laminar covering of ovules and faint striations suggestive of fine, parallel venation. Paratype, USGS 8959-1b. $\times$ 8.5.

2. Counterpart of specimen illustrated in figure 1, showing adaxial view of six closely appressed ovules. Note incomplete fold in lamina at upper (right) edge of mast distal ovule (arrow), indicating flattening out of inrolled lamina covering the ovules. Paratype, USGS 8959-1a. $\times 8.5$.

3. Mold of adaxial side of megasporophyll, showing stout midrib, five pairs of oppositely attached ovules, and distal expansion of sterile lamina. Paratype, USGS 8877-3. $\times 6$.

4. Cast of adaxial side of megasporophyll, showing stout midrib, five pairs of opposite ovules, and coalified residue of laminar tissue that originally intruded between contiguous ovules. Several ovules show circular scars of attachment; these are best shown in the distal (uppermost) pairs of ovules. Paratype, USGS 8877-2. $\times 6$.

5. Cast of adaxial side of megasporophyll, with nine ovules (lower right ovule broken off). Note fairly strong development of sterile distal lamina, with fold extending distally and diagonally from midrib. Holotype, USGS 8877-1. $\times 6$. 

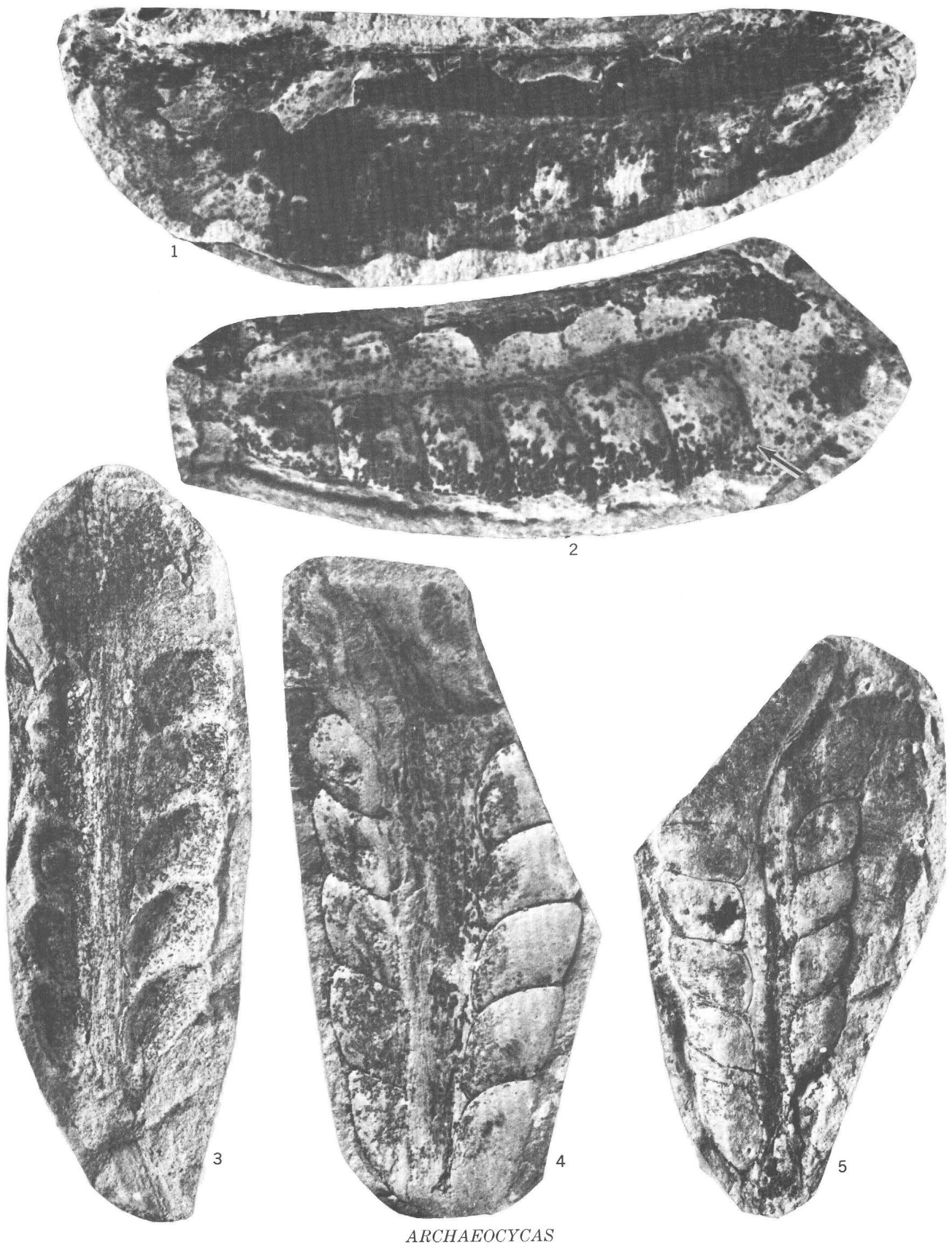


\section{PLATE 2}

1. ?Phasmatocycas sp. (p. 21).

Fragmentary impression of stout axis with evidence of approximately 12 pairs of opposite seedlike bodies and suggestion of outline of surrounding foliar lamina. USGS 10064-1. $\times 2$.

2. Spermopteris sp. (p. 7).

Fragmentary impression of taeniopterid leaf, bearing two marginal rows of ovoid swellings suggestive of immature ovules. USGS $6233-1 . \times 2$.

3. Cycadospadix yochelsoni n. sp. (p. 24).

Small appendage with broad peduncle and deeply pinnatifid lamina. Holatype, USGS 10057-1. $\times 3$.

4. ?Cycadean male cone (p. 23).

Fragmentary mold of conelike organ, with deep rhomboidal impressions, probably representing distal faces of microsporophylls. Note distally curved spinelike molds, apparently impressions of rigid attenuated termini of microsporophylls. USGS 10064-2. $\times 1$.

5-7. Archaeocycas whitei Mamay (p. 8).

5. Mold of adaxial side of megasporophyll with four pairs of ovules. Each ovule shows a circular scar of attachment near the rachis; three lower left ovules in turn have tiny central markings, probably representing vascular strands from lamina to base of ovules. USGS $8959-2 \mathrm{a} . \times 6$.

6. Counterpart of specimen shown in figure 5. USGS 8959-2b. $\times 6$.

7. Cast of megasporophyll, exposed in lateral view. Most proximal ovule partly broken away; contiguous ovule showing attachment scar near midrib. Note expanded base of midrib, indicative of perpendicular attachment to an axis; also note fragmentary but apparently well-developed sterile lamina at right. Paratype, USGS 8877-4. $\times 6$. 

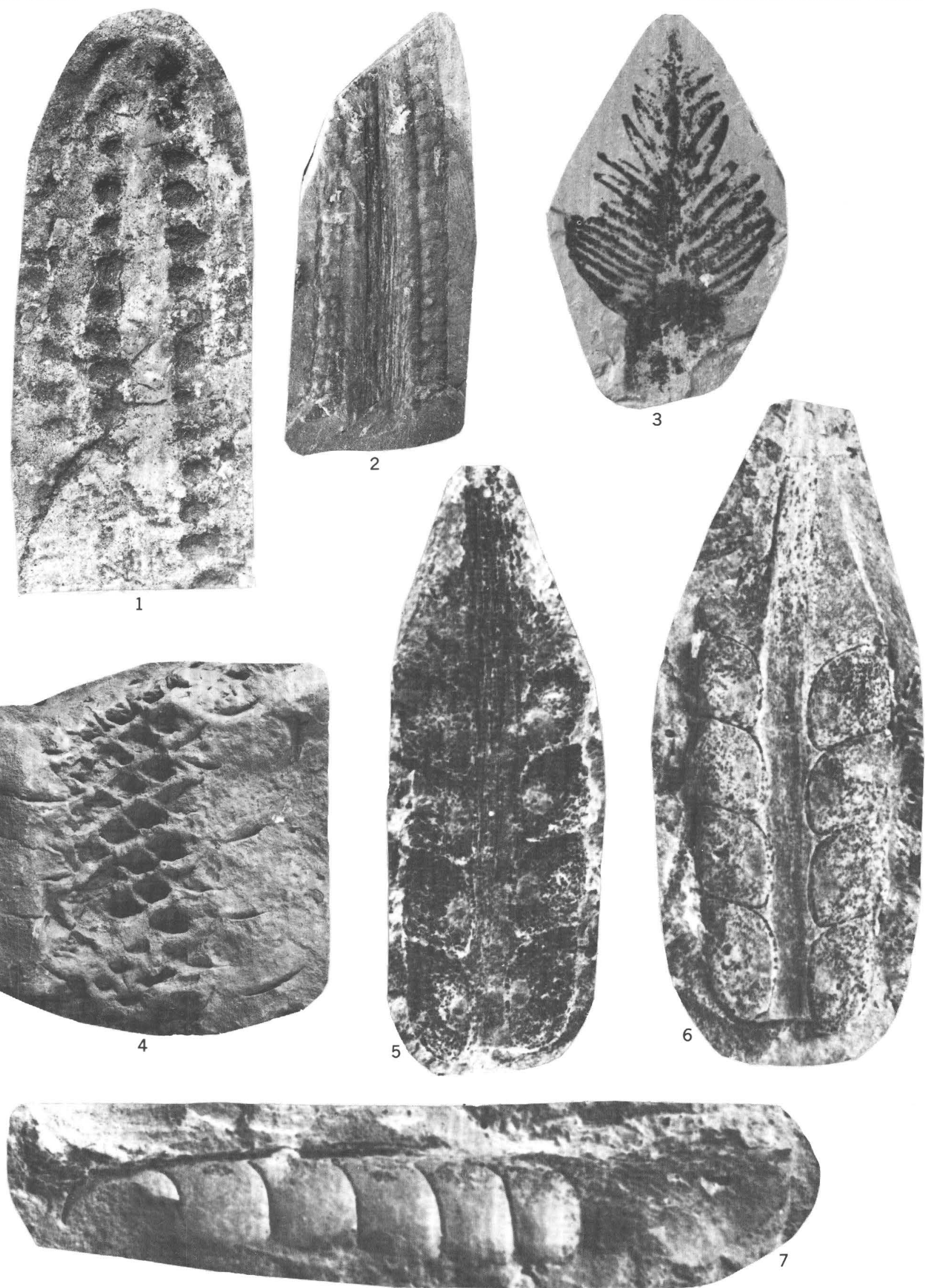

?PHASMATOCYCAS, SPERMOPTERIS, CYCADOSPADIX, AND ARCHAEOCYCAS 


\section{PLATE 3}

Figures 1-5. Phasmatocycas kansana Mamay (p. 12).

1,2. Counterparts of holotype, showing stout axis with two lateral rows of seeds, one displaced from original position. Figure 1, USGS 8869-1a; figure 2, USGS 8869-1b. $\times 4$.

3. Seed on USGS $8869-1$ b, oriented with apex upward. Spherical glandlike bodies at base of seed (indicated by arrows) one at either side. $\times 21$.

4. Part of USGS 8869-1b, enlarged. Second complete seed from top at left side appears in figure 3 . $\times 9$.

5. Line tracing of figure 4, showing distribution of glandlike bodies relative to seeds. Solid black circles represent actual glands; unshaded circles represent impressions of glands, $\times 9$. 

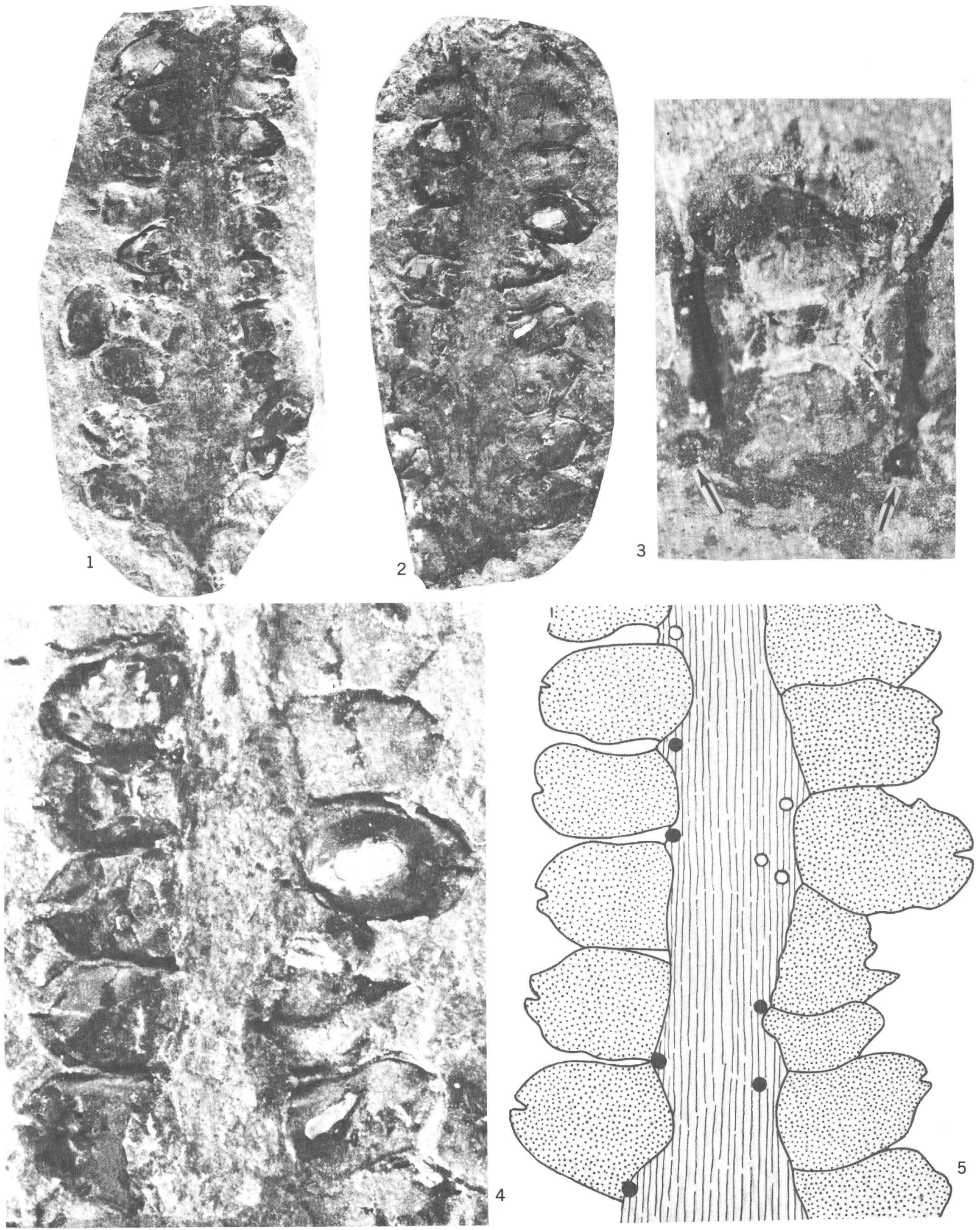

PHASMATOCYCAS 


\section{PLATE 4}

Figưres 1-5. Phasmatocycas kansana Mamay (p. 12).

Chemically cleared cuticular systems of three seeds removed from holotype (USGS 8869-1b).

1,2. Apical region of seed fragment, showing short, relatively broad micropyle and two cuticles. Outer cuticle (inner integument) is thin and delicate; inner layer (nucellar integument) is thicker, with isodiametric, heavy-walled cells. Note absence of any pollen-chamber mechanisms. Fig $1, \times 100$; fig. $2, \times 30$.

3. Nearly complete specimen, showing double nature of cuticle to approximate "shoulders," and heavy megaspore membrane. Light area below center represents damage in which part of megaspore membrane is missing; darkest streaks represent folds in megaspore membrane, in which at least three thicknesses of membrane are present. $\times 30$.

4,5. Two views of third specimen, fig. 5 showing details of micropylar area, double cuticle, and top of megaspore membrane seen as a dark arc across bottom of figure. Fig. $4, \times 30 ;$ fig. $5, \times 100$. 


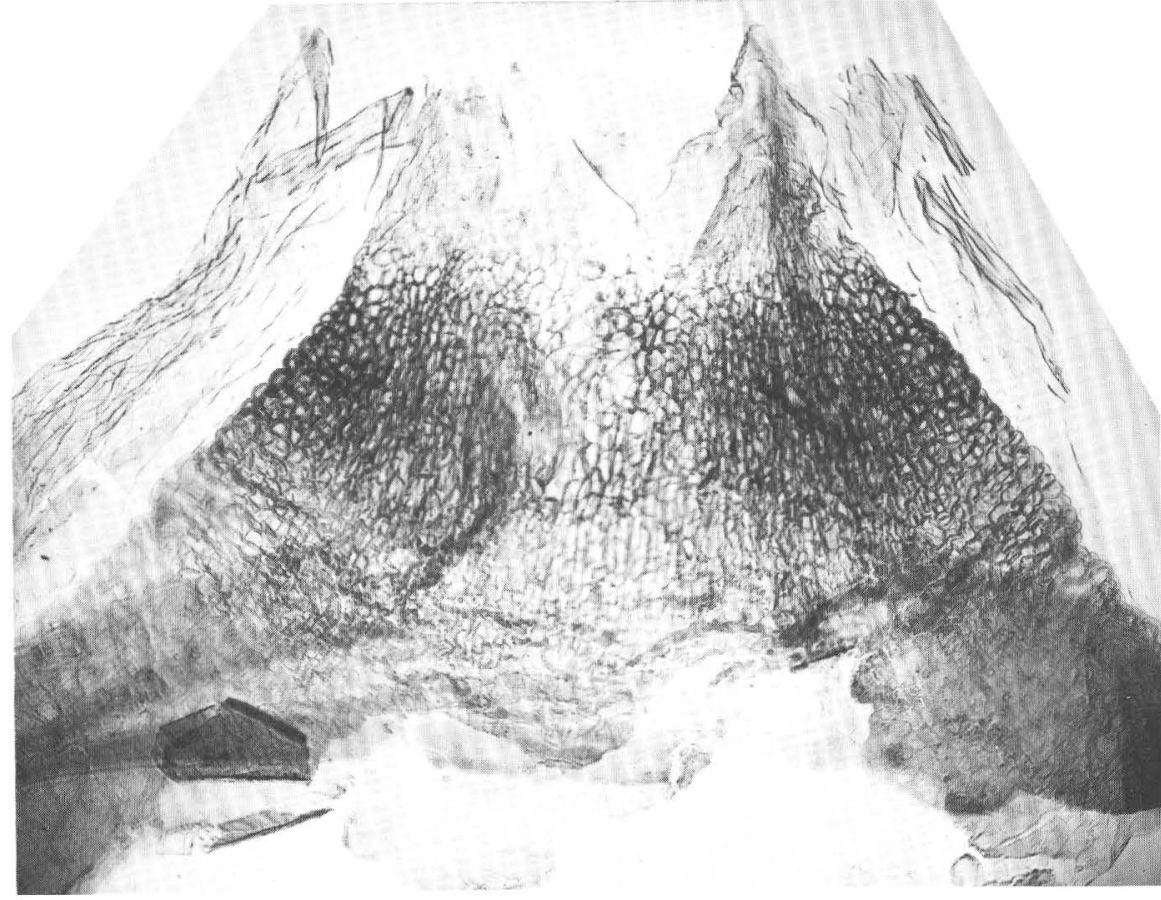

1
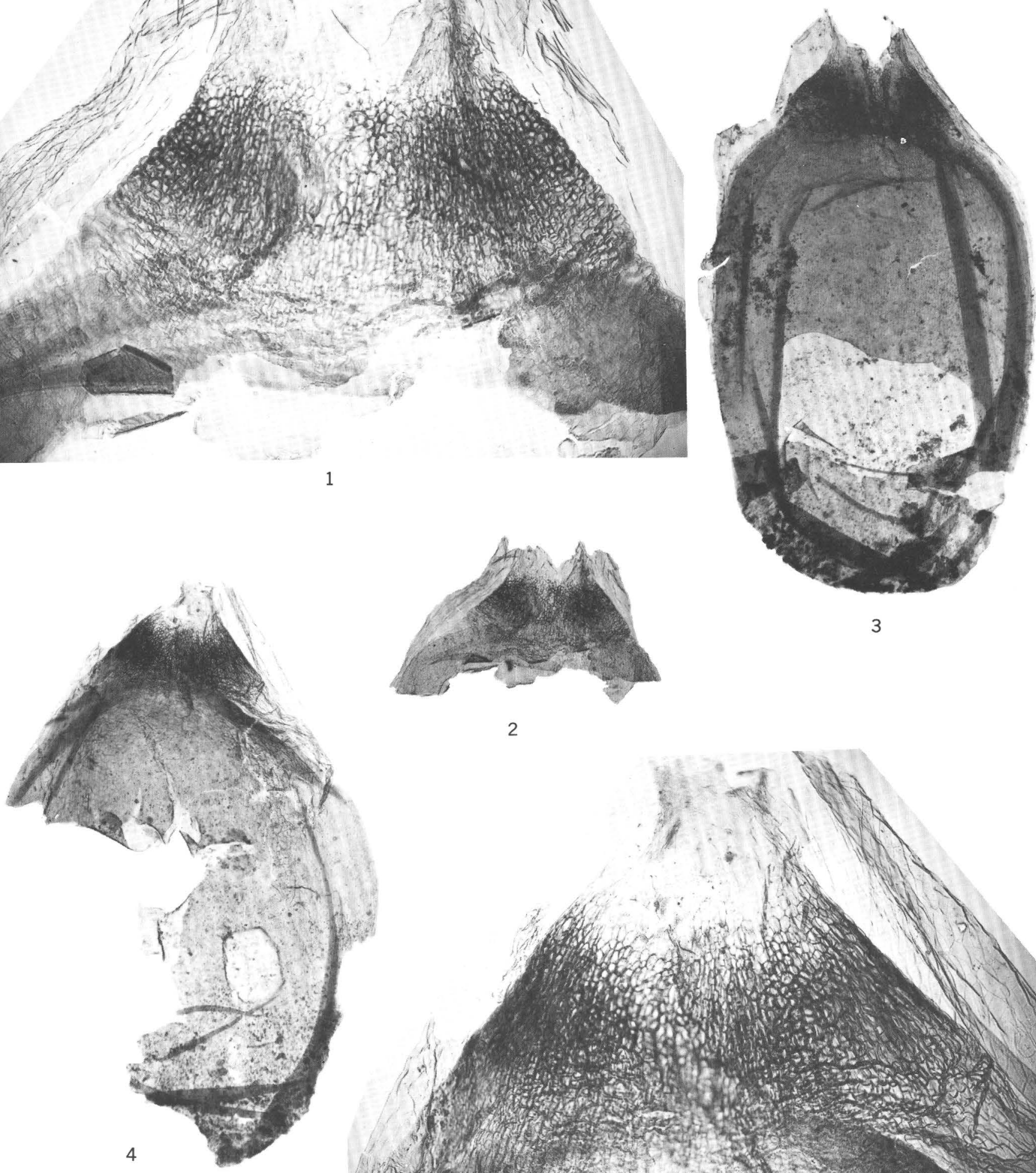

3

2

5
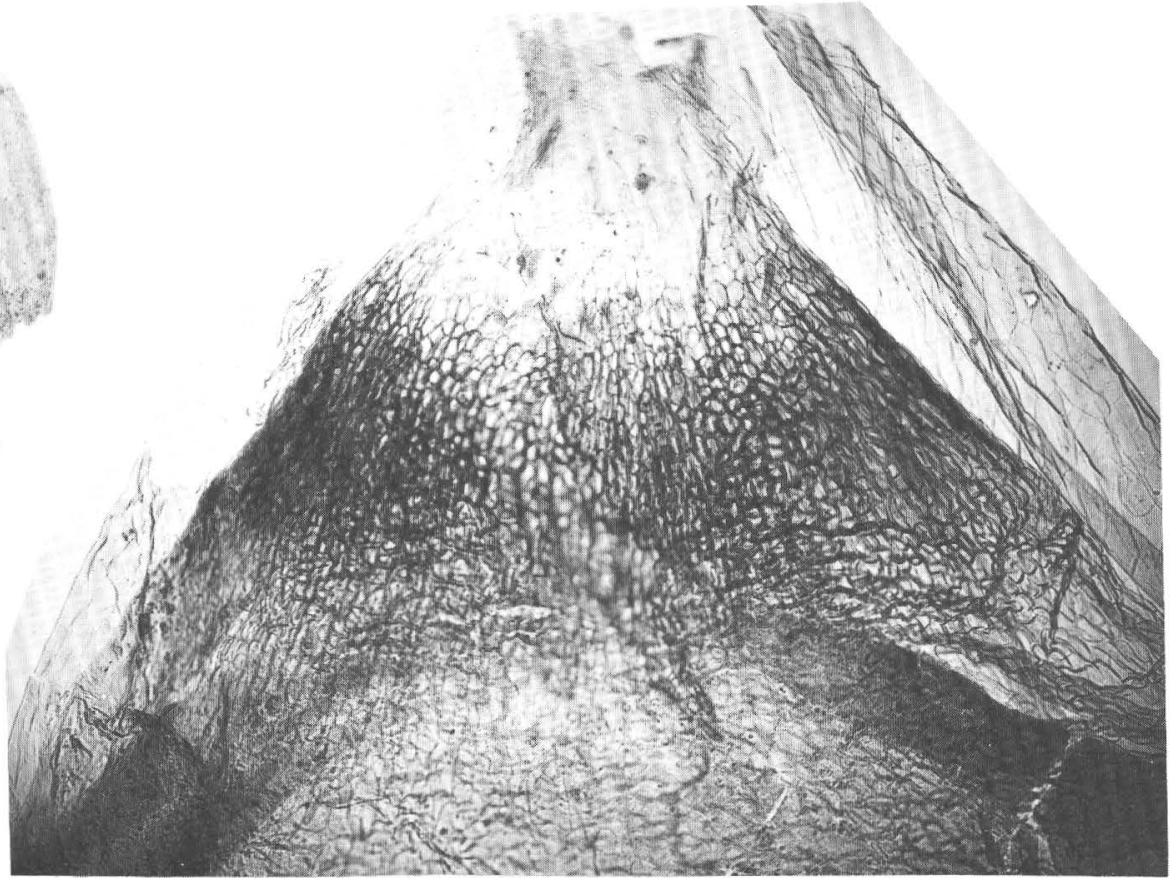

PHASMATOCYCAS 


\section{PLATE 5}

Figures 1-4. ?Phasmatocycas spectabilis Mamay, n. sp. (p. 22),

1. Unusually long, stout axis with about 60 seeds, borne in two lateral rows. Holotype, USGS 8959-3. $\times 1$.

2-4. Paratype specimens, clearly demonstrating lack of evidence of seed attachments between lateral rows. Fig. 2, USGS 8877-5, $\times 1$; fig. 3, USGS 8877-6, $\times 2$; fig. 4, USGS $8877-7, \times 1$.

5-7. Specimen of Taeniopteris sp., associated with holotype of Phasmatocycas kansana, and showing abundant spherical, intercostal, resinoid glandlike bodies. Compare those in fig. 7 with similar bodies shown in pl. 3, fig. 3. Figure 5, $\times 2$; fig. $6, \times 5$; figure 7 , $\times 20$. USGS 8869-2. 
GEOLOGICAL SURVEY
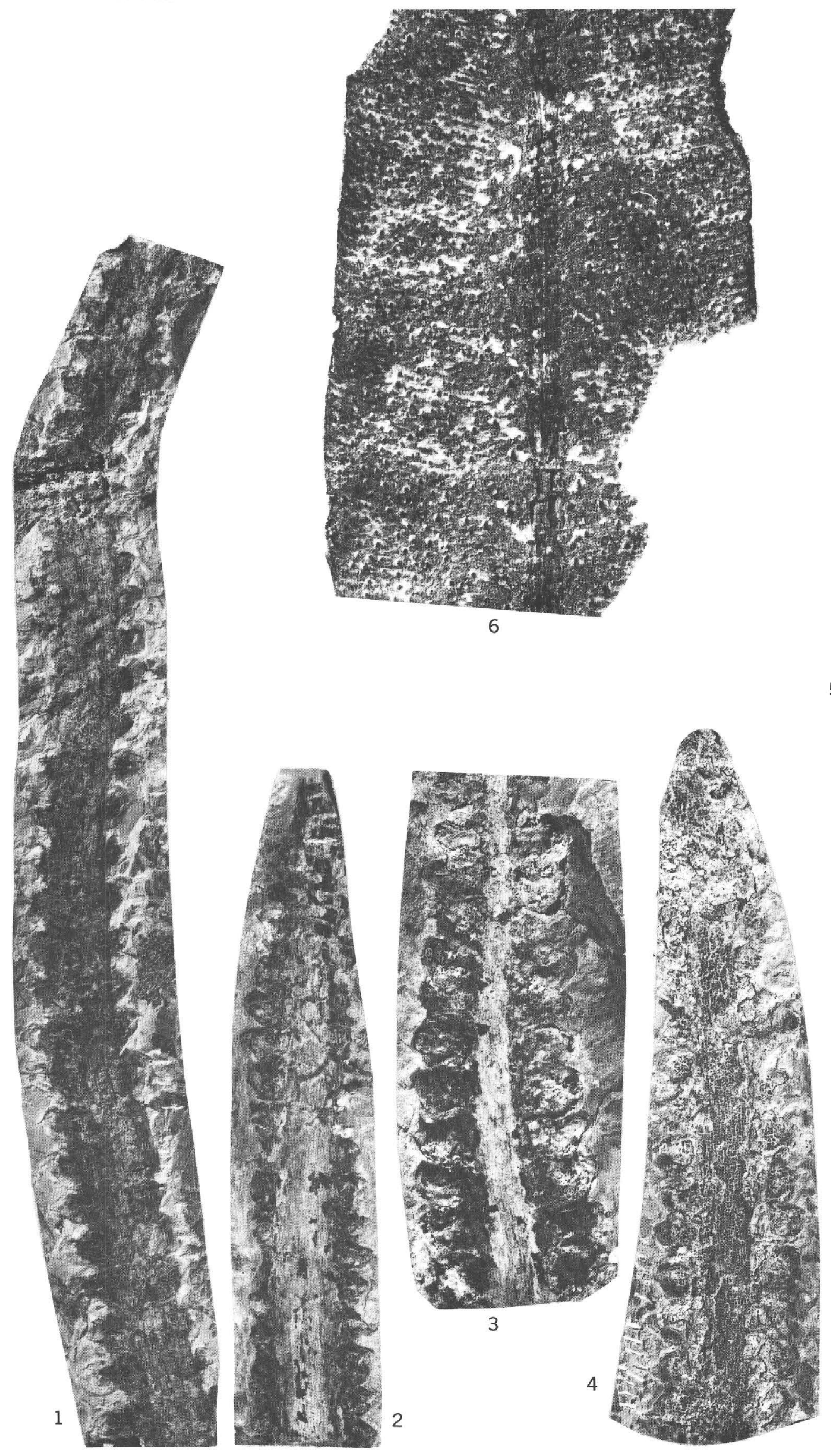

?PHASMATOCYCAS AND TAENIOPTERIS
PROFESSIONAL PAPER 934 PLATE 5

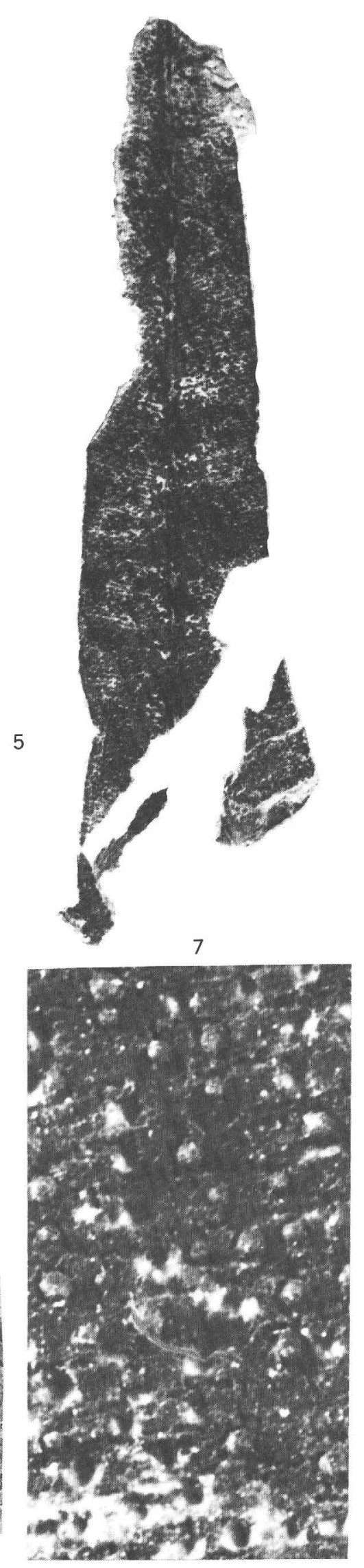


